\title{
Dover Dam Physical Model Study, Tuscarawas River, Dover OH
}

Elizabeth C. Burg

September 2009

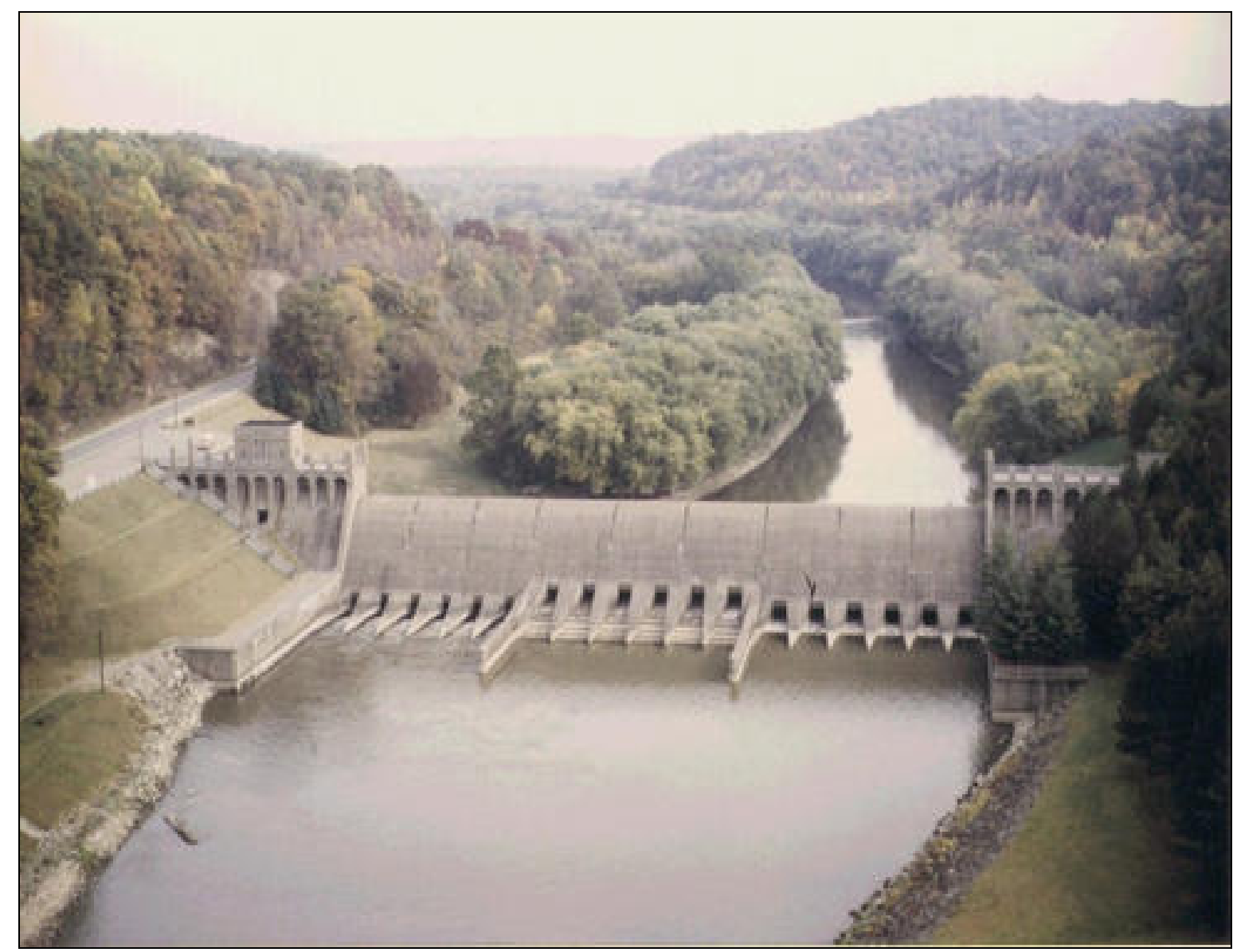




\section{Dover Dam Physical Model Study, Tuscarawas River, Dover OH}

Elizabeth C. Burg

Coastal and Hydraulic Laboratory

U.S. Army Engineer Research and Development Center

3909 Halls Ferry Road

Vicksburg, MS 39180-6199

Final report

Approved for public release; distribution is unlimited.

Prepared for U.S. Army Corps of Engineers Huntington District $5028^{\text {th }}$ Street

Huntington, WV 25701 


\begin{abstract}
Dover Dam is located on the Tuscarawas and Muskingum Rivers near Dover, OH. Based on data collected since the dam's original construction, it is possible that the dam will be overtopped by the Probable Maximum Flood. Several design alternatives are being considered to address this issue. A physical model study was conducted at the U.S. Army Engineer Research and Development Center, Coastal and Hydraulics Laboratory to collect data for use in a structural stability analysis. During the experiments, pressures were measured and potential erosion areas were noted. Forces exerted on the baffle blocks and stilling basin, as well as the potential undermining of the stilling basin were of major interest during the study.
\end{abstract}

DISCLAIMER: The contents of this report are not to be used for advertising, publication, or promotional purposes. Citation of trade names does not constitute an official endorsement or approval of the use of such commercial products. All product names and trademarks cited are the property of their respective owners. The findings of this report are not to be construed as an official Department of the Army position unless so designated by other authorized documents. 


\section{Contents}

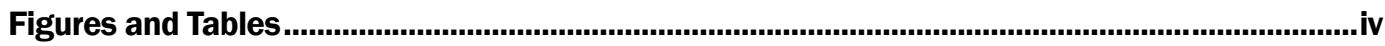

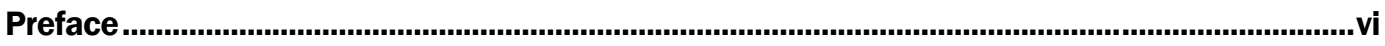

Unit Conversion Factors.............................................................................................................tii

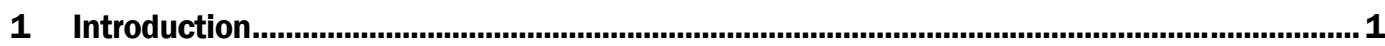

2 Problem

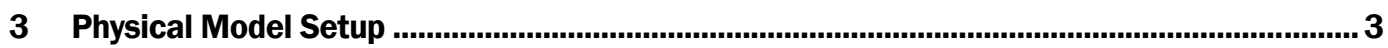

Flume

Bathymetry

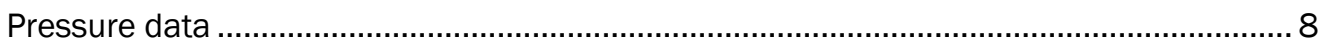

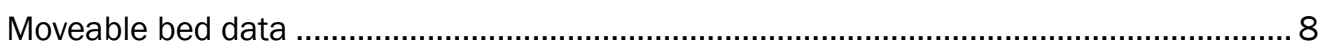

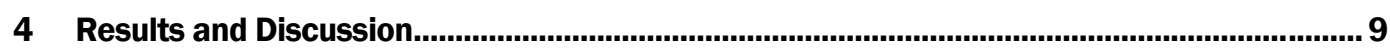

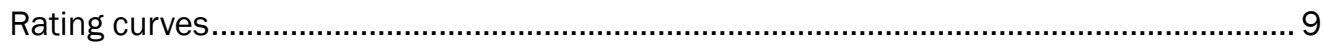

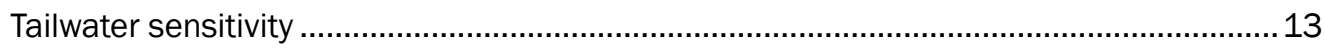

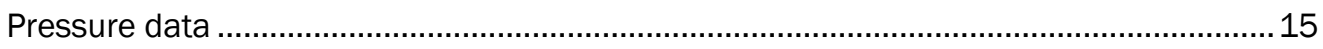

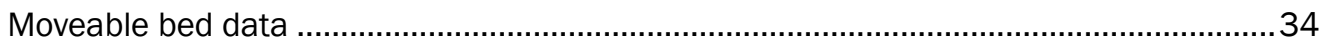

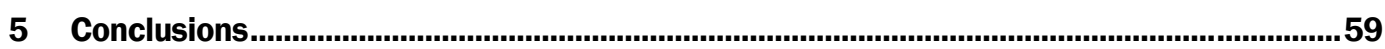

\section{Report Documentation Page}




\section{Figures and Tables}

\section{Figures}

Figure 1. Location map of Dover Dam ...................................................................................... 1

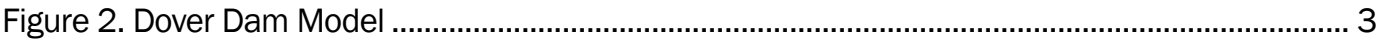

Figure 3b. Plan and profile drawings of Dover Dam, Monoliths 10-11-12 ……….......................... 6

Figure 3c. Plan and profile drawings of Dover Dam, Monoliths 13-14-15. ........................................ 7

Figure 4. Baffle blocks and pressure cells, Monoliths 7-8-9 ........................................................... 8

Figure 5. Spillway rating curve with measured model data overlaid on rating curve provided by Huntington District......................................................................................................... 9

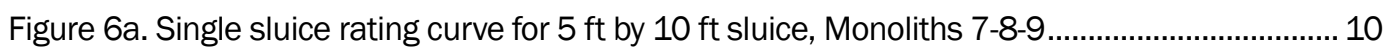

Figure 6b. Single sluice rating curve for $7 \mathrm{ft}$ by $7 \mathrm{ft}$ sluice, Monoliths 10-11-12............................. 10

Figure 6c. Single sluice rating curve for $7 \mathrm{ft}$ by $7 \mathrm{ft}$ sluice, Monoliths 13-14-15. ............................ 11

Figure 7a. Structure rating curve, Monoliths 7-8-9......................................................................... 11

Figure 7b. Structure rating curve, Monoliths 10-11-12 ............................................................... 12

Figure 7c. Structure rating curve, Monoliths 13-14-15 ............................................................. 12

Figure 8. Combined structure rating curve................................................................................ 13

Figure 9a. Tailwater sensitivity data for flow through Monoliths 7-8-9 only...................................... 14

Figure 9b. Tailwater sensitivity data for flow through Monoliths 10-11-12 only............................... 14

Figure 10a. Piezometer and pressure cell locations for Monoliths 7-8-9...................................... 17

Figure 10b. Piezometer and pressure cell locations for Monoliths 10-11-12................................ 18

Figure 10c. Piezometer and pressure cell locations for Monoliths 13-14-15.................................. 19

Figure 11a. Water surface profile for Monoliths 7-8-9, Condition 1................................................ 35

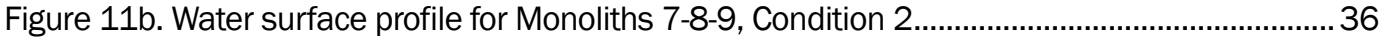

Figure 11c. Water surface profile for Monoliths 7-8-9, Condition 3.................................................. 37

Figure 11d. Water surface profile for Monoliths 7-8-9, Condition 4 ...................................................38

Figure 11e. Water surface profile for Monoliths 7-8-9, Condition 5 ................................................. 39

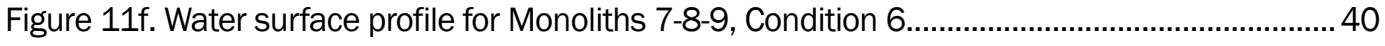

Figure 11g. Water surface profile for Monoliths 7-8-9, Condition 7 ................................................ 41

Figure 12a. Water surface profile for Condition 1, Monoliths 10-11-12 ......................................... 42

Figure 12b. Water surface profile for Condition 2, Monoliths 10-11-12 ......................................... 43

Figure 12c. Water surface profile for Condition 3, Monoliths 10-11-12 ......................................... 44

Figure 12d. Water surface profile for Condition 4, Monoliths 10-11-12 ......................................... 45

Figure 12e. Water surface profile for Condition 5, Monoliths 10-11-12 .......................................... 46

Figure 12f. Water surface profile for Condition 6, Monoliths 10-11-12 ........................................ 47

Figure 13a. Water surface profile for Condition 1, Monoliths 13-14-15......................................... 48

Figure 13b. Water surface profile for Condition 2, Monoliths 13-14-15 ........................................... 49

Figure 13c. Water surface profile for Condition 3, Monoliths 13-14-15 .........................................50 
Figure 13d. Water surface profile for Condition 4, Monoliths 13-14-15 ....................................... 51

Figure 13e. Water surface profile for Condition 5, Monoliths 13-14-15.........................................52

Figure 13f. Water surface profile for Condition 6, Monoliths 13-14-15 ......................................... 53

Figure 14a. Erosion pattern for Monoliths 7-8-9with end sill intact............................................... 54

Figure 14b. Erosion pattern for Monoliths 7-8-9 with end sill removed..........................................55

Figure 15a. Erosion pattern for Monoliths 10-11-12 with end sill intact...........................................56

Figure 15b. Erosion pattern for Monoliths 10-11-12 with end sill removed ..................................... 57

Figure 16. Erosion pattern for Monoliths 13-14-15 ................................................................58

\section{Tables}

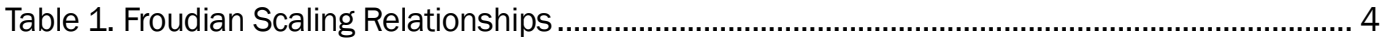

Table 2. Discharge conditions for model testing .......................................................................... 7

Table 3a. Pressure cell and piezometer locations for Monoliths 7-8-9........................................... 15

Table 3b. Pressure cell and piezometer locations for Monoliths 10-11-12...................................... 16

Table 3c. Pressure cell and piezometer locations for Monoliths 13-14-15................................... 16

Table 4a. Pressure cell and piezometer readings for Monoliths 7-8-9, Condition 1.........................2 20

Table 4b. Pressure cell and piezometer readings for Monoliths 7-8-9, Condition 2. ....................... 20

Table 4c. Pressure cell and piezometer readings for Monoliths 7-8-9, Condition 3......................... 21

Table 4d. Pressure cell and piezometer readings for Monoliths 7-8-9, Condition 4. ........................ 22

Table 4e. Pressure cell and piezometer readings for Monoliths 7-8-9, Condition 5.......................... 22

Table 4f. Pressure cell and piezometer readings for Monoliths 7-8-9, Condition 6. ......................... 23

Table 4g. Pressure cell and piezometer readings for Monoliths 7-8-9, Condition 7......................... 24

Table 5a. Pressure cell and piezometer readings for Monoliths 10-11-12, Condition 1. ................. 24

Table 5b. Pressure cell and piezometer readings for Monoliths 10-11-12, Condition 2. ................. 25

Table 5c. Pressure cell and piezometer readings for Monoliths 10-11-12, Condition 3................... 26

Table 5d. Pressure cell and piezometer readings for Monoliths 10-11-12, Condition 4. ................. 26

Table 5e. Pressure cell and piezometer readings for Monoliths 10-11-12, Condition 5. ................. 27

Table 5f. Pressure cell and piezometer readings for Monoliths 10-11-12, Condition 6. .................. 28

Table 6a. Pressure cell and piezometer readings for Monoliths 13-14-15, Condition 1. ................. 29

Table 6b. Pressure cell and piezometer readings for Monoliths 13-14-15, Condition 2. .................. 29

Table 6c. Pressure cell and piezometer readings for Monoliths 13-14-15, Condition 3...................30

Table 6d. Pressure cell and piezometer readings for Monoliths 13-14-15, Condition 4. ................. 31

Table 6e. Pressure cell and piezometer readings for Monoliths 13-14-15, Condition 5. ................. 31

Table 6f. Pressure cell and piezometer readings for Monoliths 13-14-15, Condition 6. ..................32

Table 7a. Estimated and recorded flow conditions for Monoliths 7-8-9...........................................33

Table 7b. Estimated and recorded flow conditions for Monoliths 10-11-12 ....................................33

Table 7c. Estimated and recorded flow conditions for Monoliths 13-14-15. ...................................33 


\section{Preface}

This study was authorized by U.S. Army Engineer District, Huntington (LRH), and was conducted by personnel of the U.S. Army Engineer Research and Development Center's (ERDC) Coastal and Hydraulic Laboratory (CHL). The project was completed during the period from March to October 2008. Points of contact at LRH for the study were Ken Halstead and Scott Wheeler.

The physical model study was conducted by personnel of the Harbors and Entrances Branch (HN-H) of the Navigation Division (HN), under the direction of Thomas Richardson and Dr. William Martin, Director and Assistant Director, CHL, respectively, Dr. Rose Kress, Chief, HN, and Jacqueline Pettway, Chief, HN-HH. David Mobley, Engineering Technician, HN-HI, Elizabeth Burg, Research Hydraulic Engineer, HN-HI, and Glenn Davis, Research Hydraulic Engineer, HN-HI, conducted the experiments for this study. Ms. Burg analyzed the data and prepared this report.

COL Gary E. Johnston was Commander and Executive Director of ERDC. Dr. James R. Houston was Director. 


\section{Unit Conversion Factors}

\begin{tabular}{|l|c|l|}
\hline Multiply & By & To Obtain \\
\hline Acre-feet & $1,233.5$ & Cubic meters \\
\hline Cubic feet & 0.02831685 & Cubic meters \\
\hline Feet & 0.3048 & Meters \\
\hline Miles (U.S. statute) & $1,609.347$ & Meters \\
\hline Inches & 0.0254 & Meters \\
\hline Degrees & 0.01745329 & Radians \\
\hline Pounds (force) & 0.006894757 & Megapascals \\
\hline
\end{tabular}




\section{Introduction}

Dover Dam is a reservoir project constructed for flood control on the Tuscarawas and Muskingum Rivers, approximately 3.5 miles northeast of Dover, Ohio (Figure 1). The project includes a concrete gravity dam with 18 gated sluices, an uncontrolled ogee spillway, and a stilling basin. Dover has a total reservoir capacity of 203,000 acre-feet at a maximum flood control pool of $916^{1}$ feet above mean sea level (MSL).

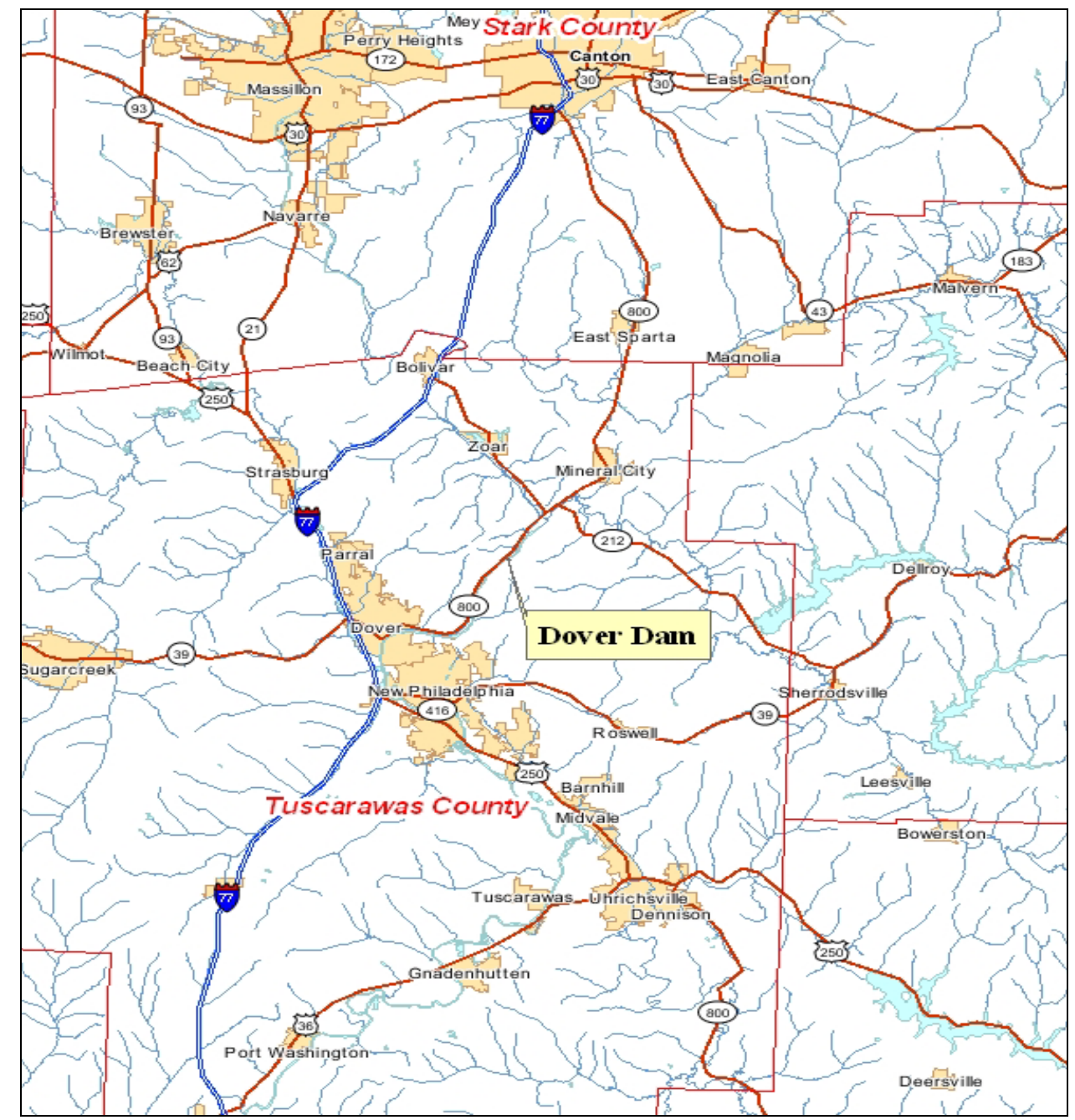

Figure 1. Location map of Dover Dam

1 Unless otherwise stated, all elevations (el) cited herein are in feet referenced to Mean Sea Level (MSL). To convert feet to meters, multiply by 0.3048 . 


\section{Problem}

Based on hydrologic data collected in the 70 years since the dam's construction, it is estimated that the Probable Maximum Flood (PMF) would overtop the dam by 6.4 feet. Flows close to the PMF have never been experienced at the site and the forces that will possibly be exerted on the baffle blocks and stilling basin are unknown.

The purpose of the physical model is to develop discharge ratings for the structure, to collect pressure data for locations on the spillway crest, stilling basin floor, baffle blocks, and end sill to assist with a stability analysis of the structure, and to determine the erosion potential of bed material beneath and downstream of the dam, which could potentially undermine the structure. It has been proposed that a cutoff wall should be constructed at the end sill to prevent erosion that may occur during the PMF, but the depth of the wall is unknown. 


\section{Physical Model Setup}

\section{Flume}

The physical model study was conducted at the U.S. Army Engineer Research and Development Center's Coastal and Hydraulics Laboratory in Vicksburg, MS. The model was built at an undistorted linear scale of 1:30 (model:prototype), which was determined to be the largest scale for which the model sections could be reproduced in the flume (Figure 2). This scale maximizes the model size to be used in the model facility and is within typical scales used for determining the desired prototype quantities. Hydrodynamics were modeled based on Froude similitude. All dimensions and results in this report are presented in prototype scale, with all elevations referenced to (MSL) unless otherwise noted.

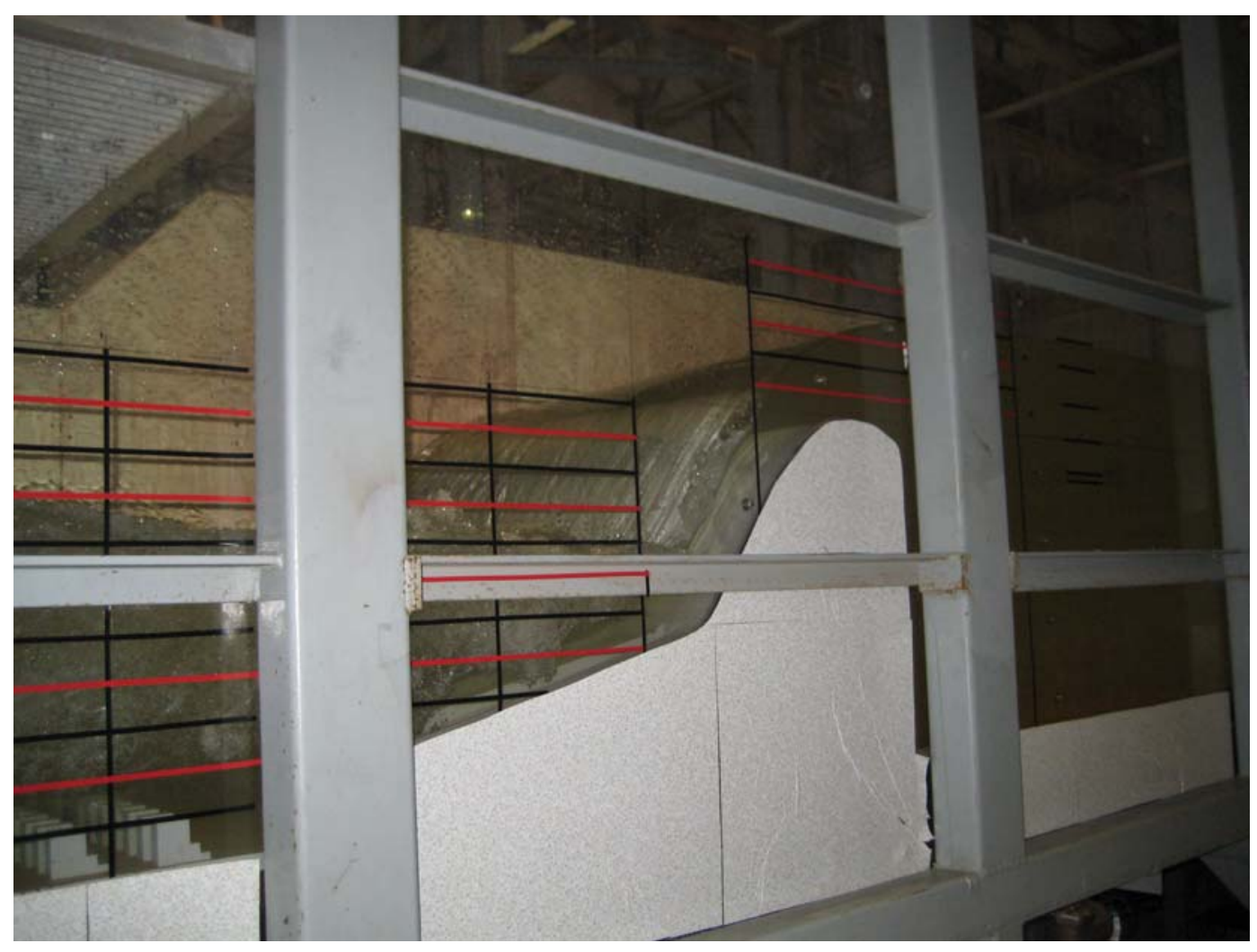

Figure 2. Dover Dam Model

The accepted equations of hydraulic similitude, based on Froudian relations, were used to express mathematical relations between the dimensions and hydraulic quantities of the model and prototype. General 
relations for the transfer of the model data to prototype equivalents, or vice versa, are presented in the following tabulation:

Table 1. Froudian Scaling Relationships

\begin{tabular}{|c|c|c|}
\hline Characteristic & Scale Relations Dimensions & Model : Prototype \\
\hline \multicolumn{3}{|c|}{ 1:30 Scale General Model } \\
\hline Length & $\mathrm{L}_{\mathrm{r}}=\mathrm{Lm}_{\mathrm{m}} / \mathrm{L}_{\mathrm{p}}$ & $1: 30$ \\
\hline Area & $A_{r}=A m / A p=L_{r}^{2}$ & 1:900 \\
\hline Velocity & $V_{r}=V m / V p=L_{r}{ }^{1 / 2}$ & 1:5.477 \\
\hline Discharge & $Q_{r}=Q m / Q p=L_{r} 5 / 2$ & $1: 4,929$ \\
\hline Volume & $V_{r}=V m / V p=L r^{3}$ & $1: 27,000$ \\
\hline Time & $T_{r}=L_{r}{ }^{1 / 2}$ & $1: 5.477$ \\
\hline
\end{tabular}

Certain model data can be accepted quantitatively, while other data are reliable only in a qualitative sense because of the nature of the phenomena. Measurements in the model of discharges, water-surface elevations, pressures, and velocities can be transferred quantitatively from model to prototype using the preceding scale relations.

\section{Bathymetry}

Based on provided hydrographic surveys and discussion with the Huntington District, bathymetry was constructed at the average elevations of $858 \mathrm{MSL}$ and $859 \mathrm{MSL}$, upstream and downstream of the dam, respectively, using plastic-coated plywood.

\section{Monolith cross sections}

Model sections were constructed of acrylic using a 5-axis router. The structure was divided into three sections for construction and testing; Monoliths 7-8-9, Monoliths 10-11-12, and Monoliths 13-14-15. Each section of monoliths consisted of six sluices and had a unique stilling basin elevation and end sill design, which was the reasoning behind dividing the structure in such a manner for testing. Plan and profile drawings for the three sections are shown in Figure 3.

\section{Discharge conditions}

Seven flow conditions were provided by the Huntington District for model testing (Table 2). Condition 6 corresponds to the PMF event and Condition 7 is an actual flood event that occurred at the project in January 2005. Prototype operation during Condition 7 , consisted of discharge through three sluices in Monoliths 7-8-9 only, and was replicated in the model. 


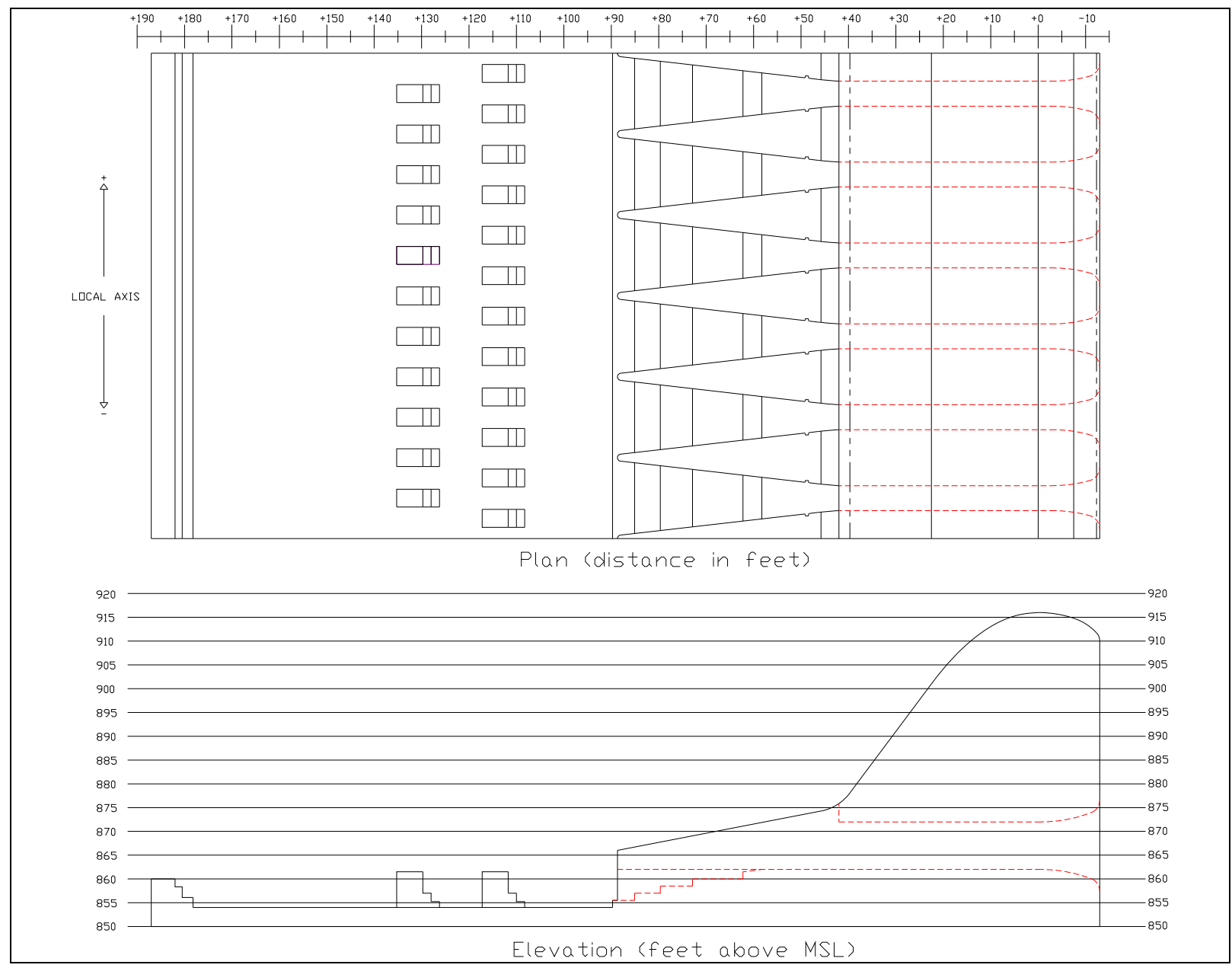

Figure 3a. Plan and profile drawings of Dover Dam, Monoliths 7-8-9. 


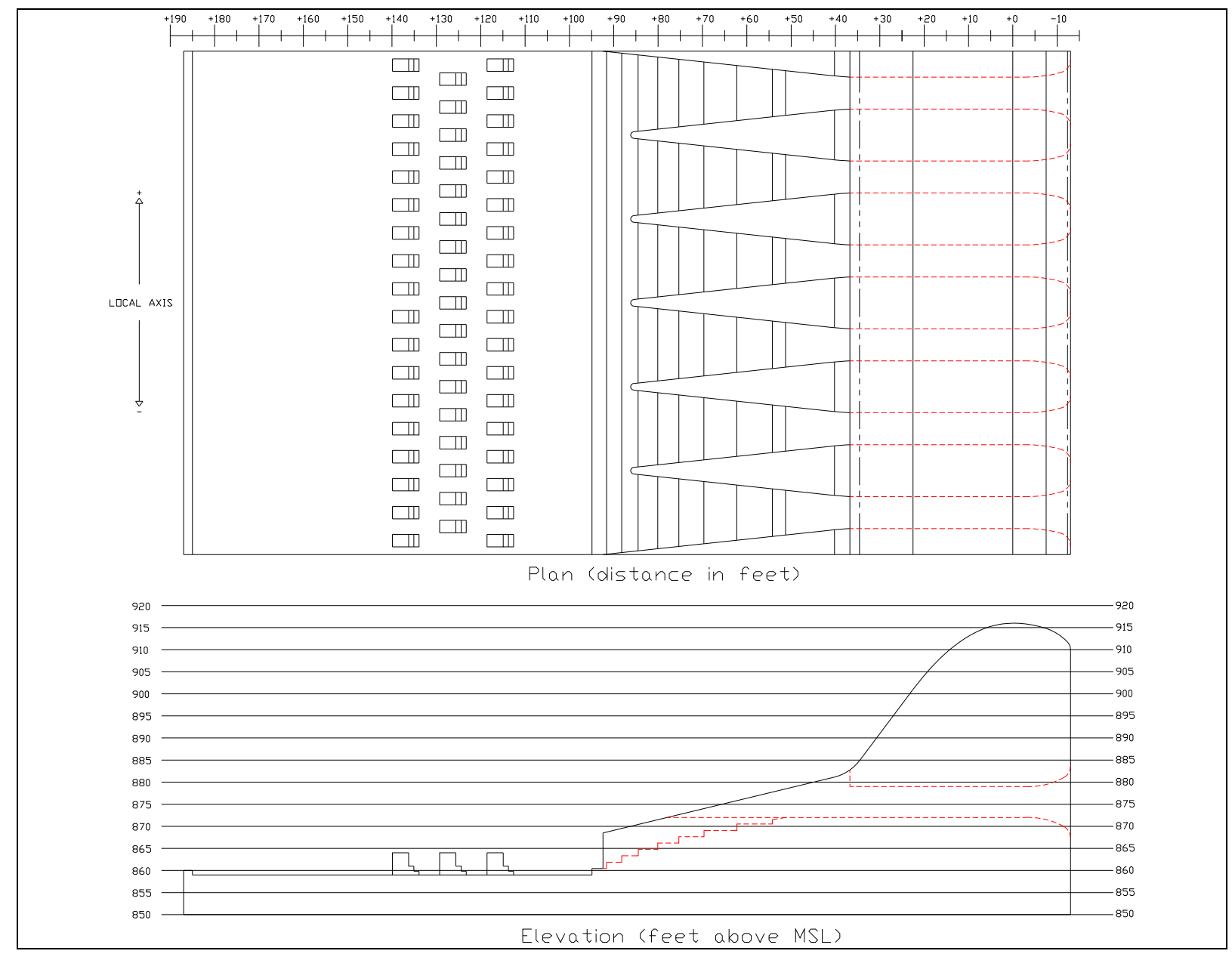

Figure 3b. Plan and profile drawings of Dover Dam, Monoliths 10-11-12. 


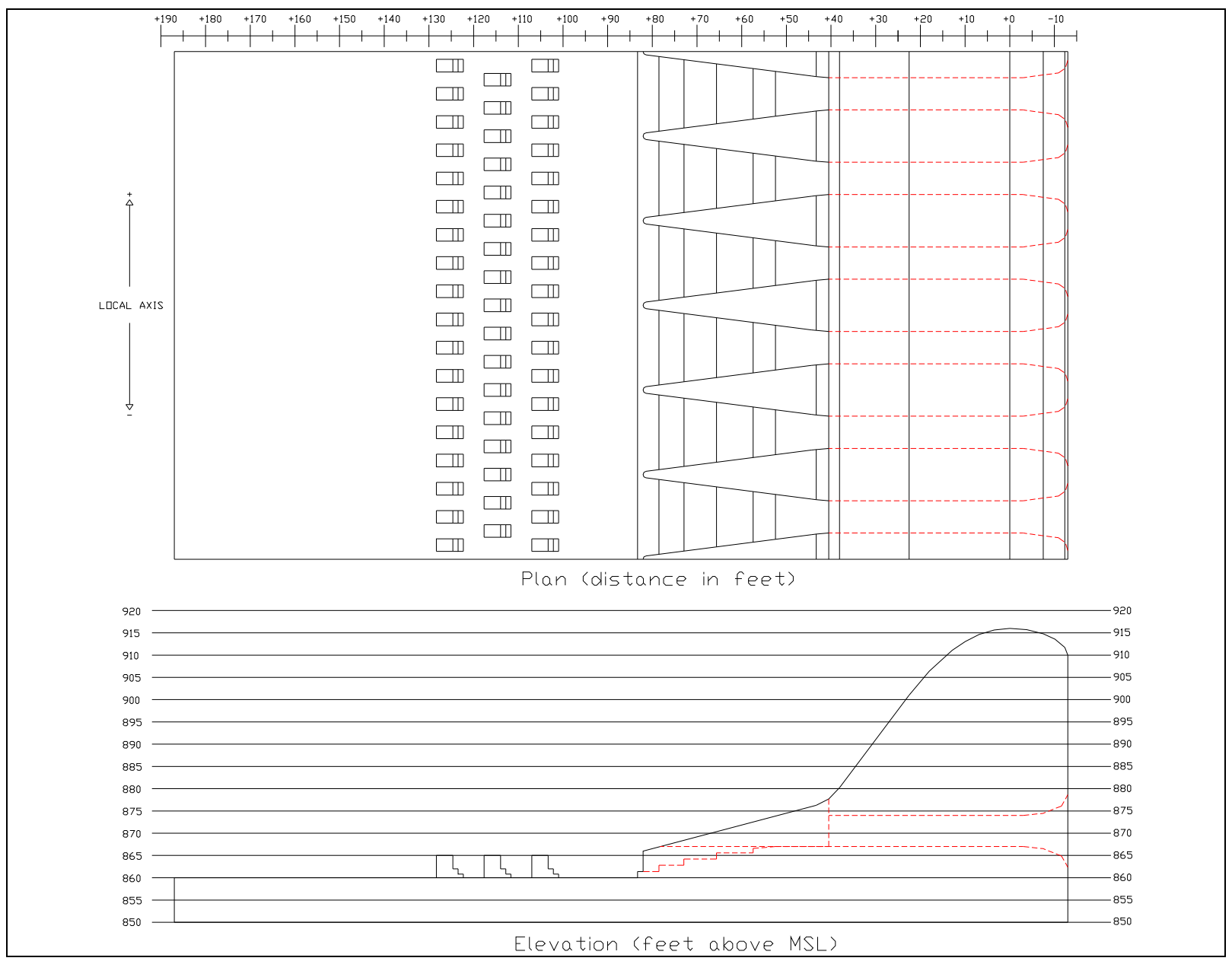

Figure 3c. Plan and profile drawings of Dover Dam, Monoliths 13-14-15.

Table 2. Discharge conditions for model testing

\begin{tabular}{|l|l|l|l|}
\hline Condition Number & Discharge (kcfs) & $\begin{array}{l}\text { Estimated Pool } \\
\text { Elevation (MSL) }\end{array}$ & Tailwater Elevation (MSL) \\
\hline 1 & 23.5 & 890.0 & 881.2 \\
\hline 2 & 38.0 & 909.0 & 885.3 \\
\hline 3 & 42.0 & 916.0 & 886.3 \\
\hline 4 & 72.5 & 923.5 & 892.4 \\
\hline 5 & 125 & 931.3 & 898.5 \\
\hline 6 (PMF) & 207 & 937.4 & 907.0 \\
\hline $7 *$ & 8.9 & 907.35 & 874.1 \\
\hline
\end{tabular}

*Condition 7 was only tested on Monoliths 7-8-9 to reflect the actual prototype condition. 


\section{Pressure data}

The model was designed to allow the measurement of pressures on the upstream and downstream faces of the baffle blocks, as well as the tops of the baffle blocks. Pressures were also collected at various locations on the sluice steps and the stilling basin floor. Pressure cells were used to collect time series pressure data and piezometers were used for average pressure readings (Figure 4 ).

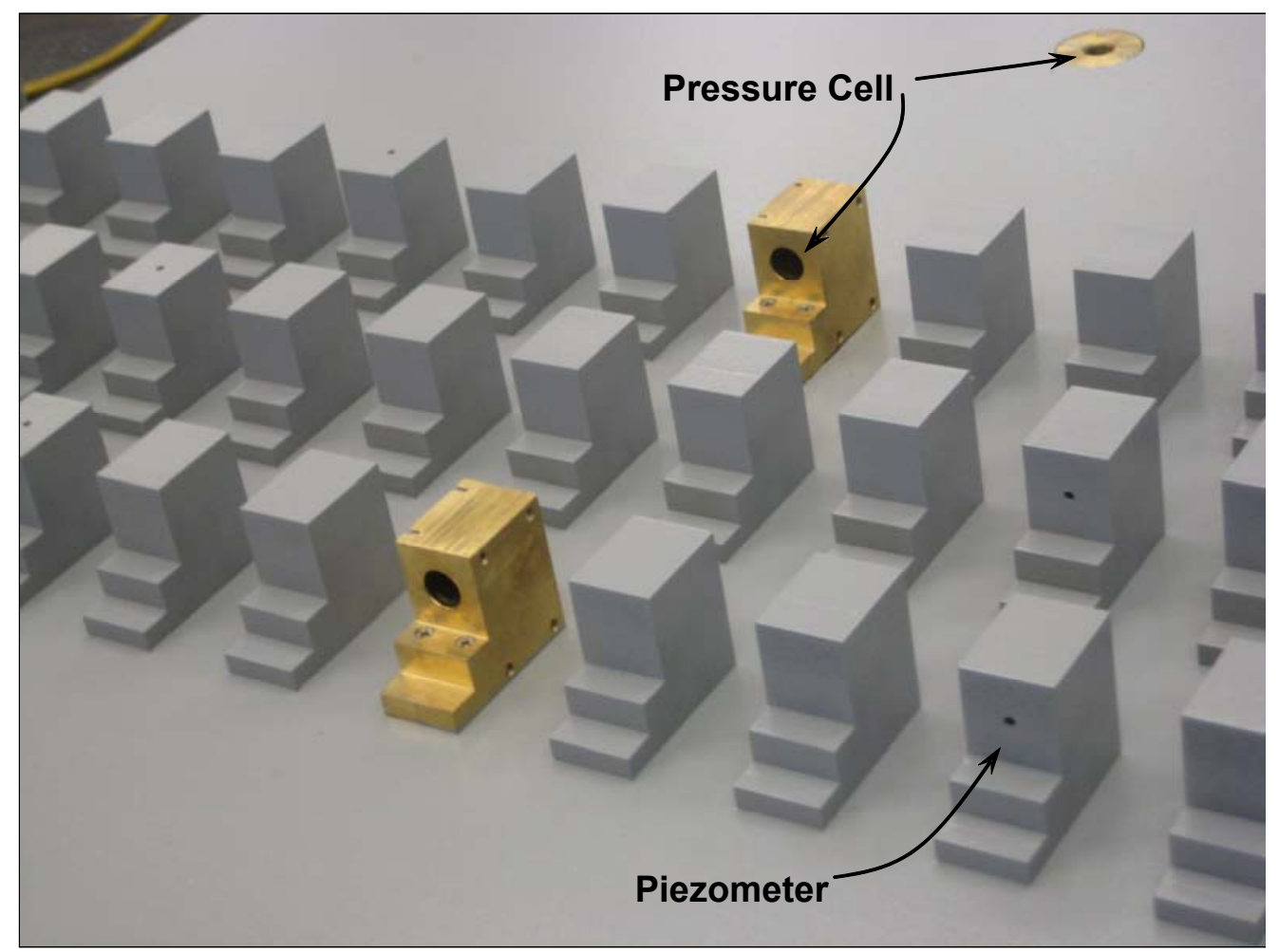

Figure 4. Baffle blocks and pressure cells, Monoliths 7-8-9

\section{Moveable bed data}

The bathymetry downstream of the end sill was constructed so it could be easily removed and replaced with material that would show potential scour during dam operation. Quantitative modeling of fractured rock is not possible. The material was not scaled in a manner that accurately represents the bed material present at the prototype, and was placed purely to perform a qualitative evaluation. 


\section{Results and Discussion}

\section{Rating curves}

Discharge rating curves were produced for the spillway crest, a single sluice, and each full structure with full sluice and spillway flow. Figure 5 shows the rating curve for the spillway crest compared to the rating curve provided by the Huntington District. Since the full crest length could not be tested at one time in the flume, the discharge per unit length of crest was computed and then multiplied by the total crest length to give the total discharge for the full crest. Discharges were computed using each of the four inflow lines to verify that all flow meters were reading correctly. Based on how well the rating curves match up, there is confidence in that the ogee shape accurately reflects that of the prototype and that the flow meters themselves are reading correctly. Figure 6 gives the rating curves produced by flow through a single sluice for each section and Figure 7 shows the rating curve for each set of monoliths with full sluice and spillway flow. Figure 8 is a combined rating curve using the data collected from each individual set of monoliths.

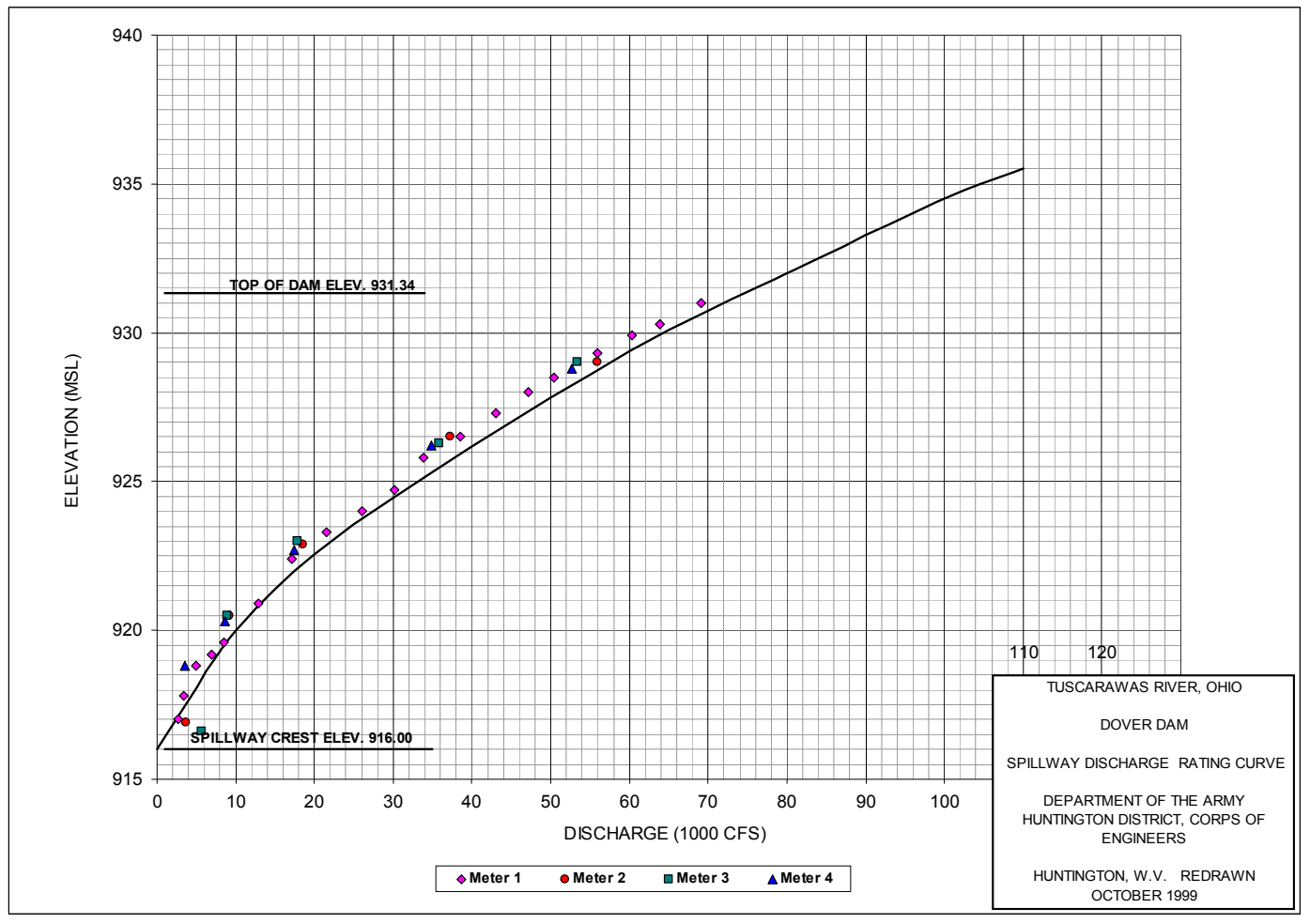

Figure 5. Spillway rating curve with measured model data overlaid on rating curve provided by Huntington District. 


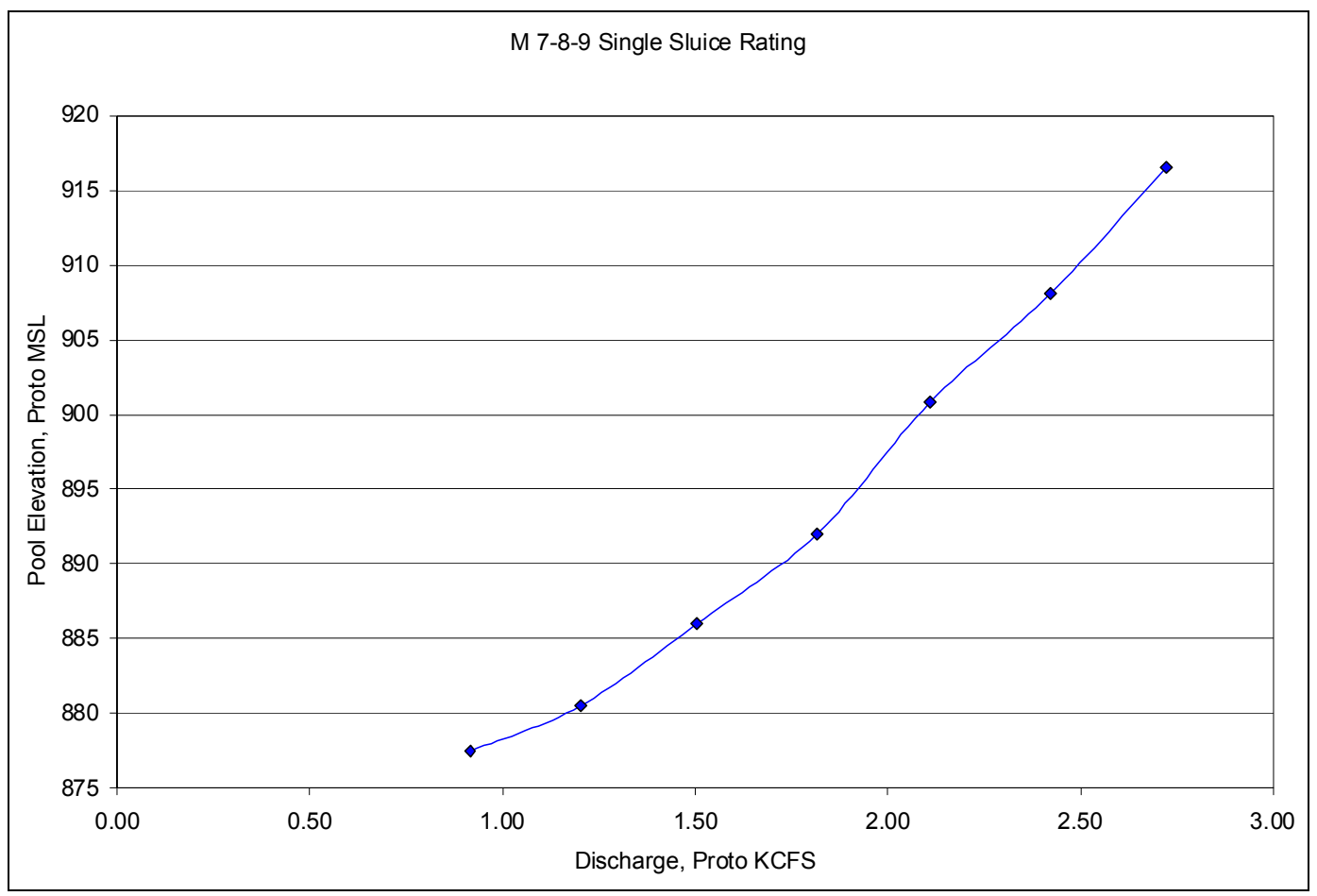

Figure $6 a$. Single sluice rating curve for $5 \mathrm{ft}$ by $10 \mathrm{ft}$ sluice, Monoliths 7-8-9

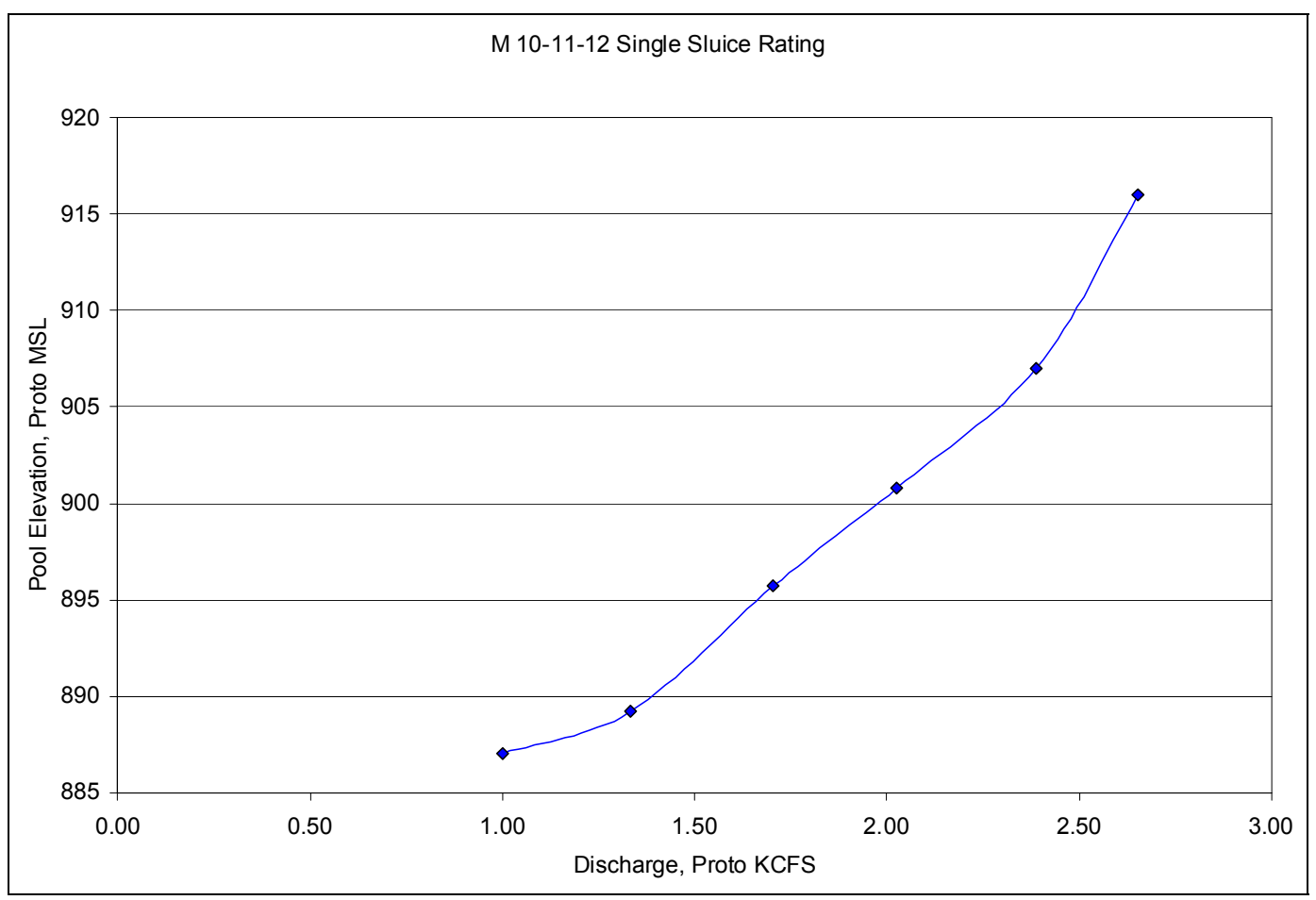

Figure $6 \mathrm{~b}$. Single sluice rating curve for $7 \mathrm{ft}$ by $7 \mathrm{ft}$ sluice, Monoliths $10-11-12$. 


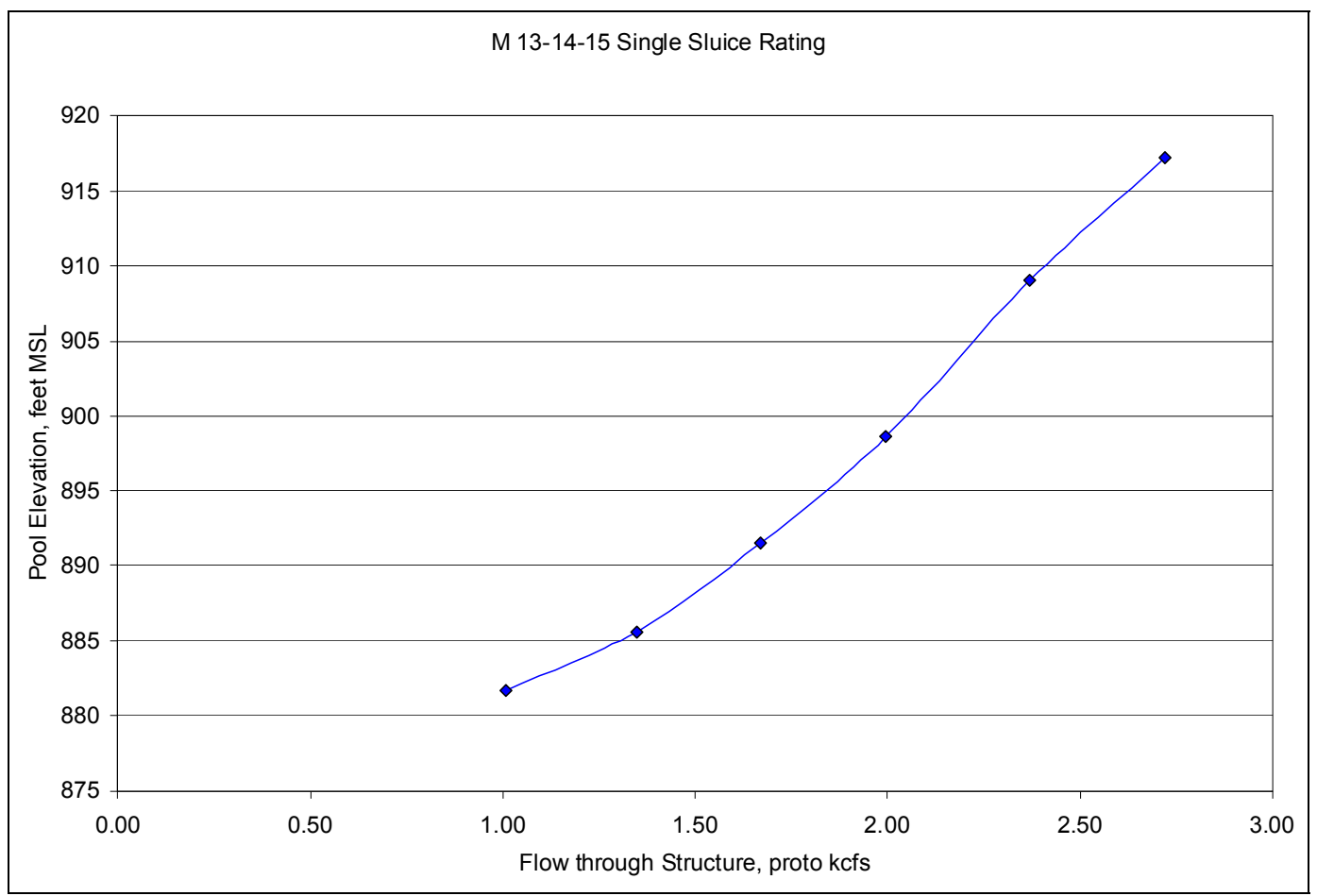

Figure $6 \mathrm{c}$. Single sluice rating curve for $7 \mathrm{ft}$ by $7 \mathrm{ft}$ sluice, Monoliths $13-14-15$.

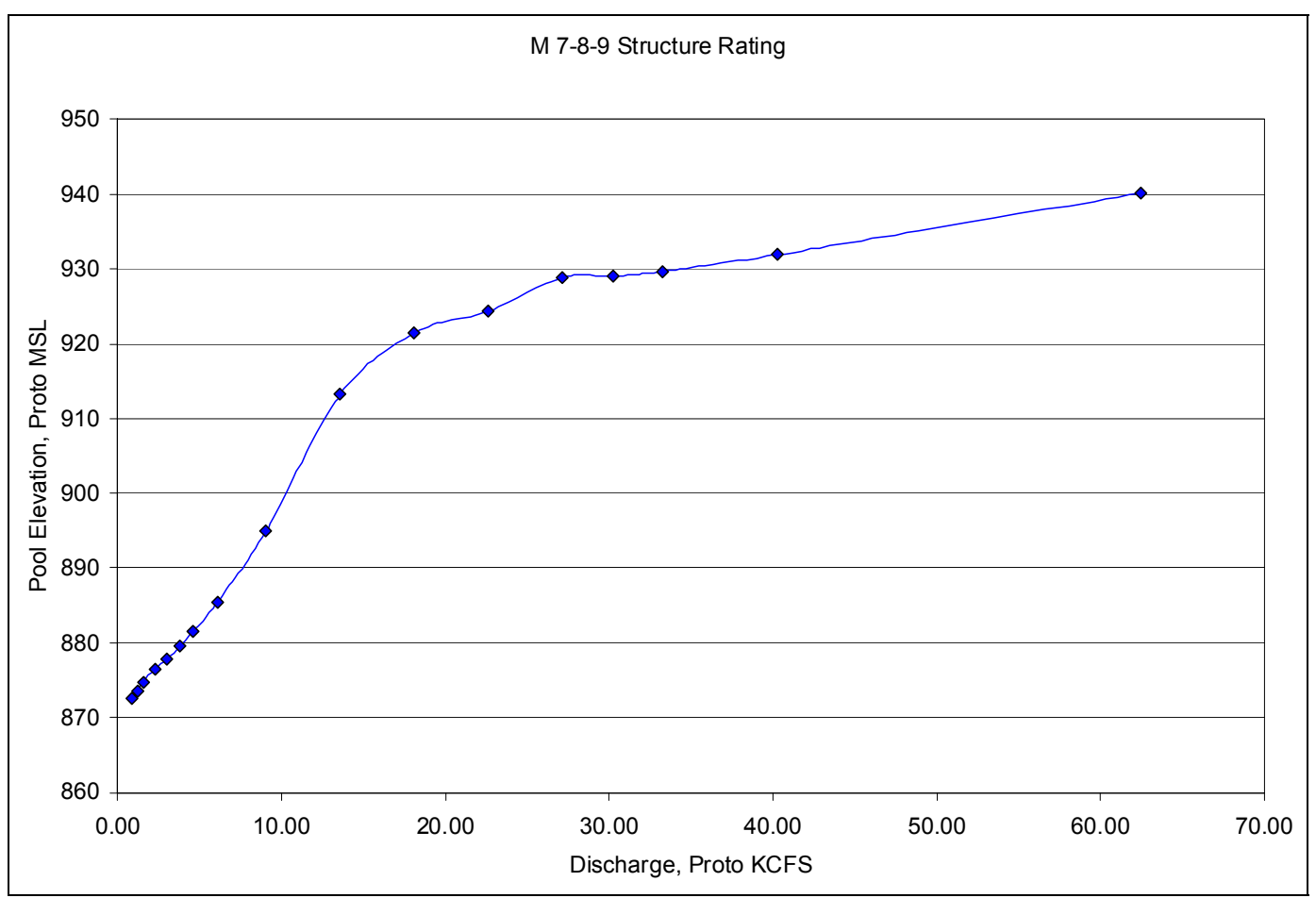

Figure 7a. Structure rating curve, Monoliths 7-8-9. 


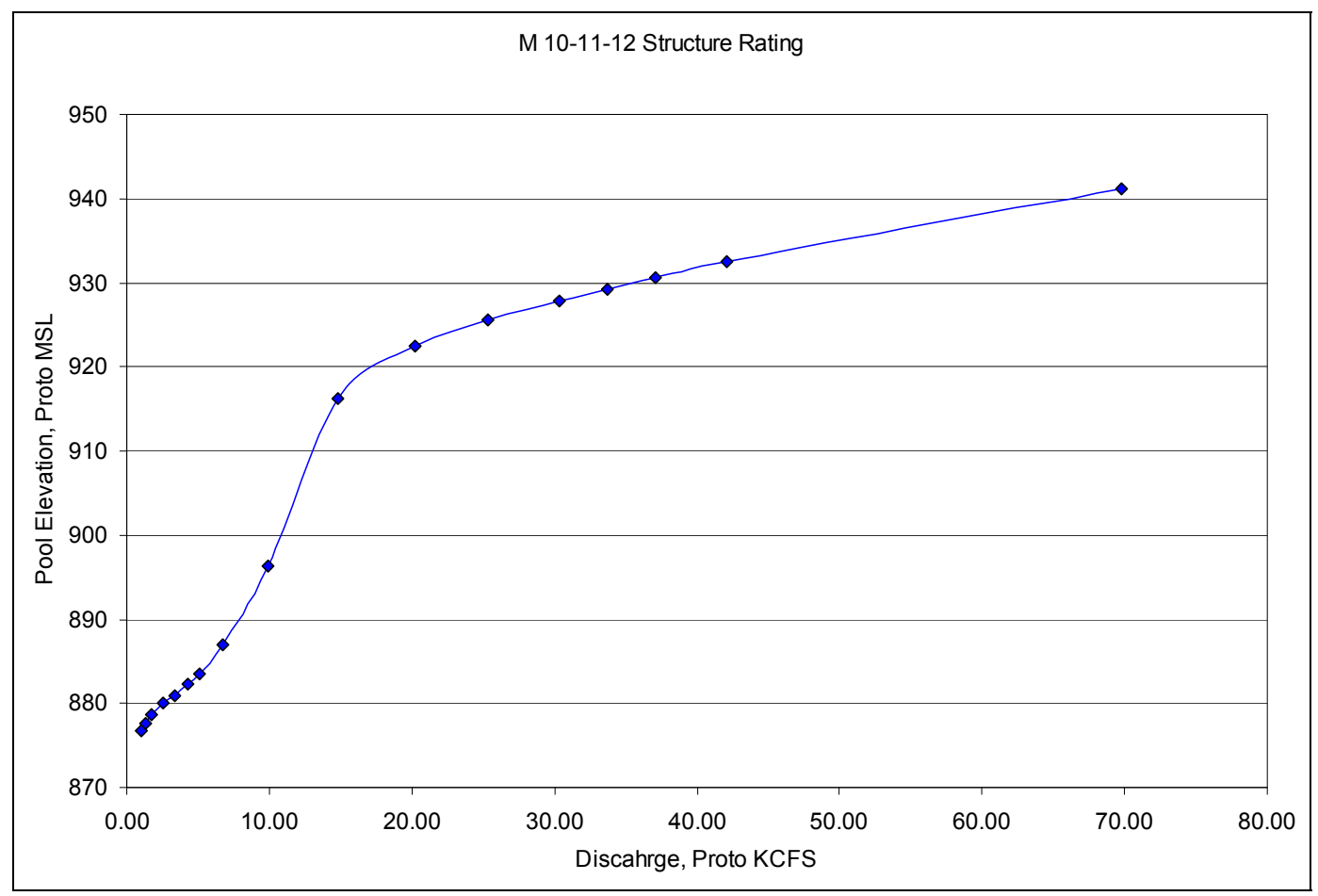

Figure 7b. Structure rating curve, Monoliths 10-11-12.

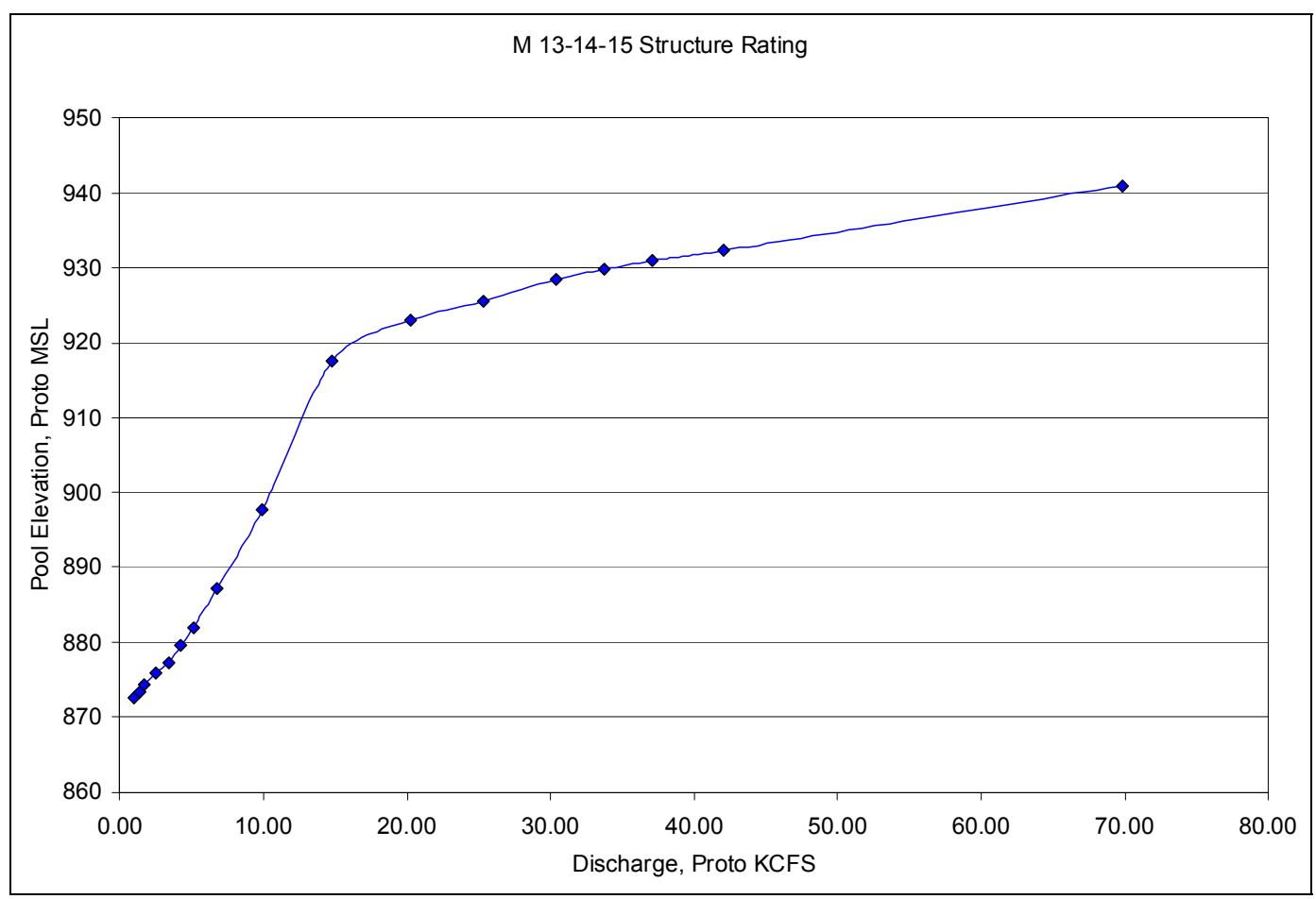

Figure 7c. Structure rating curve, Monoliths 13-14-15. 


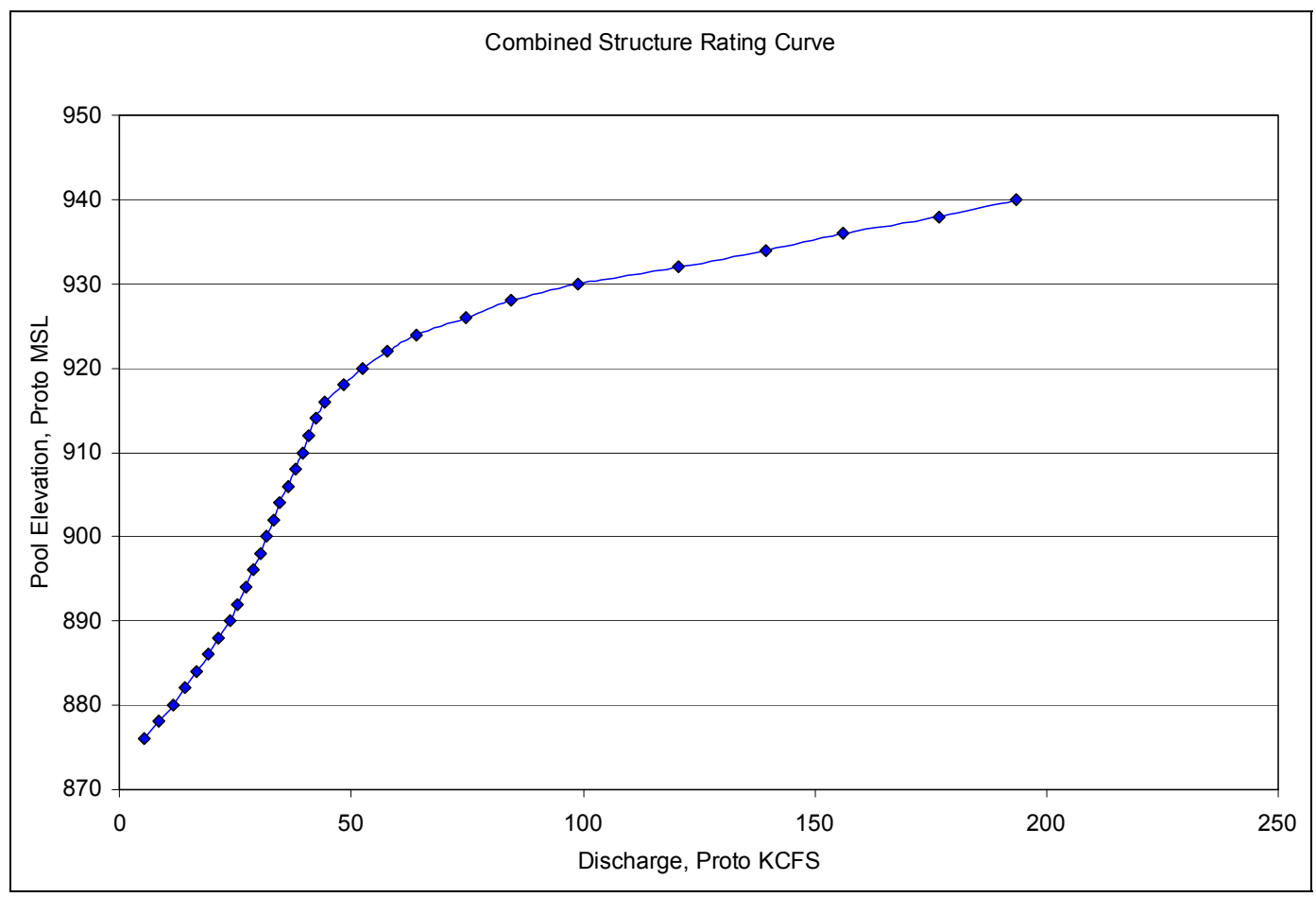

Figure 8. Combined structure rating curve.

\section{Tailwater sensitivity}

Early in the study, prior to data collection, it was observed that for the tailwater and flow conditions given for condition 7, a higher than estimated pool was achieved. It was thought that the higher pool elevation may have resulted from a tailwater effect influencing the sluice discharge. To test this theory, a constant inflow was set and pool elevations were evaluated over a range of tailwater elevations. It was found that once the tailwater reached an elevation that covered the sluice outlets, there was a backwater effect that caused a rise in the pool. Tailwater sensitivity was evaluated for Monoliths 7-8-9 and Monoliths 10-11-12. Results from these tests are shown in Figure 9. Discharges for the tailwater sensitivity tests are reported as prototype flow through the Monoliths being tested only; flow is not converted back to total river discharge for these figures. 


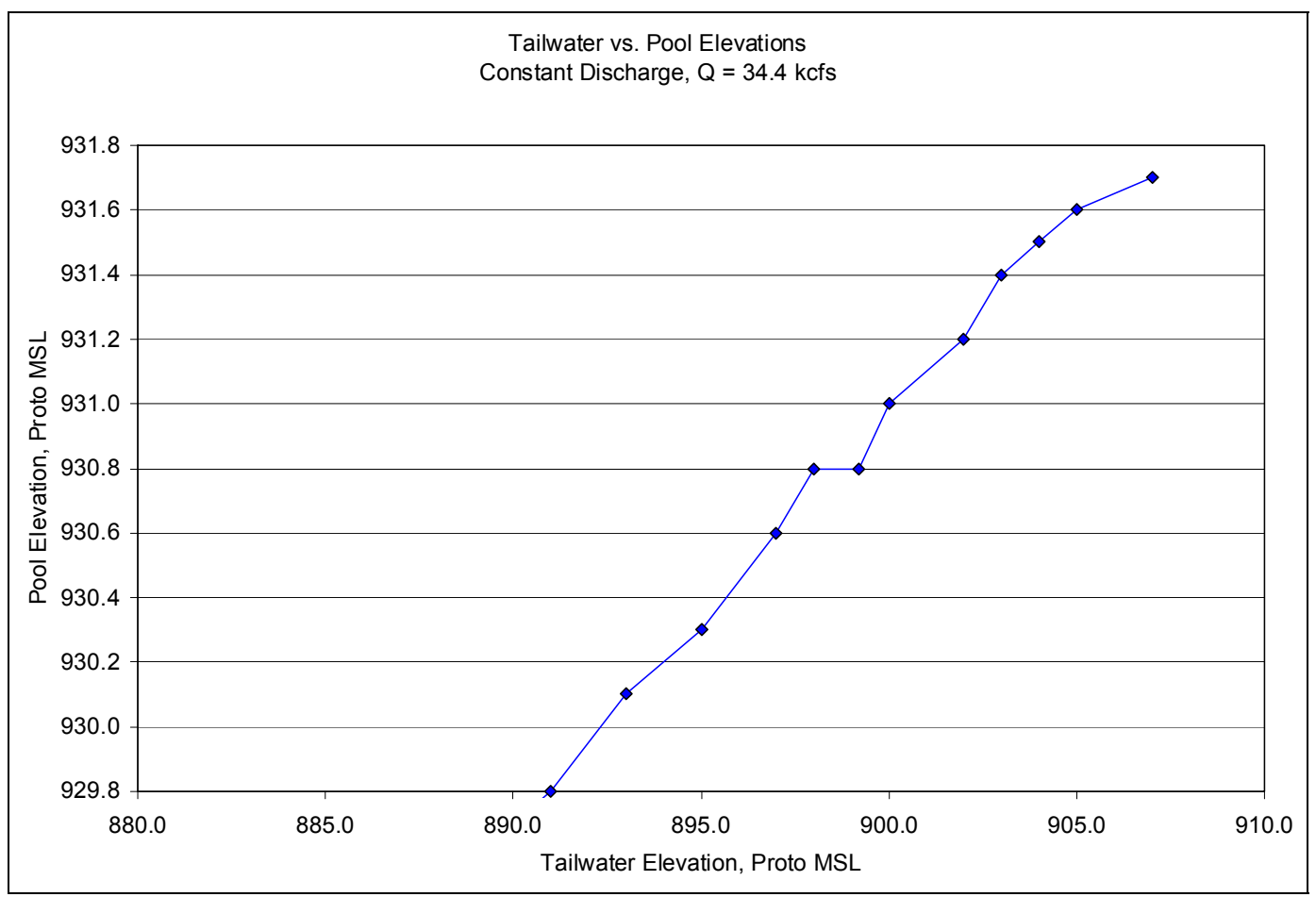

Figure 9a. Tailwater sensitivity data for flow through Monoliths 7-8-9 only.

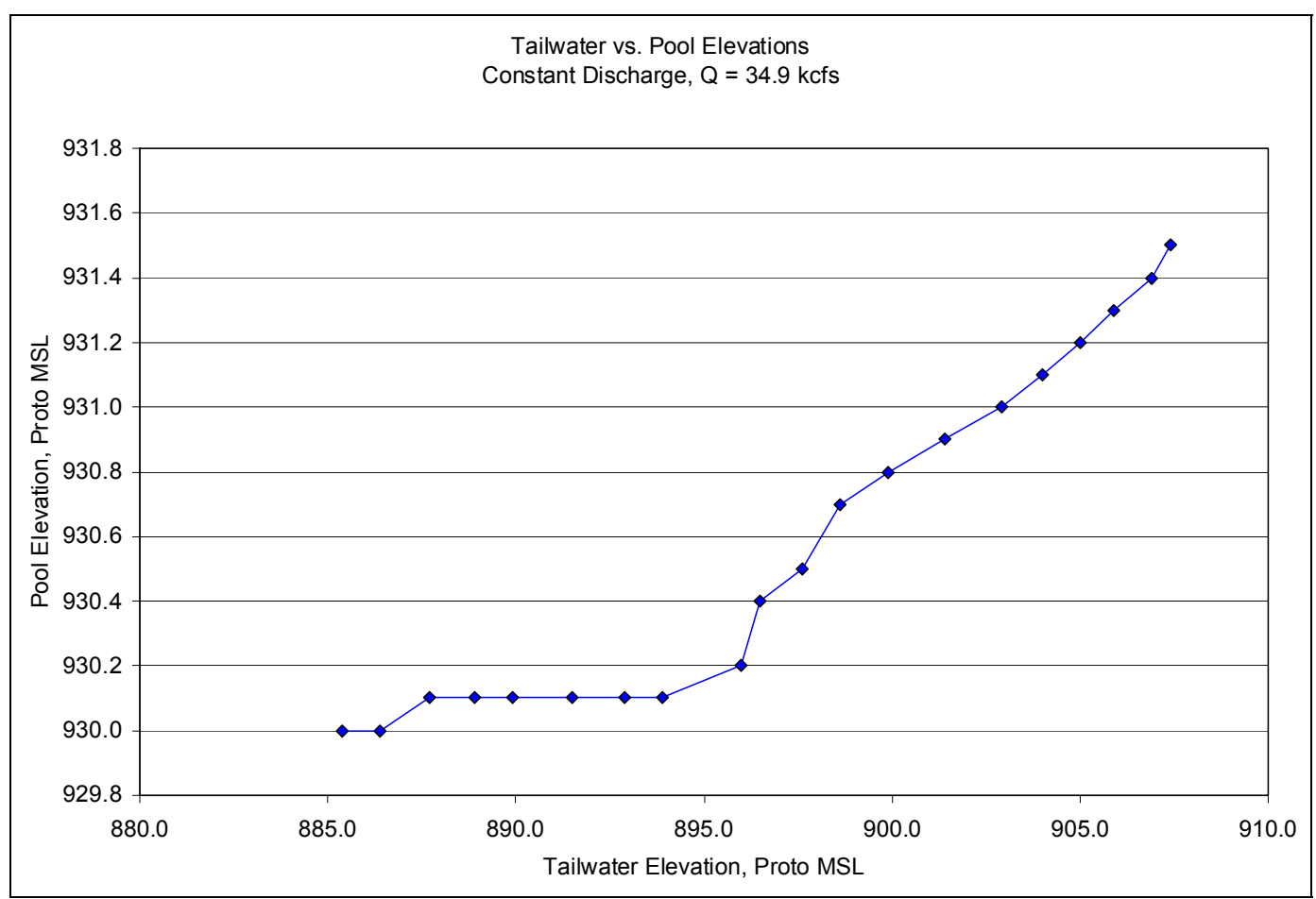

Figure 9b. Tailwater sensitivity data for flow through Monoliths 10-11-12 only. 


\section{Pressure data}

Several locations on the structure were selected for pressure measurements using both piezometers and pressure transducers. Druck (Type PDCR 800 Series) pressure transducers were used to collect time series pressure data at five locations on each structure, including two rows of drains, the upstream and downstream baffle blocks, and on the stilling basin apron between the sluice outlets and the upstream row of baffle blocks. Three sets of pressure data were collected during each condition for a period of 180 seconds (model) which corresponds to three data sets, approximately 16 minutes (prototype) each for each flow condition. Tables 3 a through $3 \mathrm{c}$ give the locations of the piezometers and pressure cells relative to the top of the crest and the local axis of each set of monoliths and Figure 10 shows these locations on plan and profile drawings of the structures.

Table 3a. Pressure cell and piezometer locations for Monoliths 7-8-9.

\begin{tabular}{|c|c|c|c|c|}
\hline \multirow{2}{*}{$\begin{array}{l}\text { Location } \\
\text { Number }\end{array}$} & \multirow[b]{2}{*}{ Distance Downstream From Crest (ft) } & \multicolumn{2}{|c|}{ Displacement From Local Axis (ft) } & \multirow[b]{2}{*}{ Elevation (MSL) } \\
\hline & & Pressure Cell & Piezometer & \\
\hline 1 & 0.00 & & 8.50 & 916.00 \\
\hline 2 & 5.00 & & 8.50 & 915.26 \\
\hline 3 & 10.00 & & 8.50 & 913.04 \\
\hline 4 & 15.00 & & 8.50 & 909.33 \\
\hline 5 & 20.00 & & 8.50 & 904.16 \\
\hline 6 & 25.00 & & 8.50 & 897.67 \\
\hline 7 & 30.00 & & 8.50 & 891.00 \\
\hline 9 & 81.00 & -8.50 & 8.50 & 857.00 \\
\hline 10 & 97.00 & -8.50 & 8.50 & 854.00 \\
\hline 11 & 111.75 & -12.75 & 4.25 & 859.25 \\
\hline 12 & 114.50 & & 12.75 & 891.50 \\
\hline 13 & 117.25 & & 21.40 & 857.75 \\
\hline 14 & 129.75 & -8.50 & -25.50 & 859.25 \\
\hline 15 & 132.50 & & 8.50 & 891.50 \\
\hline 16 & 135.25 & & 25.50 & 887.75 \\
\hline 17 & 163.00 & -8.50 & 8.50 & 854.00 \\
\hline 18 & 182.00 & & 8.50 & 859.18 \\
\hline 19 & 185.30 & & 25.50 & 860.00 \\
\hline 20 & 187.00 & & -25.50 & 859.00 \\
\hline
\end{tabular}


Table 3b. Pressure cell and piezometer locations for Monoliths 10-11-12.

\begin{tabular}{|c|c|c|c|l|}
\hline \multirow{2}{*}{$\begin{array}{l}\text { Location } \\
\text { Number }\end{array}$} & \multirow{2}{*}{ Distance Downstream From Crest (ft) } & \multicolumn{2}{|c|}{ Displacement From Local Axis (ft) } & \\
\cline { 4 - 5 } & & Pressure Cell & Piezometer & Elevation (MSL) \\
\hline 1 & 0.00 & & 9.50 & 916.00 \\
\hline 2 & 5.00 & & 9.50 & 915.26 \\
\hline 3 & 10.00 & & 9.50 & 913.04 \\
\hline 4 & 15.00 & & 9.50 & 909.33 \\
\hline 5 & 20.00 & & 9.50 & 904.16 \\
\hline 6 & 25.00 & & 9.50 & 897.67 \\
\hline 7 & 30.00 & -9.50 & 9.50 & 891.00 \\
\hline 9 & 81.00 & -9.50 & 9.50 & 864.75 \\
\hline 10 & 97.00 & -9.50 & 9.50 & 859.00 \\
\hline 11 & 114.92 & & 9.50 & 862.50 \\
\hline 12 & 116.75 & & -28.50 & 864.00 \\
\hline 13 & 118.58 & & 28.50 & 861.50 \\
\hline 14 & 125.58 & & 6.33 & 862.50 \\
\hline 15 & 127.42 & & -31.67 & 864.00 \\
\hline 16 & 129.25 & & 25.33 & 861.50 \\
\hline 17 & 136.25 & -9.50 & 9.50 & 862.50 \\
\hline 18 & 138.08 & & -28.50 & 864.00 \\
\hline 19 & 139.92 & & 28.50 & 861.50 \\
\hline 20 & 163.00 & & 9.50 & 859.00 \\
\hline 21 & 185.00 & & -28.50 & 859.50 \\
\hline 22 & 186.00 & & 28.50 & 860.00 \\
\hline 23 & 187.00 & & & \\
\hline & & & & \\
\hline
\end{tabular}

Table 3c. Pressure cell and piezometer locations for Monoliths 13-14-15.

\begin{tabular}{|c|c|l|l|l|}
\hline \multirow{2}{*}{$\begin{array}{l}\text { Location } \\
\text { Number }\end{array}$} & \multirow{2}{*}{ Distance Downstream From Crest (ft) } & \multicolumn{2}{|c|}{ Displacement From Local Axis (ft) } & \multirow{2}{*}{ Elevation (MSL) } \\
\cline { 3 - 4 } & & Pressure Cell & Piezometer & 916.00 \\
\hline 1 & 0.00 & & 9.50 & 915.26 \\
\hline 2 & 5.00 & & 9.50 & 913.04 \\
\hline 3 & 10.00 & & 9.50 & 909.33 \\
\hline 4 & 15.00 & & 9.50 & 904.16 \\
\hline 5 & 20.00 & & 9.50 & 897.67 \\
\hline 6 & 25.00 & & 9.50 & 891.00 \\
\hline 7 & 30.00 & & 9.50 & 861.40 \\
\hline 9 & 81.00 & -9.50 & 9.50 & 860.00 \\
\hline 10 & 97.00 & -9.50 & 9.50 & 863.50 \\
\hline 11 & 103.31 & -9.50 & 9.50 & \\
\hline
\end{tabular}




\begin{tabular}{|c|l|l|l|l|}
\hline \multirow{2}{*}{$\begin{array}{l}\text { Location } \\
\text { Number }\end{array}$} & \multirow{2}{*}{ Distance Downstream From Crest (ft) } & \multicolumn{2}{|c|}{ Displacement From Local Axis (ft) } & \multirow{2}{*}{ Elevation (MSL) } \\
\cline { 3 - 4 } & & Pressure Cell & Piezometer & 865.00 \\
\hline 12 & 105.14 & & -28.50 & 862.50 \\
\hline 13 & 106.98 & & 28.50 & 863.50 \\
\hline 14 & 113.98 & & 6.33 & 865.00 \\
\hline 15 & 115.81 & & -31.67 & 862.50 \\
\hline 16 & 117.65 & & 25.33 & 863.50 \\
\hline 17 & 124.65 & -9.50 & 9.50 & 865.00 \\
\hline 18 & 126.48 & & -28.50 & 862.50 \\
\hline 19 & 128.31 & & 28.50 & 860.00 \\
\hline 20 & 163.00 & -9.50 & 9.50 & 860.00 \\
\hline 21 & 186.00 & & 9.50 & 859.00 \\
\hline 22 & 187.00 & & 28.50 & \\
\hline
\end{tabular}

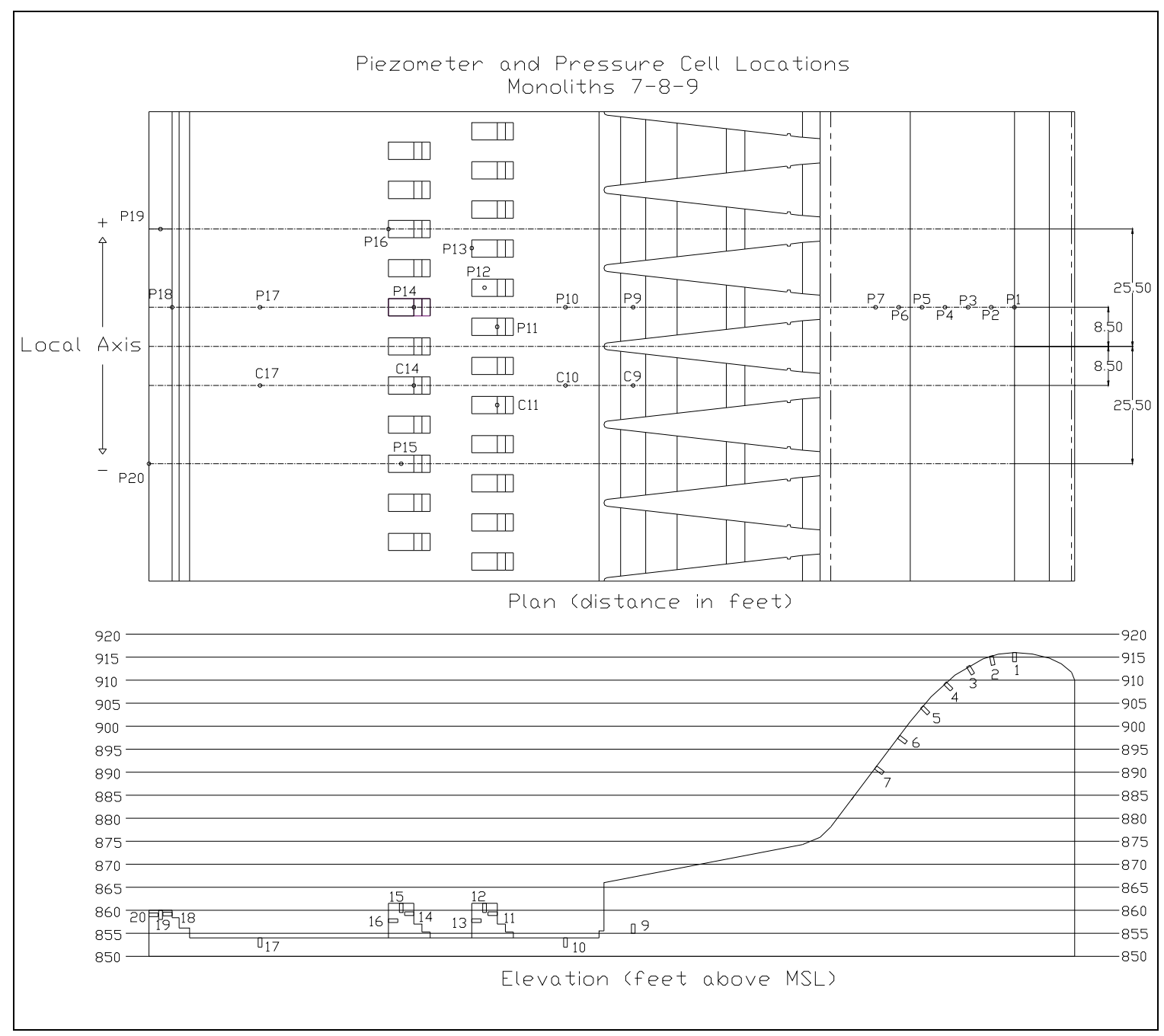

Figure 10a. Piezometer and pressure cell locations for Monoliths 7-8-9. 


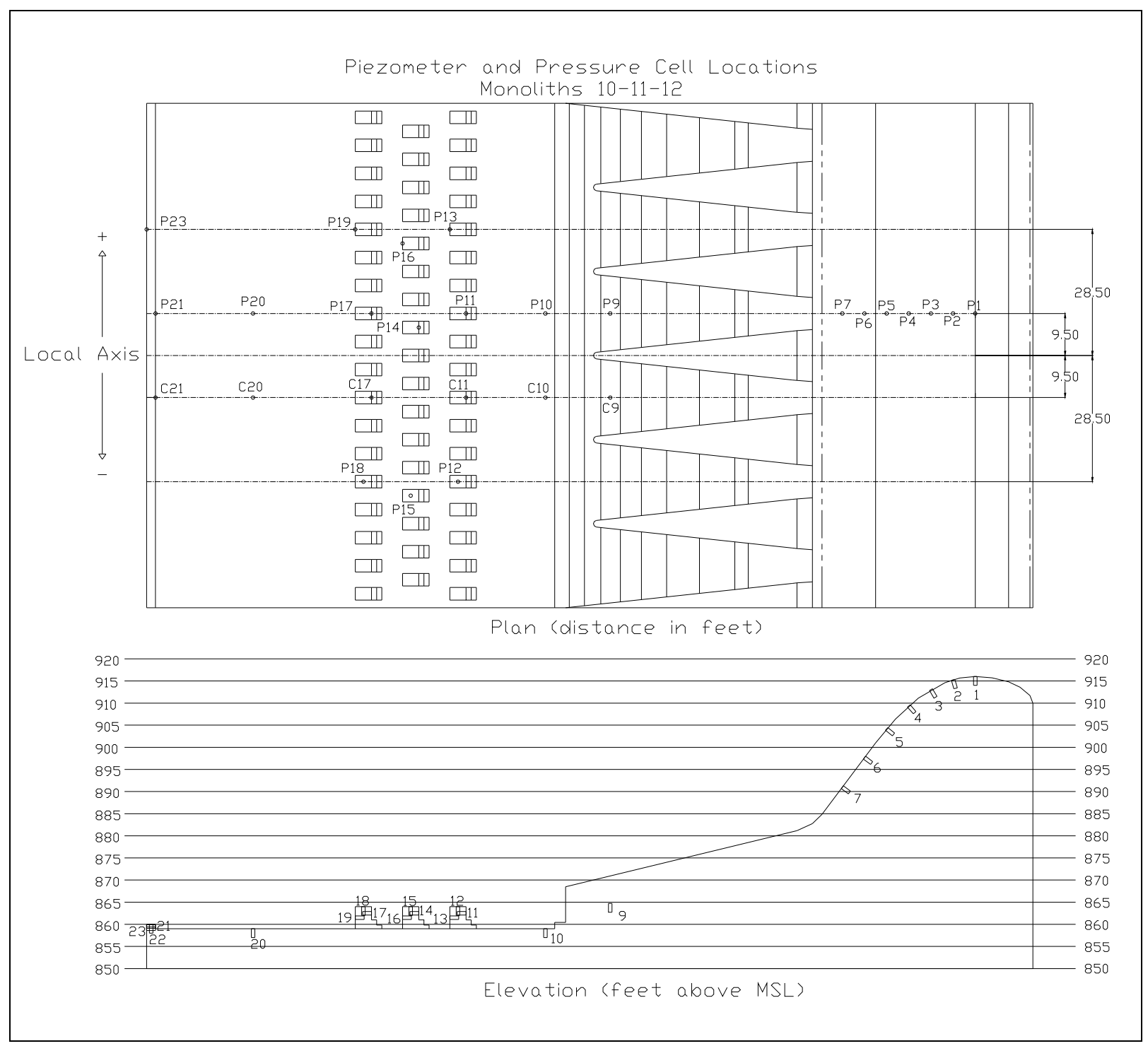

Figure 10b. Piezometer and pressure cell locations for Monoliths 10-11-12. 


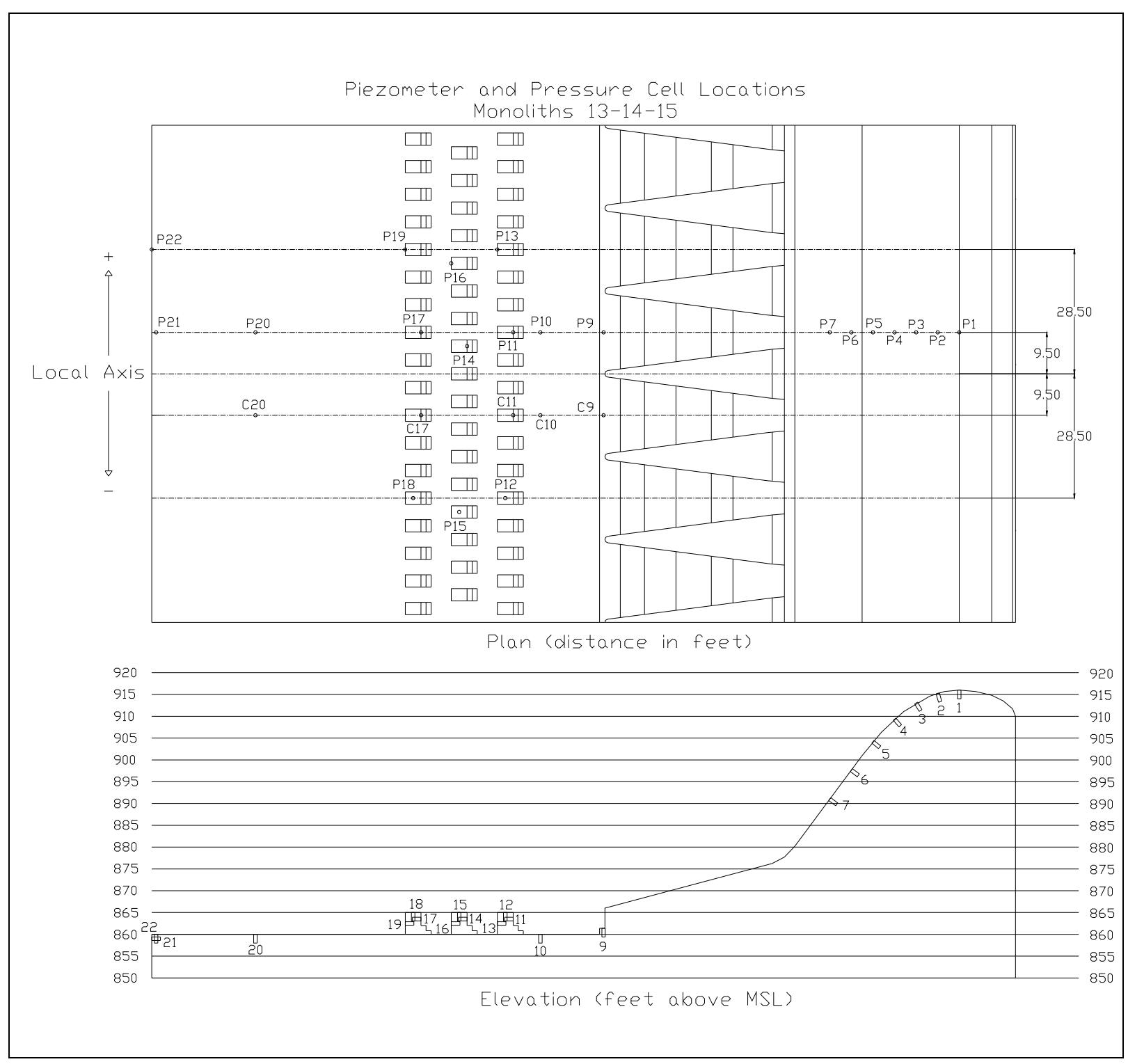

Figure 10c. Piezometer and pressure cell locations for Monoliths 13-14-15.

Tables 4, 5, and 6 give a summary of the pressure data collected for Monoliths 7-8-9, 10-11-12, and 13-14-15, respectively. Included are the minimum, maximum, and average pressure readings from the pressure transducers, as well as the average readings from each piezometer for each condition. Table 7 gives the measured flow, pool elevations, and tailwater elevations for each of the conditions while the pressure measurements were being taken. Note that Condition 7 was only recorded for Monoliths 7-8-9 since this was the only section of sluices open during the actual event. 
Table 4a. Pressure cell and piezometer readings for Monoliths 7-8-9, Condition 1.

\begin{tabular}{|c|c|c|c|c|c|c|c|c|c|c|}
\hline \multirow{2}{*}{$\begin{array}{l}\text { Location } \\
\text { Number }\end{array}$} & \multirow{2}{*}{$\begin{array}{l}\text { Average Pressure } \\
\text { From Piezometer, } \\
\text { Feet of } \mathrm{H} 2 \mathrm{O}\end{array}$} & \multicolumn{3}{|c|}{$\begin{array}{l}\text { Average Pressure From } \\
\text { Pressure Cell, Feet of H2O }\end{array}$} & \multicolumn{3}{|c|}{$\begin{array}{l}\text { Maximum Pressure From } \\
\text { Pressure Cell, Feet of H2O }\end{array}$} & \multicolumn{3}{|c|}{$\begin{array}{l}\text { Minimum Pressure From } \\
\text { Pressure Cell, Feet of H2O }\end{array}$} \\
\hline & & Test 1 & Test 2 & Test 3 & Test 1 & Test 2 & Test 3 & Test 1 & Test 2 & Test 3 \\
\hline \multicolumn{11}{|l|}{1} \\
\hline \multicolumn{11}{|l|}{2} \\
\hline \multicolumn{11}{|l|}{3} \\
\hline \multicolumn{11}{|l|}{4} \\
\hline \multicolumn{11}{|l|}{5} \\
\hline \multicolumn{11}{|l|}{6} \\
\hline \multicolumn{11}{|l|}{7} \\
\hline 9 & 21.9 & 21.73 & 21.77 & 21.74 & 23.67 & 23.73 & 23.94 & 19.47 & 19.80 & 19.11 \\
\hline 10 & 26.4 & 25.91 & 25.91 & 25.90 & 28.14 & 28.26 & 27.81 & 23.58 & 23.97 & 23.28 \\
\hline 11 & 24.0 & 23.88 & 23.86 & 23.88 & 29.73 & 29.40 & 29.07 & 20.73 & 20.76 & 20.97 \\
\hline 12 & -12.2 & & & & & & & & & \\
\hline 13 & 22.9 & & & & & & & & & \\
\hline 14 & 22.8 & 22.87 & 22.86 & 22.88 & 26.49 & 25.80 & 26.22 & 21.66 & 21.75 & 21.66 \\
\hline 15 & -10.6 & & & & & & & & & \\
\hline 16 & -6.8 & & & & & & & & & \\
\hline 17 & 27.1 & 25.49 & 25.48 & 25.48 & 25.59 & 25.59 & 25.59 & 25.38 & 25.38 & 25.38 \\
\hline 18 & 21.9 & & & & & & & & & \\
\hline 19 & 21.0 & & & & & & & & & \\
\hline 20 & 22.0 & & & & & & & & & \\
\hline
\end{tabular}

Table 4b. Pressure cell and piezometer readings for Monoliths 7-8-9, Condition 2.

\begin{tabular}{|c|l|c|c|c|c|c|c|c|c|c|}
\hline \multirow{2}{*}{$\begin{array}{l}\text { Location } \\
\text { Number }\end{array}$} & $\begin{array}{l}\text { Average Pressure } \\
\text { From Piezometer, } \\
\text { Feet of H2O }\end{array}$ & \multicolumn{2}{|c|}{$\begin{array}{l}\text { Average Pressure From } \\
\text { Pressure Cell, Feet of H2O }\end{array}$} & \multicolumn{2}{|c|}{$\begin{array}{l}\text { Maximum Pressure From } \\
\text { Pressure Cell, Feet of H2O }\end{array}$} & \multicolumn{3}{|c|}{$\begin{array}{l}\text { Minimum Pressure From } \\
\text { Pressure Cell, Feet of H2O }\end{array}$} \\
\hline & & Test 1 & Test 2 & Test 3 & Test 1 & Test 2 & Test 3 & Test 1 & Test 2 & Test 3 \\
\hline 1 & & & & & & & & & & \\
\hline 2 & & & & & & & & & & \\
\hline 3 & & & & & & & & & & \\
\hline 4 & & & & & & & & & & \\
\hline 5 & & & & & & & & & & \\
\hline 6 & & & & & & & & & & \\
\hline 7 & & & & & & & & & & \\
\hline 9 & 23.7 & 30.61 & 30.59 & 30.65 & 36.21 & 35.58 & 35.28 & 25.65 & 25.11 & 24.36 \\
\hline 10 & 31.0 & 31.76 & 31.67 & 31.71 & 45.21 & 44.55 & 42.66 & 23.94 & 23.55 & 23.64 \\
\hline 11 & 30.8 & & & & & & & & & \\
\hline 12 & -11.5 & & & & & & & & & \\
\hline 13 & 25.3 & & & & & & & & & \\
\hline
\end{tabular}




\begin{tabular}{|c|c|c|c|c|c|c|c|c|c|c|}
\hline \multirow{2}{*}{$\begin{array}{l}\text { Location } \\
\text { Number }\end{array}$} & \multirow{2}{*}{$\begin{array}{l}\text { Average Pressure } \\
\text { From Piezometer, } \\
\text { Feet of } \mathrm{H} 2 \mathrm{O}\end{array}$} & \multicolumn{3}{|c|}{$\begin{array}{l}\text { Average Pressure From } \\
\text { Pressure Cell, Feet of } \mathrm{H} 2 \mathrm{O}\end{array}$} & \multicolumn{3}{|c|}{$\begin{array}{l}\text { Maximum Pressure From } \\
\text { Pressure Cell, Feet of H2O }\end{array}$} & \multicolumn{3}{|c|}{$\begin{array}{l}\text { Minimum Pressure From } \\
\text { Pressure Cell, Feet of H2O }\end{array}$} \\
\hline & & Test 1 & Test 2 & Test 3 & Test 1 & Test 2 & Test 3 & Test 1 & Test 2 & Test 3 \\
\hline 14 & 28.8 & 29.09 & 29.05 & 29.19 & 36.15 & 37.47 & 38.07 & 24.72 & 25.50 & 25.53 \\
\hline 15 & -7.3 & & & & & & & & & \\
\hline 16 & -2.8 & & & & & & & & & \\
\hline 17 & 31.2 & 29.68 & 29.68 & 29.70 & 29.85 & 29.85 & 29.88 & 29.46 & 29.43 & 29.46 \\
\hline 18 & 26.3 & & & & & & & & & \\
\hline 19 & 25.0 & & & & & & & & & \\
\hline 20 & 26.1 & & & & & & & & & \\
\hline
\end{tabular}

Table 4c. Pressure cell and piezometer readings for Monoliths 7-8-9, Condition 3.

\begin{tabular}{|c|c|c|c|c|c|c|c|c|c|c|}
\hline \multirow{2}{*}{$\begin{array}{l}\text { Location } \\
\text { Number }\end{array}$} & \multirow{2}{*}{$\begin{array}{l}\text { Average Pressure } \\
\text { From Piezometer, } \\
\text { Feet of } \mathrm{H}_{2} \mathrm{O}\end{array}$} & \multicolumn{3}{|c|}{$\begin{array}{l}\text { Average Pressure From } \\
\text { Pressure Cell, Feet of } \mathrm{H}_{2} \mathrm{O}\end{array}$} & \multicolumn{3}{|c|}{$\begin{array}{l}\text { Maximum Pressure From } \\
\text { Pressure Cell, Feet of } \mathrm{H}_{2} \mathrm{O}\end{array}$} & \multicolumn{3}{|c|}{$\begin{array}{l}\text { Minimum Pressure From } \\
\text { Pressure Cell, Feet of } \mathrm{H}_{2} \mathrm{O}\end{array}$} \\
\hline & & Test 1 & Test 2 & Test 3 & Test 1 & Test 2 & Test 3 & Test 1 & Test 2 & Test 3 \\
\hline \multicolumn{11}{|l|}{1} \\
\hline \multicolumn{11}{|l|}{2} \\
\hline \multicolumn{11}{|l|}{3} \\
\hline \multicolumn{11}{|l|}{4} \\
\hline \multicolumn{11}{|l|}{5} \\
\hline \multicolumn{11}{|l|}{6} \\
\hline \multicolumn{11}{|l|}{7} \\
\hline 9 & 24.3 & 24.44 & 24.45 & 24.45 & 29.43 & 29.31 & 30.18 & 18.33 & 19.11 & 20.13 \\
\hline 10 & 31.0 & 31.63 & 31.63 & 31.69 & 36.99 & 36.78 & 37.32 & 25.86 & 25.98 & 27.00 \\
\hline 11 & 32.8 & 33.05 & 33.18 & 33.19 & 47.04 & 46.05 & 46.92 & 24.03 & 23.82 & 23.43 \\
\hline 12 & -11.5 & & & & & & & & & \\
\hline 13 & 26.0 & & & & & & & & & \\
\hline 14 & 30.0 & 30.29 & 30.34 & 30.37 & 38.31 & 39.24 & 40.59 & 25.86 & 25.98 & 26.31 \\
\hline 15 & -6.3 & & & & & & & & & \\
\hline 16 & -2.0 & & & & & & & & & \\
\hline 17 & 32.2 & 30.58 & 30.58 & 30.58 & 30.78 & 30.78 & 30.84 & 30.33 & 30.30 & 30.36 \\
\hline 18 & 27.2 & & & & & & & & & \\
\hline 19 & 26.2 & & & & & & & & & \\
\hline 20 & 27.2 & & & & & & & & & \\
\hline
\end{tabular}


Table 4d. Pressure cell and piezometer readings for Monoliths 7-8-9, Condition 4.

\begin{tabular}{|c|c|c|c|c|c|c|c|c|c|c|}
\hline \multirow{2}{*}{$\begin{array}{l}\text { Location } \\
\text { Number }\end{array}$} & \multirow{2}{*}{$\begin{array}{l}\text { Average Pressure } \\
\text { From Piezometer, } \\
\text { Feet of } \mathrm{H} 2 \mathrm{O}\end{array}$} & \multicolumn{3}{|c|}{$\begin{array}{l}\text { Average Pressure From } \\
\text { Pressure Cell, Feet of } \mathrm{H} 2 \mathrm{O}\end{array}$} & \multicolumn{3}{|c|}{$\begin{array}{l}\text { Maximum Pressure From } \\
\text { Pressure Cell, Feet of H2O }\end{array}$} & \multicolumn{3}{|c|}{$\begin{array}{l}\text { Minimum Pressure From } \\
\text { Pressure Cell, Feet of } \mathrm{H} 2 \mathrm{O}\end{array}$} \\
\hline & & Test 1 & Test 2 & Test 3 & Test 1 & Test 2 & Test 3 & Test 1 & Test 2 & Test 3 \\
\hline 1 & 4.3 & & & & & & & & & \\
\hline 2 & 2.4 & & & & & & & & & \\
\hline 3 & 1.3 & & & & & & & & & \\
\hline 4 & 0.9 & & & & & & & & & \\
\hline 5 & 1.1 & & & & & & & & & \\
\hline 6 & 1.8 & & & & & & & & & \\
\hline 7 & 1.5 & & & & & & & & & \\
\hline 9 & 36.7 & 26.73 & 26.74 & 26.88 & 31.77 & 32.01 & 31.56 & 22.38 & 21.45 & 22.47 \\
\hline 10 & 40.0 & 39.83 & 39.86 & 39.88 & 45.33 & 45.63 & 45.06 & 34.32 & 35.40 & 34.41 \\
\hline 11 & 47.8 & 47.92 & 47.97 & 48.12 & 61.35 & 63.96 & 63.42 & 36.60 & 36.72 & 36.33 \\
\hline 12 & -12.0 & & & & & & & & & \\
\hline 13 & 29.0 & & & & & & & & & \\
\hline 14 & 41.8 & 43.09 & 43.15 & 42.99 & 55.74 & 56.19 & 54.69 & 33.00 & 31.62 & 31.17 \\
\hline 15 & -6.0 & & & & & & & & & \\
\hline 16 & 1.5 & & & & & & & & & \\
\hline 17 & 37.9 & 35.97 & 35.96 & 35.99 & 36.75 & 36.72 & 36.63 & 35.16 & 35.25 & 35.46 \\
\hline 18 & 33.0 & & & & & & & & & \\
\hline 19 & 32.0 & & & & & & & & & \\
\hline 20 & 33.0 & & & & & & & & & \\
\hline
\end{tabular}

Table 4e. Pressure cell and piezometer readings for Monoliths 7-8-9, Condition 5.

\begin{tabular}{|c|c|c|c|c|c|c|l|c|c|c|}
\hline \multirow{2}{*}{$\begin{array}{l}\text { Location } \\
\text { Number }\end{array}$} & $\begin{array}{l}\text { Average Pressure } \\
\text { From Piezometer, } \\
\text { Feet of H2O }\end{array}$ & \multicolumn{2}{|c|}{$\begin{array}{l}\text { Average Pressure From } \\
\text { Pressure Cell, Feet of H2O }\end{array}$} & \multicolumn{2}{|c|}{$\begin{array}{l}\text { Maximum Pressure From } \\
\text { Pressure Cell, Feet of H2O }\end{array}$} & \multicolumn{2}{|c|}{$\begin{array}{l}\text { Minimum Pressure From } \\
\text { Pressure Cell, Feet of H20 }\end{array}$} \\
\hline & Test 1 & Test 2 & Test 3 & Test 1 & Test 2 & Test 3 & Test 1 & Test 2 & Test 3 \\
\hline 1 & 5.2 & & & & & & & & & \\
\hline 2 & 1.5 & & & & & & & & & \\
\hline 3 & -0.3 & & & & & & & & & \\
\hline 4 & -1.0 & & & & & & & & & \\
\hline 5 & 1.0 & & & & & & & & & \\
\hline 6 & 3.3 & & & & & & & & & \\
\hline 7 & 1.3 & & & & & & & & & \\
\hline 9 & 28.7 & 29.05 & 28.93 & 29.15 & 35.55 & 35.73 & 36.30 & 24.15 & 22.86 & 22.62 \\
\hline 10 & 46.1 & 46.11 & 45.95 & 46.12 & 53.61 & 53.10 & 52.92 & 38.13 & 37.86 & 37.83 \\
\hline 11 & 58.8 & 60.98 & 60.60 & 60.57 & 77.10 & 76.32 & 79.44 & 39.75 & 39.84 & 39.12 \\
\hline 12 & -17.5 & & & & & & & & & \\
\hline 13 & 31.3 & & & & & & & & & \\
\hline
\end{tabular}




\begin{tabular}{|c|c|c|c|c|c|c|c|c|c|c|}
\hline \multirow{2}{*}{$\begin{array}{l}\text { Location } \\
\text { Number }\end{array}$} & \multirow{2}{*}{$\begin{array}{l}\text { Average Pressure } \\
\text { From Piezometer, } \\
\text { Feet of } \mathrm{H} 2 \mathrm{O}\end{array}$} & \multicolumn{3}{|c|}{$\begin{array}{l}\text { Average Pressure From } \\
\text { Pressure Cell, Feet of H2O }\end{array}$} & \multicolumn{3}{|c|}{$\begin{array}{l}\text { Maximum Pressure From } \\
\text { Pressure Cell, Feet of H2O }\end{array}$} & \multicolumn{3}{|c|}{$\begin{array}{l}\text { Minimum Pressure From } \\
\text { Pressure Cell, Feet of H2O }\end{array}$} \\
\hline & & Test 1 & Test 2 & Test 3 & Test 1 & Test 2 & Test 3 & Test 1 & Test 2 & Test 3 \\
\hline 14 & 51.8 & 53.93 & 53.56 & 53.62 & 63.57 & 63.57 & 63.57 & 37.11 & 35.94 & 36.81 \\
\hline 15 & -4.5 & & & & & & & & & \\
\hline 16 & -24.7 & & & & & & & & & \\
\hline 17 & 42.7 & 42.07 & 42.04 & 42.16 & 43.29 & 43.32 & 43.35 & 40.95 & 40.77 & 41.04 \\
\hline 18 & 38.0 & & & & & & & & & \\
\hline 19 & 37.1 & & & & & & & & & \\
\hline 20 & 38.1 & & & & & & & & & \\
\hline
\end{tabular}

Table 4f. Pressure cell and piezometer readings for Monoliths 7-8-9, Condition 6.

\begin{tabular}{|c|c|c|c|c|c|c|l|c|c|c|}
\hline \multirow{2}{*}{$\begin{array}{l}\text { Location } \\
\text { Number }\end{array}$} & \multirow{2}{*}{$\begin{array}{l}\text { Average Pressure } \\
\text { From Piezometer, } \\
\text { Feet of H20 }\end{array}$} & \multicolumn{2}{|c|}{$\begin{array}{c}\text { Average Pressure From } \\
\text { Pressure Cell, Feet of H2O }\end{array}$} & \multicolumn{2}{|c|}{$\begin{array}{l}\text { Maximum Pressure From } \\
\text { Pressure Cell, Feet of H2O }\end{array}$} & \multicolumn{2}{|c|}{$\begin{array}{l}\text { Minimum Pressure From } \\
\text { Pressure Cell, Feet of H20 }\end{array}$} \\
\hline 1 & 2.5 & & & & & & & & & \\
\hline 2 & -3.3 & & & & & & & & & \\
\hline 3 & -5.1 & & & & & & & & & \\
\hline 4 & -3.8 & & & & & & & & & \\
\hline 5 & -0.2 & & & & & & & & & \\
\hline 6 & 5.5 & & & & & & & & & \\
\hline 7 & 9.6 & & & & & & & & & \\
\hline 9 & 36.0 & 36.54 & 36.60 & 36.60 & 43.71 & 45.09 & 44.73 & 30.15 & 30.24 & 31.17 \\
\hline 10 & 56.0 & 55.32 & 55.24 & 55.32 & 57.66 & 57.66 & 57.66 & 46.23 & 45.90 & 45.93 \\
\hline 11 & 74.2 & 75.77 & 75.54 & 75.52 & 85.29 & 85.29 & 85.29 & 46.56 & 46.32 & 41.82 \\
\hline 12 & -16.0 & & & & & & & & & \\
\hline 13 & 34.6 & & & & & & & & & \\
\hline 14 & 69.4 & 62.53 & 62.50 & 62.60 & 63.57 & 63.57 & 63.57 & 43.47 & 40.83 & 38.94 \\
\hline 15 & -3.8 & & & & & & & & & \\
\hline 16 & -9.8 & & & & & & & & & \\
\hline 17 & 49.9 & 49.16 & 49.12 & 49.14 & 103.59 & 141.99 & 141.99 & 44.79 & 45.15 & 44.46 \\
\hline 18 & 45.4 & & & & & & & & & \\
\hline 19 & 43.4 & & & & & & & & & \\
\hline 20 & 45.0 & & & & & & & & & \\
\hline
\end{tabular}


Table 4g. Pressure cell and piezometer readings for Monoliths 7-8-9, Condition 7.

\begin{tabular}{|c|c|c|c|c|c|c|l|c|c|c|}
\hline \multirow{2}{*}{$\begin{array}{l}\text { Location } \\
\text { Number }\end{array}$} & $\begin{array}{l}\text { Average Pressure } \\
\text { From Piezometer, } \\
\text { Feet of H2O }\end{array}$ & \multicolumn{2}{|c|}{$\begin{array}{c}\text { Average Pressure From } \\
\text { Pressure Cell, Feet of H2O }\end{array}$} & \multicolumn{2}{|c|}{$\begin{array}{l}\text { Maximum Pressure From } \\
\text { Pressure Cell, Feet of H2O }\end{array}$} & \multicolumn{3}{|c|}{$\begin{array}{l}\text { Minimum Pressure From } \\
\text { Pressure Cell, Feet of H2O }\end{array}$} \\
\hline & Test 1 & Test 2 & Test 3 & Test 1 & Test 2 & Test 3 & Test 1 & Test 2 & Test 3 \\
\hline 1 & 1.6 & & & & & & & & & \\
\hline 2 & 1.0 & & & & & & & & & \\
\hline 3 & -5.3 & & & & & & & & & \\
\hline 4 & 0.7 & & & & & & & & & \\
\hline 5 & 0.8 & & & & & & & & & \\
\hline 6 & 1.0 & & & & & & & & & \\
\hline 7 & 0.4 & 5.78 & 5.84 & 5.86 & 11.31 & 12.69 & 12.18 & 1.29 & 1.47 & 1.14 \\
\hline 9 & 6.5 & 20.89 & 20.96 & 20.97 & 28.98 & 29.73 & 28.74 & 12.99 & 11.70 & 11.25 \\
\hline 10 & 20.8 & 33.02 & 33.01 & 33.02 & 59.16 & 56.76 & 58.23 & 16.41 & 16.35 & 16.20 \\
\hline 11 & 29.8 & & & & & & & & & \\
\hline 12 & -28.5 & & & & & & & & & \\
\hline 13 & 12.8 & 27.91 & 27.77 & 27.91 & 46.83 & 48.48 & 48.57 & 15.96 & 15.66 & 15.00 \\
\hline 14 & 27.3 & & & & & & & & & \\
\hline 15 & -23.0 & & & & & & & & & \\
\hline 16 & -26.0 & 18.85 & 18.85 & 18.84 & 19.62 & 19.62 & 19.50 & 18.15 & 18.15 & 18.15 \\
\hline 17 & 18.7 & & & & & & & & & \\
\hline 18 & 14.6 & & & & & & & & & \\
\hline 19 & 13.3 & 14.2 & & & & & & & & \\
\hline 20 & & & & & & & & & & \\
\hline
\end{tabular}

Table 5a. Pressure cell and piezometer readings for Monoliths 10-11-12, Condition 1.

\begin{tabular}{|c|l|c|c|c|c|c|c|c|c|c|}
\hline \multirow{2}{*}{$\begin{array}{l}\text { Location } \\
\text { Number }\end{array}$} & $\begin{array}{l}\text { Average Pressure } \\
\text { From Piezometer, } \\
\text { Feet of H2O }\end{array}$ & \multicolumn{2}{|c|}{$\begin{array}{l}\text { Average Pressure From } \\
\text { Pressure Cell, Feet of H2O }\end{array}$} & \multicolumn{2}{|c|}{$\begin{array}{l}\text { Maximum Pressure From } \\
\text { Pressure Cell, Feet of H2O }\end{array}$} & \multicolumn{3}{c|}{$\begin{array}{l}\text { Minimum Pressure From } \\
\text { Pressure Cell, Feet of H2O }\end{array}$} \\
\hline & Test 1 & Test 2 & Test 3 & Test 1 & Test 2 & Test 3 & Test 1 & Test 2 & Test 3 \\
\hline 1 & & & & & & & & & & \\
\hline 2 & & & & & & & & & & \\
\hline 3 & & & & & & & & & & \\
\hline 4 & & & & & & & & & & \\
\hline 5 & & & & & & & & & & \\
\hline 6 & & & & & & & & & & \\
\hline 7 & & & & & & & & & & \\
\hline 9 & 14.8 & 20.74 & 20.73 & 20.72 & 23.34 & 23.40 & 23.37 & 19.14 & 19.35 & 19.23 \\
\hline 10 & 22.0 & 20.09 & 20.09 & 20.16 & 24.69 & 24.33 & 24.30 & 18.06 & 17.91 & 17.85 \\
\hline 11 & 20.5 & & & & & & & & & \\
\hline 12 & 14.9 & & & & & & & & & \\
\hline 13 & 19.0 & & & & & & & & & \\
\hline
\end{tabular}




\begin{tabular}{|c|c|c|c|c|c|c|c|c|c|c|}
\hline \multirow{2}{*}{$\begin{array}{l}\text { Location } \\
\text { Number }\end{array}$} & \multirow{2}{*}{$\begin{array}{l}\text { Average Pressure } \\
\text { From Piezometer, } \\
\text { Feet of } \mathrm{H} 2 \mathrm{O}\end{array}$} & \multicolumn{3}{|c|}{$\begin{array}{l}\text { Average Pressure From } \\
\text { Pressure Cell, Feet of } \mathrm{H} 2 \mathrm{O}\end{array}$} & \multicolumn{3}{|c|}{$\begin{array}{l}\text { Maximum Pressure From } \\
\text { Pressure Cell, Feet of } \mathrm{H} 2 \mathrm{O}\end{array}$} & \multicolumn{3}{|c|}{$\begin{array}{l}\text { Minimum Pressure From } \\
\text { Pressure Cell, Feet of } \mathrm{H} 2 \mathrm{O}\end{array}$} \\
\hline & & Test 1 & Test 2 & Test 3 & Test 1 & Test 2 & Test 3 & Test 1 & Test 2 & Test 3 \\
\hline 14 & 20.0 & & & & & & & & & \\
\hline 15 & 16.6 & & & & & & & & & \\
\hline 16 & 19.4 & & & & & & & & & \\
\hline 17 & 18.7 & 18.39 & 18.38 & 18.34 & 19.38 & 19.38 & 19.41 & 18.00 & 18.00 & 17.97 \\
\hline 18 & 17.0 & & & & & & & & & \\
\hline 19 & 19.5 & & & & & & & & & \\
\hline 20 & 22.0 & 21.29 & 21.29 & 21.29 & 21.48 & 21.51 & 21.48 & 21.12 & 21.09 & 21.09 \\
\hline 21 & 14.2 & & & & & & & & & \\
\hline 22 & 21.1 & & & & & & & & & \\
\hline 23 & 22.2 & & & & & & & & & \\
\hline
\end{tabular}

Table 5b. Pressure cell and piezometer readings for Monoliths 10-11-12, Condition 2.

\begin{tabular}{|c|c|c|c|c|c|c|c|c|c|c|}
\hline \multirow{2}{*}{$\begin{array}{l}\text { Location } \\
\text { Number }\end{array}$} & \multirow{2}{*}{$\begin{array}{l}\text { Average Pressure } \\
\text { From Piezometer, } \\
\text { Feet of } \mathrm{H} 2 \mathrm{O}\end{array}$} & \multicolumn{3}{|c|}{$\begin{array}{l}\text { Average Pressure From } \\
\text { Pressure Cell, Feet of H2O }\end{array}$} & \multicolumn{3}{|c|}{$\begin{array}{l}\text { Maximum Pressure From } \\
\text { Pressure Cell, Feet of H2O }\end{array}$} & \multicolumn{3}{|c|}{$\begin{array}{l}\text { Minimum Pressure From } \\
\text { Pressure Cell, Feet of } \mathrm{H} 2 \mathrm{O}\end{array}$} \\
\hline & & Test 1 & Test 2 & Test 3 & Test 1 & Test 2 & Test 3 & Test 1 & Test 2 & Test 3 \\
\hline \multicolumn{11}{|l|}{1} \\
\hline \multicolumn{11}{|l|}{2} \\
\hline \multicolumn{11}{|l|}{3} \\
\hline \multicolumn{11}{|l|}{4} \\
\hline \multicolumn{11}{|l|}{5} \\
\hline \multicolumn{11}{|l|}{6} \\
\hline \multicolumn{11}{|l|}{7} \\
\hline 9 & 18.05 & 16.18 & 16.31 & 16.20 & 26.34 & 27.33 & 26.40 & 8.46 & 7.83 & 7.62 \\
\hline 10 & 25.0 & 24.08 & 23.99 & 23.96 & 30.39 & 29.82 & 30.96 & 18.72 & 18.63 & 17.85 \\
\hline 11 & $24.5-26.5$ & 24.63 & 24.36 & 24.27 & 35.61 & 38.52 & 35.61 & 20.04 & 19.71 & 19.98 \\
\hline 12 & 21.0 & & & & & & & & & \\
\hline 13 & 21.5 & & & & & & & & & \\
\hline 14 & $22.5-25.5$ & & & & & & & & & \\
\hline 15 & 20.0 & & & & & & & & & \\
\hline 16 & 23.3 & & & & & & & & & \\
\hline 17 & 23.0 & 22.49 & 22.45 & 22.42 & 26.64 & 25.77 & 26.19 & 20.91 & 20.91 & 21.18 \\
\hline 18 & 20.7 & & & & & & & & & \\
\hline 19 & 23.5 & & & & & & & & & \\
\hline 20 & 26.3 & 25.39 & 25.40 & 25.39 & 25.95 & 25.89 & 26.04 & 24.63 & 24.72 & 24.90 \\
\hline 21 & 21.1 & & & & & & & & & \\
\hline 22 & 25.2 & & & & & & & & & \\
\hline 23 & 26.4 & & & & & & & & & \\
\hline
\end{tabular}


Table 5c. Pressure cell and piezometer readings for Monoliths 10-11-12, Condition 3.

\begin{tabular}{|c|c|c|c|c|c|c|c|c|c|c|}
\hline \multirow{2}{*}{$\begin{array}{l}\text { Location } \\
\text { Number }\end{array}$} & \multirow{2}{*}{$\begin{array}{l}\text { Average Pressure } \\
\text { From Piezometer, } \\
\text { Feet of H2O }\end{array}$} & \multicolumn{3}{|c|}{$\begin{array}{l}\text { Average Pressure From } \\
\text { Pressure Cell, Feet of } \mathrm{H} 2 \mathrm{O}\end{array}$} & \multicolumn{3}{|c|}{$\begin{array}{l}\text { Maximum Pressure From } \\
\text { Pressure Cell, Feet of } \mathrm{H} 2 \mathrm{O}\end{array}$} & \multicolumn{3}{|c|}{$\begin{array}{l}\text { Minimum Pressure From } \\
\text { Pressure Cell, Feet of H2O }\end{array}$} \\
\hline & & Test 1 & Test 2 & Test 3 & Test 1 & Test 2 & Test 3 & Test 1 & Test 2 & Test 3 \\
\hline \multicolumn{11}{|l|}{1} \\
\hline \multicolumn{11}{|l|}{2} \\
\hline \multicolumn{11}{|l|}{3} \\
\hline \multicolumn{11}{|l|}{4} \\
\hline \multicolumn{11}{|l|}{5} \\
\hline \multicolumn{11}{|l|}{6} \\
\hline \multicolumn{11}{|l|}{7} \\
\hline 9 & 17.7 & 16.18 & 16.19 & 16.16 & 28.59 & 29.67 & 29.79 & 5.40 & 4.89 & 3.12 \\
\hline 10 & 26.5 & 24.65 & 24.69 & 24.71 & 37.71 & 33.18 & 34.65 & 19.17 & 16.02 & 18.00 \\
\hline 11 & 24.5 & 26.18 & 26.17 & 26.25 & 40.50 & 39.87 & 39.93 & 20.31 & 20.31 & 20.94 \\
\hline 12 & 15.5 & & & & & & & & & \\
\hline 13 & 23.5 & & & & & & & & & \\
\hline 14 & 23.4 & & & & & & & & & \\
\hline 15 & 21.0 & & & & & & & & & \\
\hline 16 & 24.1 & & & & & & & & & \\
\hline 17 & 24.0 & 23.34 & 23.35 & 23.31 & 26.55 & 28.08 & 27.24 & 21.45 & 21.00 & 21.21 \\
\hline 18 & 21.5 & & & & & & & & & \\
\hline 19 & 24.2 & & & & & & & & & \\
\hline 20 & 27.0 & 26.31 & 26.31 & 26.27 & 26.97 & 27.00 & 26.88 & 25.53 & 25.71 & 25.74 \\
\hline 21 & 21.1 & & & & & & & & & \\
\hline 22 & 25.2 & & & & & & & & & \\
\hline 23 & 26.4 & & & & & & & & & \\
\hline
\end{tabular}

Table 5d. Pressure cell and piezometer readings for Monoliths 10-11-12, Condition 4.

\begin{tabular}{|c|c|c|c|c|c|c|c|c|c|c|}
\hline \multirow{2}{*}{$\begin{array}{l}\text { Location } \\
\text { Number }\end{array}$} & $\begin{array}{l}\text { Average Pressure } \\
\text { From Piezometer, } \\
\text { Feet of H2O }\end{array}$ & \multicolumn{2}{|c|}{$\begin{array}{c}\text { Average Pressure From } \\
\text { Pressure Cell, Feet of H2O }\end{array}$} & \multicolumn{2}{|c|}{$\begin{array}{l}\text { Maximum Pressure From } \\
\text { Pressure Cell, Feet of H2O }\end{array}$} & \multicolumn{2}{|c|}{$\begin{array}{l}\text { Minimum Pressure From } \\
\text { Pressure Cell, Feet of H2O }\end{array}$} \\
\hline & Test 1 & Test 2 & Test 3 & Test 1 & Test 2 & Test 3 & Test 1 & Test 2 & Test 3 \\
\hline 1 & 4.6 & & & & & & & & & \\
\hline 2 & 2.3 & & & & & & & & & \\
\hline 3 & 1.6 & & & & & & & & & \\
\hline 4 & 1.1 & & & & & & & & & \\
\hline 5 & 1.3 & & & & & & & & & \\
\hline 6 & 1.9 & & & & & & & & & \\
\hline 7 & 2.8 & & & & & & & & & \\
\hline
\end{tabular}




\begin{tabular}{|c|l|c|c|c|c|c|c|c|c|c|}
\hline \multirow{2}{*}{$\begin{array}{l}\text { Location } \\
\text { Number }\end{array}$} & \multirow{2}{*}{$\begin{array}{l}\text { Average Pressure } \\
\text { From Piezometer, } \\
\text { Feet of H20 }\end{array}$} & \multicolumn{2}{|c|}{$\begin{array}{c}\text { Average Pressure From } \\
\text { Pressure Cell, Feet of H2O }\end{array}$} & \multicolumn{2}{|c|}{$\begin{array}{l}\text { Maximum Pressure From } \\
\text { Pressure Cell, Feet of H2O }\end{array}$} & \multicolumn{3}{|c|}{$\begin{array}{l}\text { Minimum Pressure From } \\
\text { Pressure Cell, Feet of H20 }\end{array}$} \\
\hline & Test 1 & Test 2 & Test 3 & Test 1 & Test 2 & Test 3 & Test 1 & Test 2 & Test 3 \\
\hline 9 & $14.95-16.95$ & 20.19 & 20.21 & 20.22 & 35.31 & 36.90 & 34.53 & 14.43 & 14.67 & 14.07 \\
\hline 10 & 34.0 & 32.34 & 32.26 & 32.29 & 39.93 & 42.39 & 41.52 & 26.70 & 26.25 & 26.91 \\
\hline 11 & 41.0 & 40.83 & 40.75 & 40.65 & 59.79 & 57.06 & 58.62 & 27.87 & 28.59 & 28.02 \\
\hline 12 & 19.5 & & & & & & & & & \\
\hline 13 & 26.0 & & & & & & & & & \\
\hline 14 & $38.0-40.0$ & & & & & & & & & \\
\hline 15 & $21.5-22.5$ & & & & & & & & & \\
\hline 16 & 28.0 & & & & & & & & & \\
\hline 17 & 30.7 & 29.92 & 29.86 & 29.81 & 36.87 & 36.18 & 36.30 & 26.58 & 26.73 & 25.98 \\
\hline 18 & 26.1 & & & & & & & & & \\
\hline 19 & 29.2 & & & & & & & & & \\
\hline 20 & 31.2 & 31.37 & 31.34 & 31.32 & 32.01 & 32.04 & 31.92 & 30.72 & 30.42 & 30.75 \\
\hline 21 & 28.9 & & & & & & & & & \\
\hline 22 & 31.2 & & & & & & & & & \\
\hline 23 & 33.4 & & & & & & & & & \\
\hline
\end{tabular}

Table 5e. Pressure cell and piezometer readings for Monoliths 10-11-12, Condition 5.

\begin{tabular}{|c|c|c|c|c|c|c|c|c|c|c|}
\hline \multirow{2}{*}{$\begin{array}{l}\text { Location } \\
\text { Number }\end{array}$} & \multirow{2}{*}{$\begin{array}{l}\text { Average Pressure } \\
\text { From Piezometer, } \\
\text { Feet of } \mathrm{H} 2 \mathrm{O}\end{array}$} & \multicolumn{3}{|c|}{$\begin{array}{l}\text { Average Pressure From } \\
\text { Pressure Cell, Feet of H2O }\end{array}$} & \multicolumn{3}{|c|}{$\begin{array}{l}\text { Maximum Pressure From } \\
\text { Pressure Cell, Feet of H2O }\end{array}$} & \multicolumn{3}{|c|}{$\begin{array}{l}\text { Minimum Pressure From } \\
\text { Pressure Cell, Feet of H2O }\end{array}$} \\
\hline & & Test 1 & Test 2 & Test 3 & Test 1 & Test 2 & Test 3 & Test 1 & Test 2 & Test 3 \\
\hline 1 & 5.1 & & & & & & & & & \\
\hline 2 & 1.4 & & & & & & & & & \\
\hline 3 & -0.3 & & & & & & & & & \\
\hline 4 & -0.7 & & & & & & & & & \\
\hline 5 & 1.0 & & & & & & & & & \\
\hline 6 & 3.6 & & & & & & & & & \\
\hline 7 & 5.2 & & & & & & & & & \\
\hline 9 & 12.6 & 20.88 & 20.94 & 21.06 & 36.54 & 39.72 & 36.39 & 12.03 & 13.77 & 12.81 \\
\hline 10 & 38.7 & 36.71 & 36.69 & 36.81 & 54.51 & 48.06 & 48.03 & 23.79 & 26.10 & 23.31 \\
\hline 11 & 54.7 & 54.10 & 53.97 & 54.30 & 73.05 & 75.66 & 76.83 & 27.93 & 29.31 & 27.96 \\
\hline 12 & 30.0 & & & & & & & & & \\
\hline 13 & 28.5 & & & & & & & & & \\
\hline 14 & 49.7 & & & & & & & & & \\
\hline 15 & 23.0 & & & & & & & & & \\
\hline
\end{tabular}




\begin{tabular}{|c|c|c|c|c|c|c|c|c|c|c|}
\hline \multirow{2}{*}{$\begin{array}{l}\text { Location } \\
\text { Number }\end{array}$} & \multirow{2}{*}{$\begin{array}{l}\text { Average Pressure } \\
\text { From Piezometer, } \\
\text { Feet of } \mathrm{H} 2 \mathrm{O}\end{array}$} & \multicolumn{3}{|c|}{$\begin{array}{l}\text { Average Pressure From } \\
\text { Pressure Cell, Feet of H2O }\end{array}$} & \multicolumn{3}{|c|}{$\begin{array}{l}\text { Maximum Pressure From } \\
\text { Pressure Cell, Feet of } \mathrm{H} 2 \mathrm{O}\end{array}$} & \multicolumn{3}{|c|}{$\begin{array}{l}\text { Minimum Pressure From } \\
\text { Pressure Cell, Feet of H2O }\end{array}$} \\
\hline & & Test 1 & Test 2 & Test 3 & Test 1 & Test 2 & Test 3 & Test 1 & Test 2 & Test 3 \\
\hline 16 & 30.6 & & & & & & & & & \\
\hline 17 & $31.3-32.7$ & 36.29 & 36.22 & 36.33 & 47.82 & 47.76 & 50.01 & 27.99 & 28.41 & 29.28 \\
\hline 18 & 29.0 & & & & & & & & & \\
\hline 19 & $31.7-33.2$ & & & & & & & & & \\
\hline 20 & 36.4 & 36.20 & 36.22 & 36.23 & 38.76 & 39.78 & 38.31 & 33.63 & 32.97 & 33.60 \\
\hline 21 & 35.6 & & & & & & & & & \\
\hline 22 & 35.2 & & & & & & & & & \\
\hline 23 & 39.4 & & & & & & & & & \\
\hline
\end{tabular}

Table 5f. Pressure cell and piezometer readings for Monoliths 10-11-12, Condition 6.

\begin{tabular}{|c|c|c|c|c|c|c|c|c|c|c|}
\hline \multirow{2}{*}{$\begin{array}{l}\text { Location } \\
\text { Number }\end{array}$} & \multirow{2}{*}{$\begin{array}{l}\text { Average Pressure } \\
\text { From Piezometer, } \\
\text { Feet of H2O }\end{array}$} & \multicolumn{3}{|c|}{$\begin{array}{l}\text { Average Pressure From } \\
\text { Pressure Cell, Feet of } \mathrm{H} 20\end{array}$} & \multicolumn{3}{|c|}{$\begin{array}{l}\text { Maximum Pressure From } \\
\text { Pressure Cell, Feet of } \mathrm{H} 2 \mathrm{O}\end{array}$} & \multicolumn{3}{|c|}{$\begin{array}{l}\text { Minimum Pressure From } \\
\text { Pressure Cell, Feet of } \mathrm{H} 2 \mathrm{O}\end{array}$} \\
\hline & & Test 1 & Test 2 & Test 3 & Test 1 & Test 2 & Test 3 & Test 1 & Test 2 & Test 3 \\
\hline 1 & 2.0 & & & & & & & & & \\
\hline 2 & -4.3 & & & & & & & & & \\
\hline 3 & -5.7 & & & & & & & & & \\
\hline 4 & -4.4 & & & & & & & & & \\
\hline 5 & 0.1 & & & & & & & & & \\
\hline 6 & 6.9 & & & & & & & & & \\
\hline 7 & 14.8 & & & & & & & & & \\
\hline 9 & 32.8 & 24.32 & 24.22 & 24.40 & 37.59 & 40.47 & 40.68 & 16.77 & 17.67 & 18.42 \\
\hline 10 & 45.0 & 43.75 & 43.58 & 43.74 & 55.23 & 55.23 & 55.23 & 30.87 & 30.36 & 31.26 \\
\hline 11 & $65.5-70.5$ & 58.50 & 57.87 & 57.26 & 83.07 & 82.02 & 79.41 & 23.70 & 20.01 & 23.19 \\
\hline 12 & 8.0 - 11.5 & & & & & & & & & \\
\hline 13 & 31.0 - 32.7 & & & & & & & & & \\
\hline 14 & 62.5 & & & & & & & & & \\
\hline 15 & 21.0 & & & & & & & & & \\
\hline 16 & 32.1 & & & & & & & & & \\
\hline 17 & 45.0 & 44.47 & 44.47 & 44.41 & 63.00 & 63.00 & 63.00 & 28.17 & 27.63 & 28.05 \\
\hline 18 & 27.0 & & & & & & & & & \\
\hline 19 & 32.5 & & & & & & & & & \\
\hline 20 & 40.0 & 39.79 & 39.75 & 39.73 & 50.07 & 49.08 & 47.94 & 31.80 & 31.65 & 31.23 \\
\hline 21 & 44.0 & & & & & & & & & \\
\hline 22 & 40.0 & & & & & & & & & \\
\hline 23 & 47.9 & & & & & & & & & \\
\hline
\end{tabular}


Table 6a. Pressure cell and piezometer readings for Monoliths 13-14-15, Condition 1.

\begin{tabular}{|c|c|c|c|c|c|c|c|c|c|c|}
\hline \multirow{2}{*}{$\begin{array}{l}\text { Location } \\
\text { Number }\end{array}$} & \multirow{2}{*}{$\begin{array}{l}\text { Average Pressure } \\
\text { From Piezometer, } \\
\text { Feet of } \mathrm{H} 2 \mathrm{O}\end{array}$} & \multicolumn{3}{|c|}{$\begin{array}{l}\text { Average Pressure From } \\
\text { Pressure Cell, Feet of H2O }\end{array}$} & \multicolumn{3}{|c|}{$\begin{array}{l}\text { Maximum Pressure From } \\
\text { Pressure Cell, Feet of H2O }\end{array}$} & \multicolumn{3}{|c|}{$\begin{array}{l}\text { Minimum Pressure From } \\
\text { Pressure Cell, Feet of H2O }\end{array}$} \\
\hline & & Test 1 & Test 2 & Test 3 & Test 1 & Test 2 & Test 3 & Test 1 & Test 2 & Test 3 \\
\hline \multicolumn{11}{|l|}{1} \\
\hline \multicolumn{11}{|l|}{2} \\
\hline \multicolumn{11}{|l|}{3} \\
\hline \multicolumn{11}{|l|}{4} \\
\hline \multicolumn{11}{|l|}{5} \\
\hline \multicolumn{11}{|l|}{6} \\
\hline \multicolumn{11}{|l|}{7} \\
\hline 9 & 17.7 & 16.75 & 16.77 & 16.75 & 21.15 & 22.26 & 22.41 & 13.26 & 13.56 & 13.38 \\
\hline 10 & 20.2 & 19.63 & 19.60 & 19.57 & 21.42 & 21.06 & 21.24 & 17.34 & 18.00 & 17.34 \\
\hline 11 & 17.4 & 20.39 & 20.29 & 20.23 & 26.70 & 26.91 & 26.61 & 16.32 & 16.53 & 16.29 \\
\hline 12 & 13.5 & & & & & & & & & \\
\hline 13 & 17.6 & & & & & & & & & \\
\hline 14 & 19.2 & & & & & & & & & \\
\hline 15 & 15.5 & & & & & & & & & \\
\hline 16 & 13.4 & & & & & & & & & \\
\hline 17 & 12.7 & 17.40 & 17.40 & 17.37 & 18.87 & 19.11 & 19.11 & 16.89 & 16.83 & 16.74 \\
\hline 18 & 15.9 & & & & & & & & & \\
\hline 19 & 18.4 & & & & & & & & & \\
\hline 20 & 20.9 & 19.79 & 19.79 & 19.77 & 19.95 & 19.95 & 19.95 & 19.62 & 19.59 & 19.56 \\
\hline 21 & 21.1 & & & & & & & & & \\
\hline 22 & 22.2 & & & & & & & & & \\
\hline
\end{tabular}

Table 6b. Pressure cell and piezometer readings for Monoliths 13-14-15, Condition 2.

\begin{tabular}{|c|l|c|c|c|c|c|c|c|c|c|}
\hline \multirow{2}{*}{$\begin{array}{l}\text { Location } \\
\text { Number }\end{array}$} & $\begin{array}{l}\text { Average Pressure } \\
\text { From Piezometer, } \\
\text { Feet of H20 }\end{array}$ & \multicolumn{3}{|c|}{$\begin{array}{l}\text { Average Pressure From } \\
\text { Pressure Cell, Feet of H2O }\end{array}$} & \multicolumn{2}{c|}{$\begin{array}{l}\text { Maximum Pressure From } \\
\text { Pressure Cell, Feet of H2O }\end{array}$} & \multicolumn{3}{|c|}{$\begin{array}{l}\text { Minimum Pressure From } \\
\text { Pressure Cell, Feet of H2O }\end{array}$} \\
\hline & Test 1 & Test 2 & Test 3 & Test 1 & Test 2 & Test 3 & Test 1 & Test 2 & Test 3 \\
\hline 1 & & & & & & & & & & \\
\hline 2 & & & & & & & & & & \\
\hline 3 & & & & & & & & & & \\
\hline 4 & & & & & & & & & & \\
\hline 5 & & & & & & & & & & \\
\hline 6 & & & & & & & & & & \\
\hline 7 & & & & & & & & & & \\
\hline 9 & 20.5 & 19.19 & 19.18 & 19.18 & 26.76 & 29.49 & 27.45 & 13.14 & 12.24 & 13.95 \\
\hline 10 & 23.4 & 23.42 & 23.42 & 23.40 & 26.67 & 26.37 & 26.34 & 19.41 & 19.53 & 18.96 \\
\hline 11 & 21.6 & 29.19 & 29.22 & 29.19 & 42.90 & 43.17 & 42.60 & 18.57 & 19.56 & 19.35 \\
\hline 12 & 13.9 & & & & & & & & & \\
\hline
\end{tabular}




\begin{tabular}{|c|c|c|c|c|c|c|l|c|c|c|}
\hline & \multirow{2}{*}{$\begin{array}{l}\text { Lecation } \\
\text { Number }\end{array}$} & $\begin{array}{l}\text { Average Pressure } \\
\text { From Piezometer, } \\
\text { Feet of H2O }\end{array}$ & \multicolumn{2}{|c|}{$\begin{array}{c}\text { Average Pressure From } \\
\text { Pressure Cell, Feet of H2O }\end{array}$} & \multicolumn{2}{|c|}{$\begin{array}{l}\text { Maximum Pressure From } \\
\text { Pressure Cell, Feet of H2O }\end{array}$} & \multicolumn{3}{|c|}{$\begin{array}{l}\text { Minimum Pressure From } \\
\text { Pressure Cell, Feet of H2O }\end{array}$} \\
\hline & Test 1 & Test 2 & Test 3 & Test 1 & Test 2 & Test 3 & Test 1 & Test 2 & Test 3 \\
\hline 13 & 20.4 & & & & & & & & & \\
\hline 14 & 27.0 & & & & & & & & & \\
\hline 15 & 18.5 & & & & & & & & & \\
\hline 16 & 22.3 & & & & & & & & & \\
\hline 17 & 16.7 & 21.92 & 21.91 & 21.90 & 24.96 & 25.50 & 25.56 & 20.13 & 20.67 & 20.61 \\
\hline 18 & 19.8 & & & & & & & & & \\
\hline 19 & 22.5 & & & & & & & & & \\
\hline 20 & 25.1 & 24.36 & 24.35 & 24.34 & 24.60 & 24.66 & 24.63 & 24.09 & 24.03 & 24.03 \\
\hline 21 & 25.1 & & & & & & & & & \\
\hline 22 & 26.1 & & & & & & & & & \\
\hline
\end{tabular}

Table 6c. Pressure cell and piezometer readings for Monoliths 13-14-15, Condition 3.

\begin{tabular}{|c|c|c|c|c|c|c|c|c|c|c|}
\hline \multirow{2}{*}{$\begin{array}{l}\text { Location } \\
\text { Number }\end{array}$} & \multirow{2}{*}{$\begin{array}{l}\text { Average Pressure } \\
\text { From Piezometer, } \\
\text { Feet of } \mathrm{H} 2 \mathrm{O}\end{array}$} & \multicolumn{3}{|c|}{$\begin{array}{l}\text { Average Pressure From } \\
\text { Pressure Cell, Feet of } \mathrm{H} 2 \mathrm{O}\end{array}$} & \multicolumn{3}{|c|}{$\begin{array}{l}\text { Maximum Pressure From } \\
\text { Pressure Cell, Feet of H2O }\end{array}$} & \multicolumn{3}{|c|}{$\begin{array}{l}\text { Minimum Pressure From } \\
\text { Pressure Cell, Feet of H2O }\end{array}$} \\
\hline & & Test 1 & Test 2 & Test 3 & Test 1 & Test 2 & Test 3 & Test 1 & Test 2 & Test 3 \\
\hline \multicolumn{11}{|l|}{1} \\
\hline \multicolumn{11}{|l|}{2} \\
\hline \multicolumn{11}{|l|}{3} \\
\hline \multicolumn{11}{|l|}{4} \\
\hline \multicolumn{11}{|l|}{5} \\
\hline \multicolumn{11}{|l|}{6} \\
\hline \multicolumn{11}{|l|}{7} \\
\hline 9 & 21.1 & 19.79 & 19.80 & 19.80 & 30.81 & 31.05 & 33.09 & 11.37 & 12.90 & 12.54 \\
\hline 10 & 24.9 & 24.56 & 24.60 & 24.55 & 27.90 & 29.49 & 28.44 & 20.43 & 20.70 & 20.52 \\
\hline 11 & 23.1 & 32.65 & 32.74 & 32.73 & 48.27 & 47.55 & 47.22 & 20.49 & 20.40 & 19.02 \\
\hline 12 & 13.2 & & & & & & & & & \\
\hline 13 & 20.7 & & & & & & & & & \\
\hline 14 & 28.5 & & & & & & & & & \\
\hline 15 & 18.8 & & & & & & & & & \\
\hline 16 & 23.2 & & & & & & & & & \\
\hline 17 & 18.7 & 23.17 & 23.22 & 23.17 & 27.42 & 28.32 & 27.75 & 21.39 & 21.33 & 21.51 \\
\hline 18 & 21.0 & & & & & & & & & \\
\hline 19 & 23.6 & & & & & & & & & \\
\hline 20 & 26.3 & 25.49 & 25.50 & 25.51 & 25.86 & 25.80 & 25.77 & 25.08 & 25.11 & 25.20 \\
\hline 21 & 26.6 & & & & & & & & & \\
\hline 22 & 27.4 & & & & & & & & & \\
\hline
\end{tabular}


Table 6d. Pressure cell and piezometer readings for Monoliths 13-14-15, Condition 4.

\begin{tabular}{|c|c|c|c|c|c|c|c|c|c|c|}
\hline \multirow{2}{*}{$\begin{array}{l}\text { Location } \\
\text { Number }\end{array}$} & \multirow{2}{*}{$\begin{array}{l}\text { Average Pressure } \\
\text { From Piezometer, } \\
\text { Feet of } \mathrm{H} 2 \mathrm{O}\end{array}$} & \multicolumn{3}{|c|}{$\begin{array}{l}\text { Average Pressure From } \\
\text { Pressure Cell, Feet of } \mathrm{H} 2 \mathrm{O}\end{array}$} & \multicolumn{3}{|c|}{$\begin{array}{l}\text { Maximum Pressure From } \\
\text { Pressure Cell, Feet of H2O }\end{array}$} & \multicolumn{3}{|c|}{$\begin{array}{l}\text { Minimum Pressure From } \\
\text { Pressure Cell, Feet of H2O }\end{array}$} \\
\hline & & Test 1 & Test 2 & Test 3 & Test 1 & Test 2 & Test 3 & Test 1 & Test 2 & Test 3 \\
\hline 1 & 4.5 & & & & & & & & & \\
\hline 2 & 2.2 & & & & & & & & & \\
\hline 3 & 1.4 & & & & & & & & & \\
\hline 4 & 1.0 & & & & & & & & & \\
\hline 5 & 1.3 & & & & & & & & & \\
\hline 6 & 2.0 & & & & & & & & & \\
\hline 7 & 1.7 & & & & & & & & & \\
\hline 9 & 26.1 & 24.40 & 24.38 & 24.44 & 40.20 & 38.07 & 37.41 & 17.85 & 17.58 & 18.45 \\
\hline 10 & 31.9 & 31.54 & 31.43 & 31.46 & 34.80 & 34.35 & 34.65 & 25.02 & 26.04 & 26.10 \\
\hline 11 & 28.8 & 45.55 & 45.42 & 45.55 & 59.58 & 59.85 & 61.08 & 29.94 & 29.04 & 29.64 \\
\hline 12 & 12.0 & & & & & & & & & \\
\hline 13 & 23.9 & & & & & & & & & \\
\hline 14 & 42.5 & & & & & & & & & \\
\hline 15 & 20.5 & & & & & & & & & \\
\hline 16 & 26.8 & & & & & & & & & \\
\hline 17 & 27.7 & 29.43 & 29.40 & 29.41 & 35.94 & 35.88 & 35.97 & 26.16 & 26.22 & 26.07 \\
\hline 18 & 25.1 & & & & & & & & & \\
\hline 19 & 28.3 & & & & & & & & & \\
\hline 20 & 31.2 & 30.40 & 30.36 & 30.38 & 31.53 & 31.02 & 30.99 & 29.37 & 29.34 & 29.64 \\
\hline 21 & 31.5 & & & & & & & & & \\
\hline 22 & 32.9 & & & & & & & & & \\
\hline
\end{tabular}

Table 6e. Pressure cell and piezometer readings for Monoliths 13-14-15, Condition 5.

\begin{tabular}{|c|c|c|c|c|c|c|c|c|c|c|}
\hline \multirow{2}{*}{$\begin{array}{l}\text { Location } \\
\text { Number }\end{array}$} & $\begin{array}{l}\text { Average Pressure } \\
\text { From Piezometer, } \\
\text { Feet of H20 }\end{array}$ & \multicolumn{3}{|c|}{$\begin{array}{c}\text { Average Pressure From } \\
\text { Pressure Cell, Feet of H2O }\end{array}$} & \multicolumn{2}{c|}{$\begin{array}{l}\text { Maximum Pressure From } \\
\text { Pressure Cell, Feet of H2O }\end{array}$} & \multicolumn{3}{c|}{$\begin{array}{l}\text { Minimum Pressure From } \\
\text { Pressure Cell, Feet of H2O }\end{array}$} \\
\hline & Test 1 & Test 2 & Test 3 & Test 1 & Test 2 & Test 3 & Test 1 & Test 2 & Test 3 \\
\hline 1 & 5.3 & & & & & & & & & \\
\hline 2 & 1.5 & & & & & & & & & \\
\hline 3 & -0.5 & & & & & & & & & \\
\hline 4 & -1.1 & & & & & & & & & \\
\hline 5 & 1.1 & & & & & & & & & \\
\hline 6 & 3.7 & & & & & & & & & \\
\hline 7 & 3.8 & & & & & & & & & \\
\hline 9 & 28.8 & 27.10 & 27.22 & 27.18 & 41.22 & 40.50 & 45.51 & 19.80 & 19.56 & 19.44 \\
\hline 10 & 38.3 & 38.15 & 38.18 & 38.24 & 44.88 & 45.00 & 44.28 & 29.49 & 29.10 & 29.67 \\
\hline 11 & 35.2 & 58.79 & 58.42 & 58.64 & 74.31 & 76.23 & 76.20 & 32.40 & 28.44 & 30.60 \\
\hline
\end{tabular}




\begin{tabular}{|c|c|c|c|c|c|c|c|c|c|c|}
\hline \multirow{2}{*}{$\begin{array}{l}\text { Location } \\
\text { Number }\end{array}$} & $\begin{array}{l}\text { Average Pressure } \\
\text { From Piezometer, } \\
\text { Feet of H20 }\end{array}$ & \multicolumn{2}{|c|}{$\begin{array}{c}\text { Average Pressure From } \\
\text { Pressure Cell, Feet of H2O }\end{array}$} & \multicolumn{2}{c|}{$\begin{array}{l}\text { Maximum Pressure From } \\
\text { Pressure Cell, Feet of H2O }\end{array}$} & \multicolumn{3}{|c|}{$\begin{array}{l}\text { Minimum Pressure From } \\
\text { Pressure Cell, Feet of H20 }\end{array}$} \\
\hline & Test 1 & Test 2 & Test 3 & Test 1 & Test 2 & Test 3 & Test 1 & Test 2 & Test 3 \\
\hline 12 & 7.0 & & & & & & & & & \\
\hline 13 & 26.5 & & & & & & & & & \\
\hline 14 & 53.3 & & & & & & & & & \\
\hline 15 & 20.5 & & & & & & & & & \\
\hline 16 & 29.7 & & & & & & & & & \\
\hline 17 & 36.0 & 35.55 & 35.56 & 35.60 & 48.72 & 46.35 & 47.43 & 27.99 & 25.41 & 27.30 \\
\hline 18 & 28.2 & & & & & & & & & \\
\hline 19 & 31.6 & & & & & & & & & \\
\hline 20 & 35.1 & 34.37 & 34.47 & 34.46 & 35.91 & 36.21 & 35.88 & 31.95 & 32.46 & 31.98 \\
\hline 21 & 35.8 & & & & & & & & & \\
\hline 22 & 38.0 & & & & & & & & & \\
\hline
\end{tabular}

Table 6f. Pressure cell and piezometer readings for Monoliths 13-14-15, Condition 6.

\begin{tabular}{|c|c|c|c|c|c|c|c|c|c|c|}
\hline \multirow{2}{*}{$\begin{array}{l}\text { Location } \\
\text { Number }\end{array}$} & \multirow{2}{*}{$\begin{array}{l}\text { Average Pressure } \\
\text { From Piezometer, } \\
\text { Feet of } \mathrm{H} 2 \mathrm{O}\end{array}$} & \multicolumn{3}{|c|}{$\begin{array}{l}\text { Average Pressure From } \\
\text { Pressure Cell, Feet of H2O }\end{array}$} & \multicolumn{3}{|c|}{$\begin{array}{l}\text { Maximum Pressure From } \\
\text { Pressure Cell, Feet of } \mathrm{H} 20\end{array}$} & \multicolumn{3}{|c|}{$\begin{array}{l}\text { Minimum Pressure From } \\
\text { Pressure Cell, Feet of H2O }\end{array}$} \\
\hline & & Test 1 & Test 2 & Test 3 & Test 1 & Test 2 & Test 3 & Test 1 & Test 2 & Test 3 \\
\hline 1 & 2.2 & & & & & & & & & \\
\hline 2 & -3.8 & & & & & & & & & \\
\hline 3 & -5.5 & & & & & & & & & \\
\hline 4 & -4.3 & & & & & & & & & \\
\hline 5 & -0.3 & & & & & & & & & \\
\hline 6 & 5.7 & & & & & & & & & \\
\hline 7 & 9.4 & & & & & & & & & \\
\hline 9 & 34.6 & 34.54 & 34.46 & 34.27 & 45.99 & 42.51 & 42.72 & 28.59 & 28.32 & 27.27 \\
\hline 10 & 46.5 & 47.84 & 47.83 & 47.66 & 53.91 & 54.09 & 54.00 & 37.98 & 39.30 & 38.34 \\
\hline 11 & 43.1 & 70.68 & 70.65 & 70.62 & 82.98 & 82.98 & 82.98 & 40.32 & 39.00 & 40.74 \\
\hline 12 & 5.8 & & & & & & & & & \\
\hline 13 & 29.8 & & & & & & & & & \\
\hline 14 & 63.0 & & & & & & & & & \\
\hline 15 & 22.5 & & & & & & & & & \\
\hline 16 & 33.3 & & & & & & & & & \\
\hline 17 & 43.1 & 43.68 & 43.77 & 43.44 & 63.09 & 61.65 & 59.19 & 30.06 & 29.34 & 30.12 \\
\hline 18 & 31.0 & & & & & & & & & \\
\hline 19 & 34.5 & & & & & & & & & \\
\hline 20 & 40.5 & 40.33 & 40.46 & 40.21 & 46.83 & 46.65 & 48.09 & 34.11 & 35.10 & 32.49 \\
\hline 21 & 40.9 & & & & & & & & & \\
\hline 22 & 44.0 & & & & & & & & & \\
\hline
\end{tabular}


Table 7a. Estimated and recorded flow conditions for Monoliths 7-8-9.

\begin{tabular}{|c|l|l|l|l|l|}
\hline $\begin{array}{l}\text { Condition } \\
\text { Number }\end{array}$ & $\begin{array}{l}\text { Target Flow, Total } \\
\text { River kcfs }\end{array}$ & $\begin{array}{l}\text { Recorded Flow, } \\
\text { Total River kcfs* }\end{array}$ & $\begin{array}{l}\text { Estimated Pool } \\
\text { Elevation, Feet MSL }\end{array}$ & $\begin{array}{l}\text { Recorded Pool } \\
\text { Elevation, Feet MSL }\end{array}$ & $\begin{array}{l}\text { Tailwater Elevation, } \\
\text { Feet MSL }\end{array}$ \\
\hline 1 & 23.5 & 23.5 & 890.0 & 888.7 & 881.2 \\
\hline 2 & 38.0 & 38.0 & 909.0 & 904.3 & 885.3 \\
\hline 3 & 42.0 & 42.0 & 916.0 & 907.0 & 886.3 \\
\hline 4 & 72.5 & 72.5 & 923.5 & 923.7 & 892.4 \\
\hline 5 & 125.0 & 125.0 & 931.3 & 931.9 & 898.5 \\
\hline 6 & 207.0 & 207.0 & 937.4 & 940.1 & 907.0 \\
\hline 7 & 8.94 & 8.94 & 907.4 & 918.2 & 874.1 \\
\hline
\end{tabular}

Table 7b. Estimated and recorded flow conditions for Monoliths 10-11-12.

\begin{tabular}{|c|l|l|l|l|l|}
\hline $\begin{array}{l}\text { Condition } \\
\text { Number }\end{array}$ & $\begin{array}{l}\text { Target Flow, Total } \\
\text { River kcfs }\end{array}$ & $\begin{array}{l}\text { Recorded Flow, } \\
\text { Total River kcfs* }\end{array}$ & $\begin{array}{l}\text { Estimated Pool } \\
\text { Elevation, Feet MSL }\end{array}$ & $\begin{array}{l}\text { Recorded Pool } \\
\text { Elevation, Feet MSL }\end{array}$ & $\begin{array}{l}\text { Tailwater Elevation, } \\
\text { Feet MSL }\end{array}$ \\
\hline 1 & 23.5 & 23.4 & 890.0 & 889.9 & 881.2 \\
\hline 2 & 38.0 & 37.9 & 909.0 & 908.0 & 885.3 \\
\hline 3 & 42.0 & 41.9 & 916.0 & 914.0 & 886.3 \\
\hline 4 & 72.5 & 72.6 & 923.5 & 925.0 & 892.4 \\
\hline 5 & 125.0 & 124.7 & 931.3 & 932.5 & 898.5 \\
\hline 6 & 207.0 & 207.0 & 937.4 & 941.1 & 907.0 \\
\hline
\end{tabular}

Table 7c. Estimated and recorded flow conditions for Monoliths 13-14-15.

\begin{tabular}{|c|l|l|l|l|l|}
\hline $\begin{array}{l}\text { Condition } \\
\text { Number }\end{array}$ & $\begin{array}{l}\text { Target Flow, } \\
\text { Total River kcfs }\end{array}$ & $\begin{array}{l}\text { Recorded Flow, } \\
\text { Total River kcfs* }\end{array}$ & $\begin{array}{l}\text { Estimated Pool } \\
\text { Elevation, Feet MSL }\end{array}$ & $\begin{array}{l}\text { Recorded Pool } \\
\text { Elevation, Feet MSL }\end{array}$ & $\begin{array}{l}\text { Tailwater Elevation, } \\
\text { Feet MSL }\end{array}$ \\
\hline 1 & 23.5 & 23.4 & 890.0 & 890.4 & 881.2 \\
\hline 2 & 38.0 & 37.9 & 909.0 & 906.3 & 885.3 \\
\hline 3 & 42.0 & 41.9 & 916.0 & 913.0 & 886.3 \\
\hline 4 & 72.5 & 72.6 & 923.5 & 924.7 & 892.4 \\
\hline 5 & 125.0 & 124.7 & 931.3 & 932.3 & 898.5 \\
\hline 6 & 207.0 & 207.0 & 937.4 & 941.0 & 907.0 \\
\hline
\end{tabular}

*The recorded total river flow is calculated by multiplying the flow measured through each section by the length ratio of the section to the total dam length. 


\section{Water surface profiles}

Along with the pressure data, water surface profiles were also taken to document the water surface elevation for flows through the sluices and over the spillway. Water surface profile drawings for each flow condition are shown in Figures 11-13 for all three monolith sections.

\section{Moveable bed data}

Moveable bed material was represented by $3 / 8$-inch $-1 / 2$-inch pea gravel, which was placed below the stilling basin from the upstream side of the first row of baffle blocks to approximately 90 feet downstream of the end sill to a depth of 60 feet, with a surface elevation of 859 MSL. The moveable bed data in this model are purely qualitative because the bed material could not be scaled to accurately represent what was present at the prototype. The moveable bed portion of this study was necessary to determine if the stilling basin and the structure as a whole have the potential to be undermined by erosion leading up to and during the PMF. Conditions 1-6 were run sequentially, allowing for scour stabilization to occur before moving to the next condition. After scour stabilization for each condition, the flume was drained and cross-sectional data were taken along the centerline of the sluice that contained the pressure cells. Scour potential was evaluated with and without the end sill to evaluate conditions should the end sill be lost during a high flow. Cross sectional drawings of scour for each group of monoliths are shown in Figures 14, 15, and 16 for monoliths 7-8-9, 10-11-12, and 13-14-15, respectively. Measurements are presented as positive downstream with the crest as +0 . With both the end sill intact and the end sill removed, for all three sets of Monoliths, no severe undermining of the stilling basin was seen. Erosion was concentrated downstream from the end sill and only minor movement was seen under the stilling basin itself. 


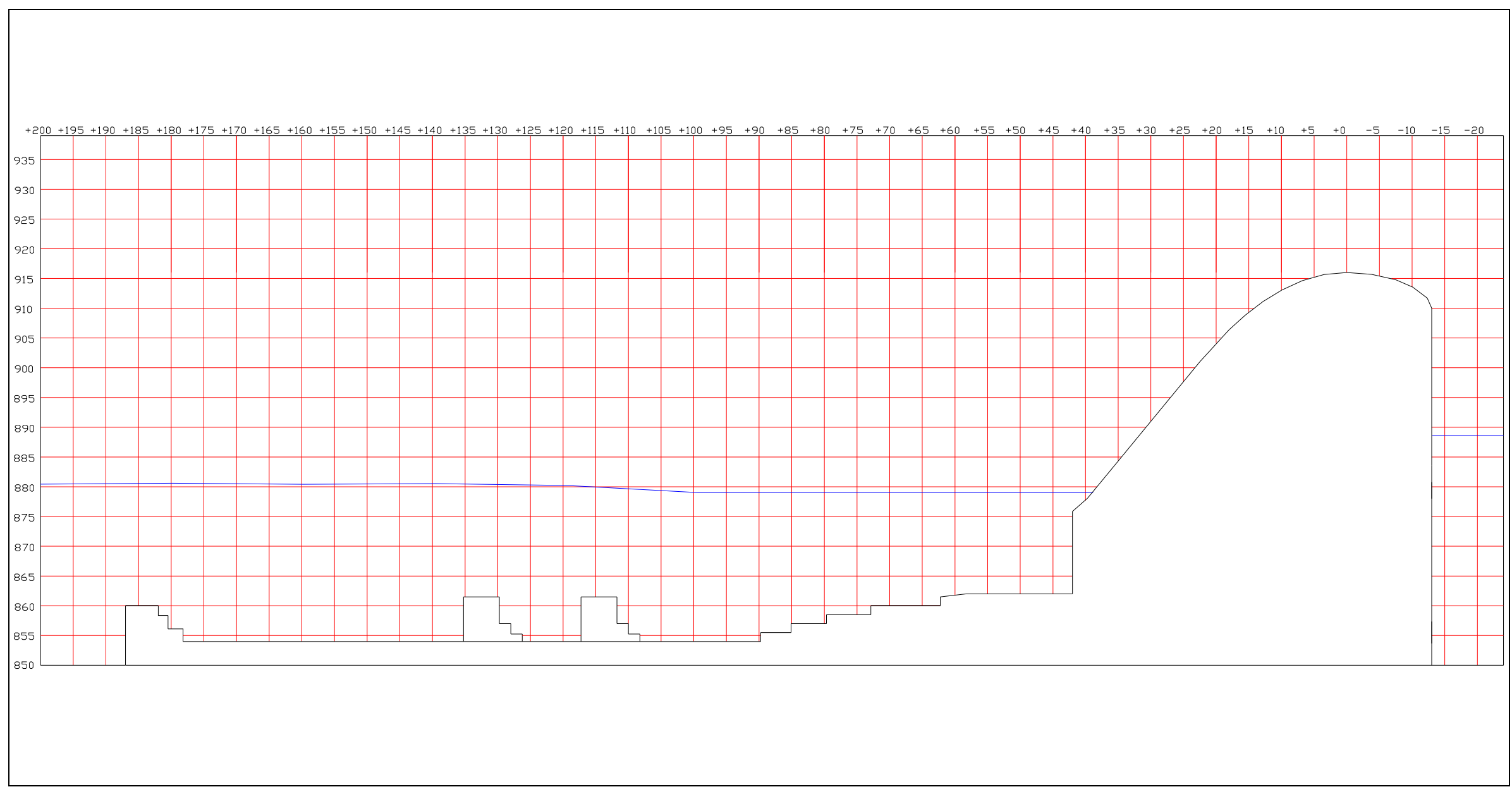

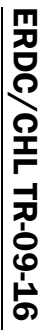

Figure 11a. Water surface profile for Monoliths 7-8-9, Condition 1. 


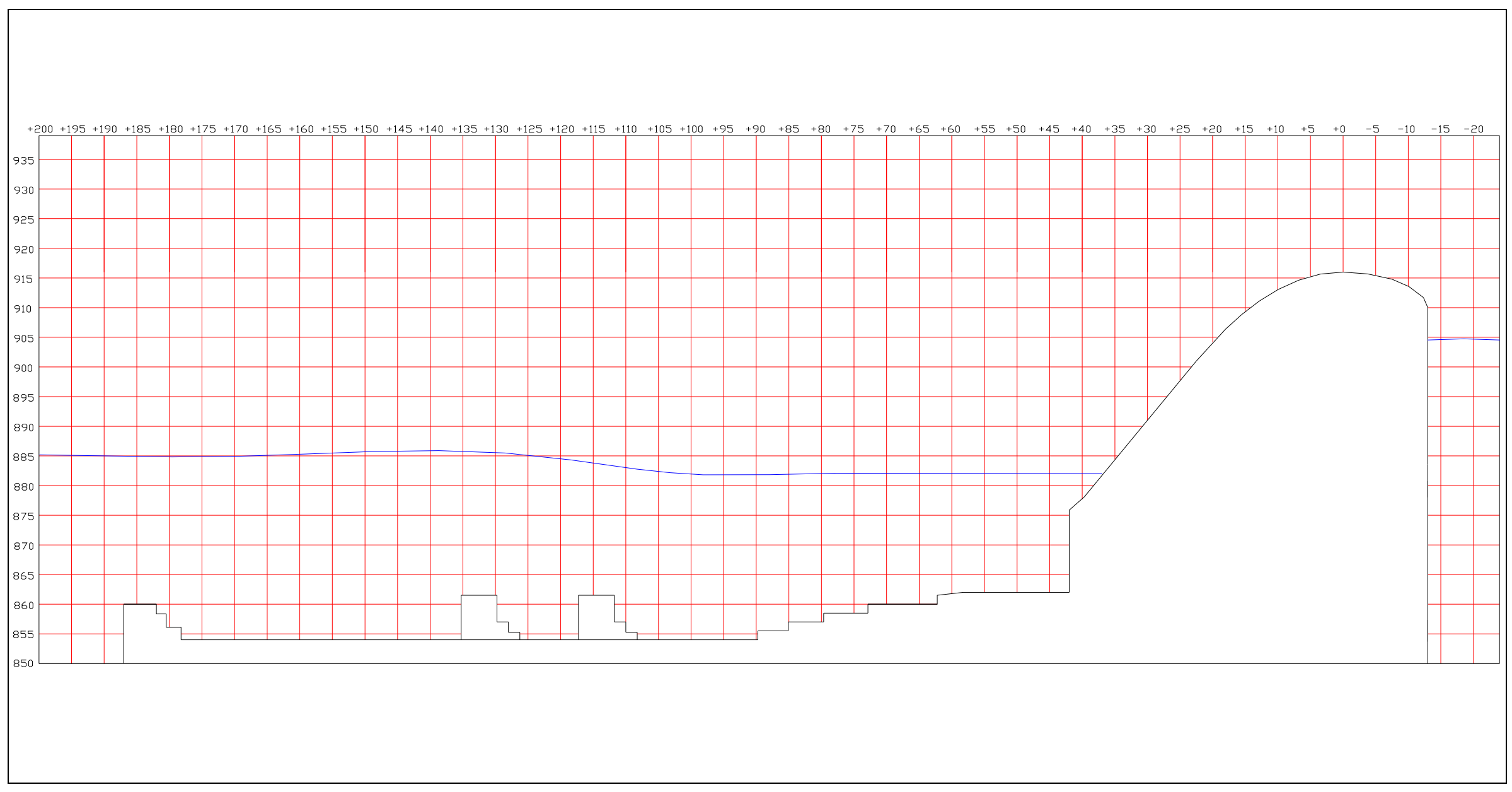

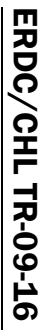

Figure 11b. Water surface profile for Monoliths 7-8-9, Condition 2. 


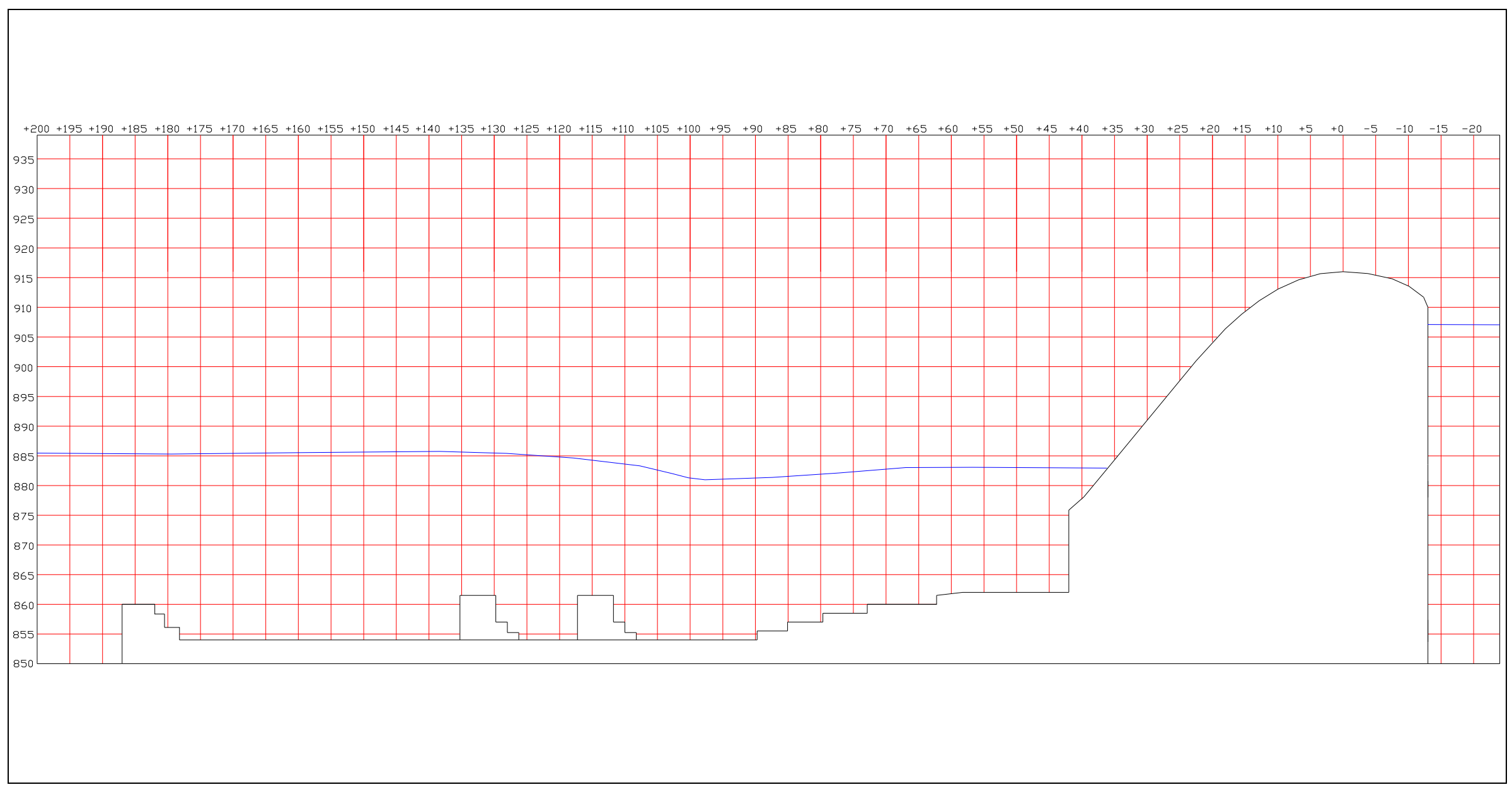

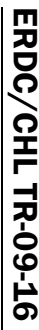

Figure 11c. Water surface profile for Monoliths 7-8-9, Condition 3. 


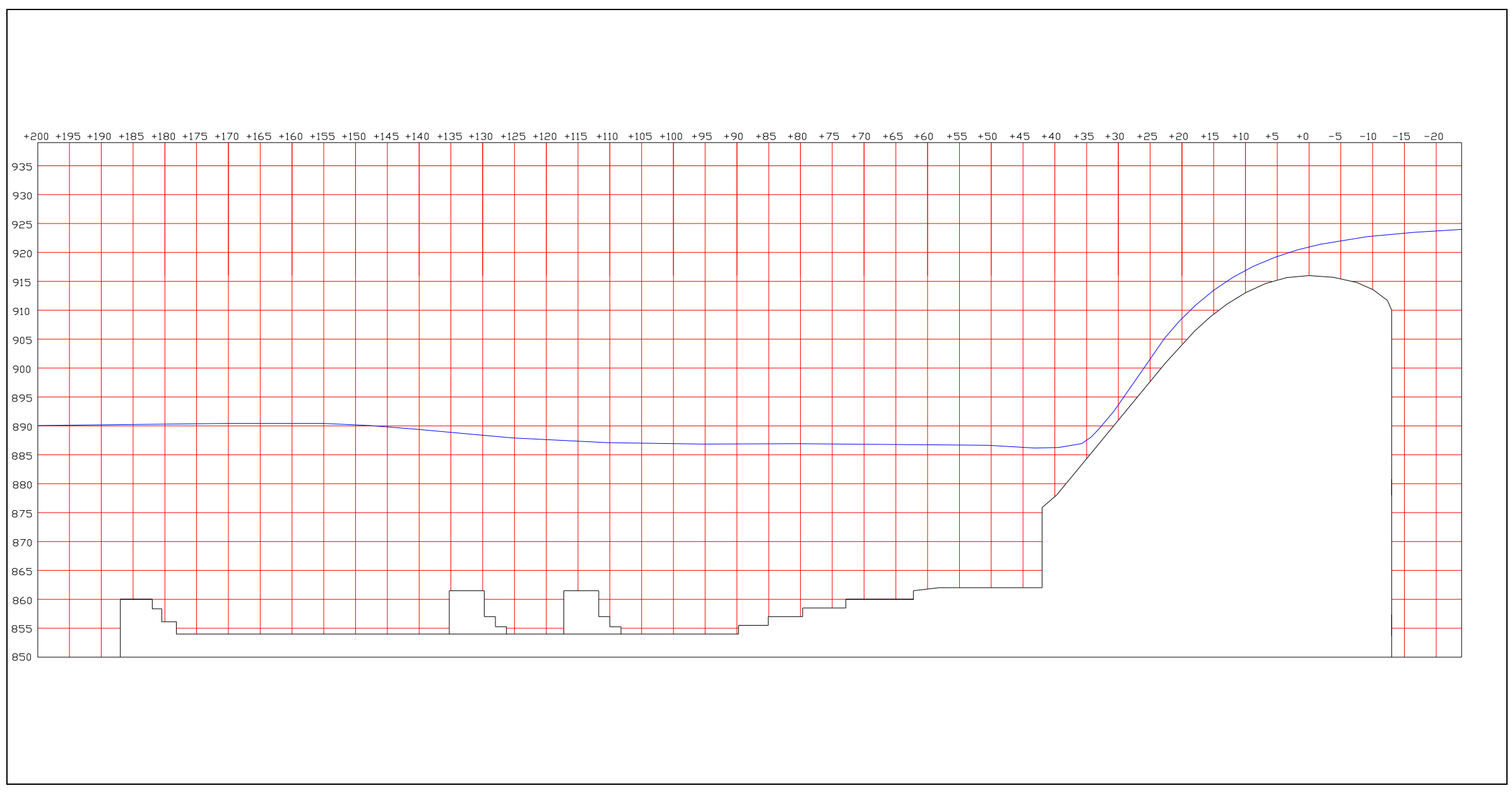

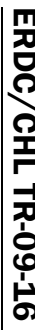

Figure 11d. Water surface profile for Monoliths 7-8-9, Condition 4. 


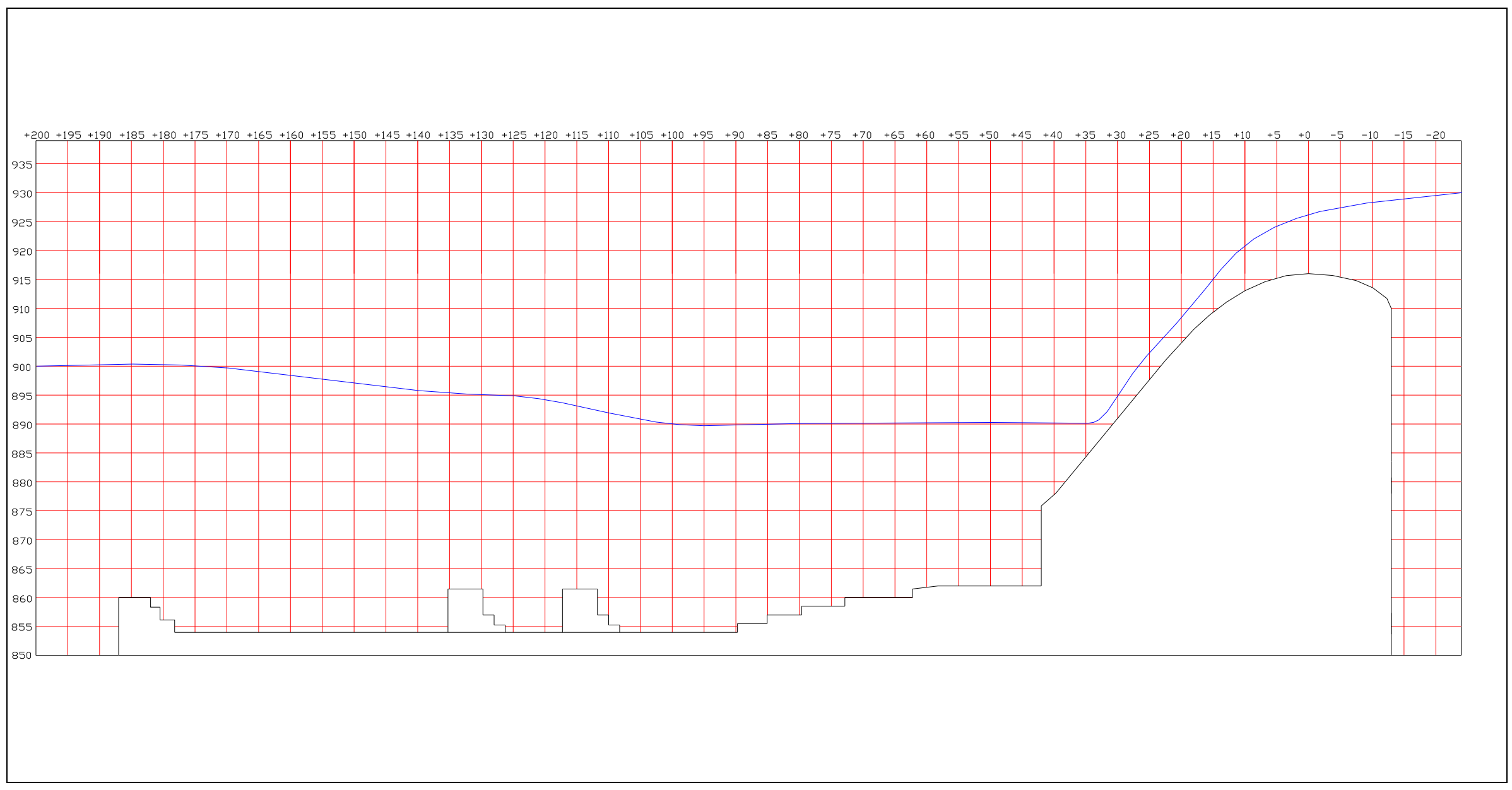

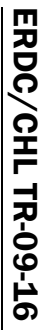

Figure 11e. Water surface profile for Monoliths 7-8-9, Condition 5. 


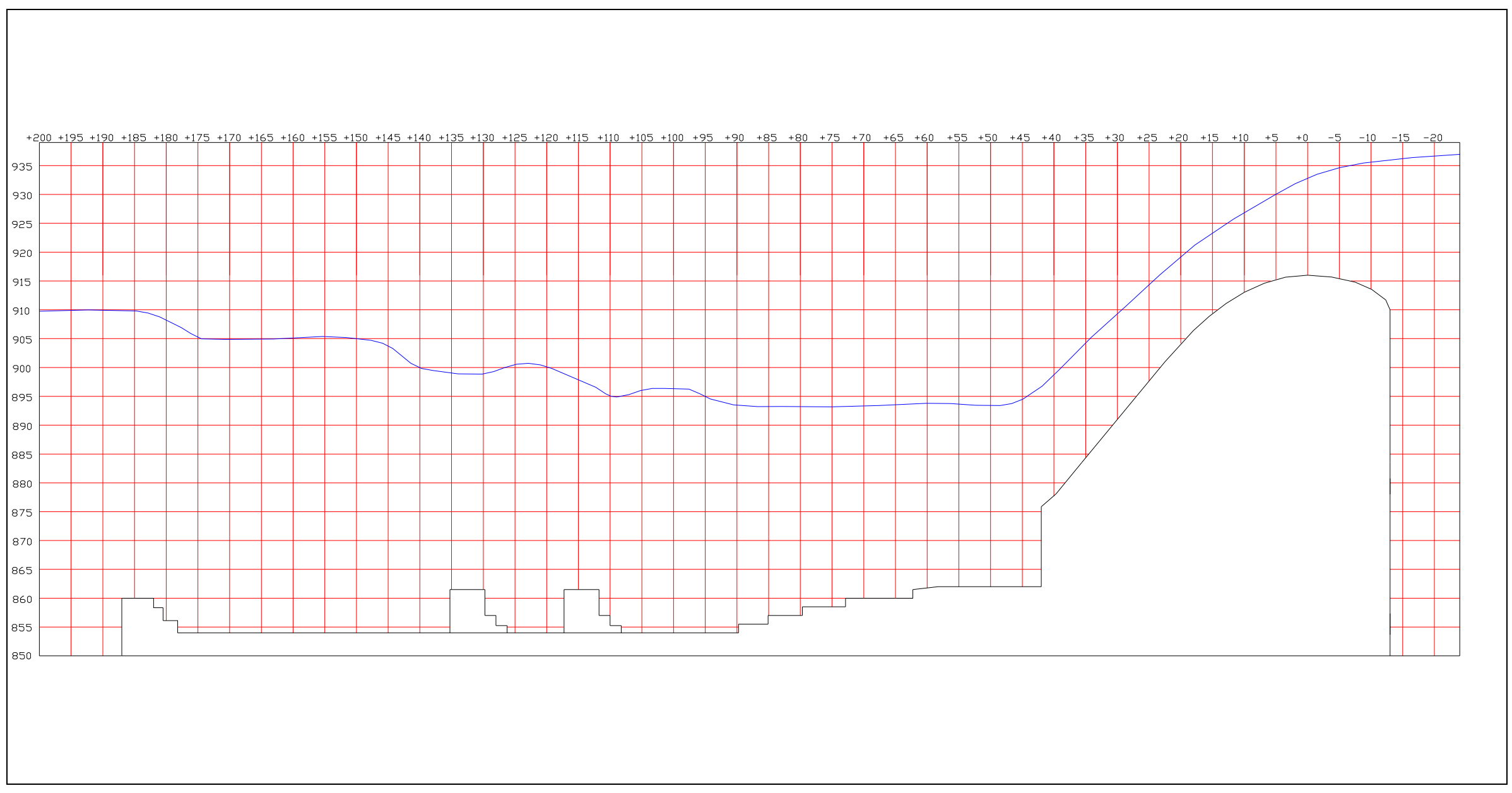

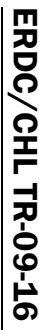

Figure 11f. Water surface profile for Monoliths 7-8-9, Condition 6. 


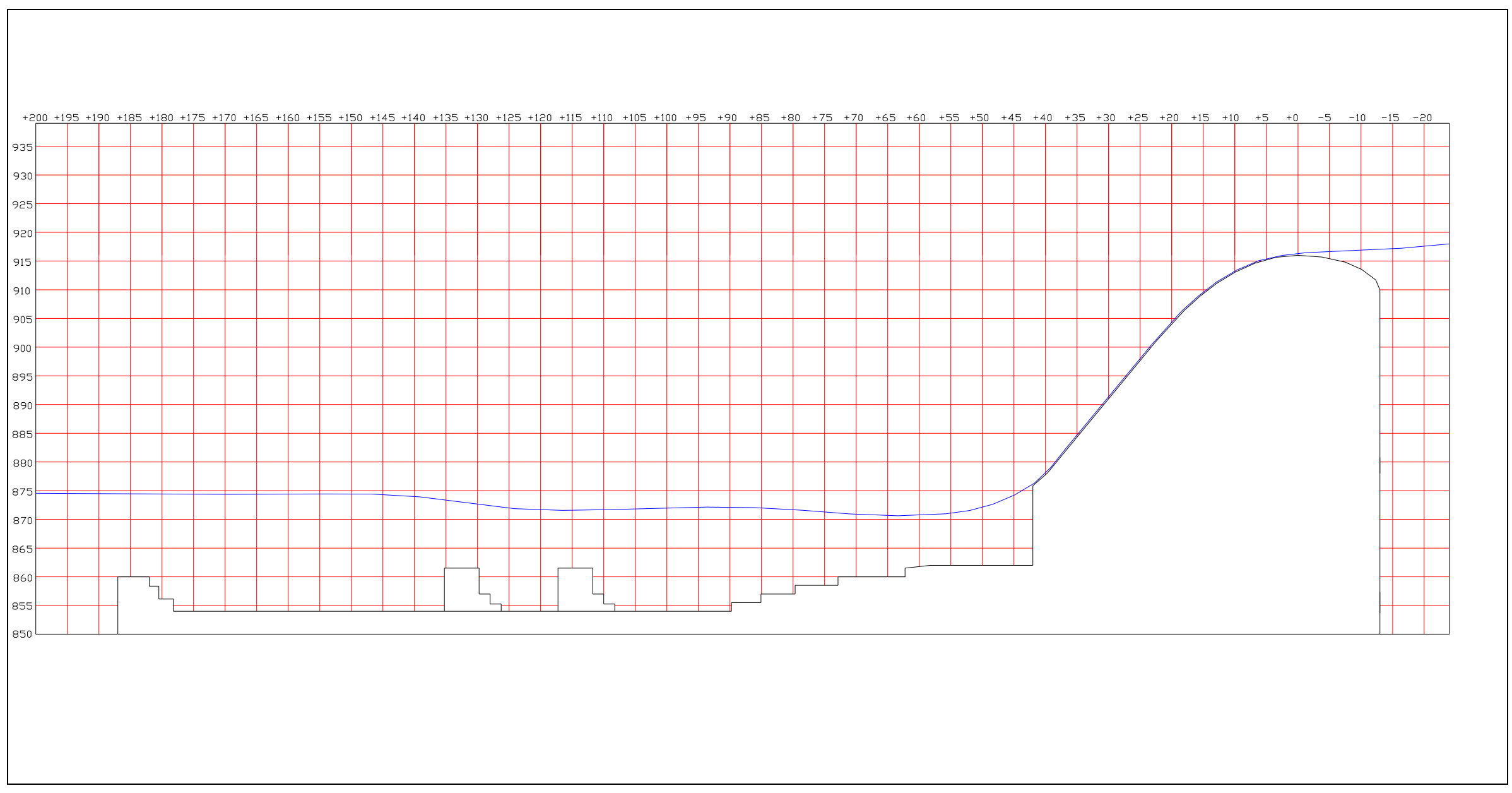

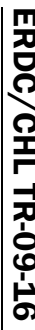

Figure 11g. Water surface profile for Monoliths 7-8-9, Condition 7. 


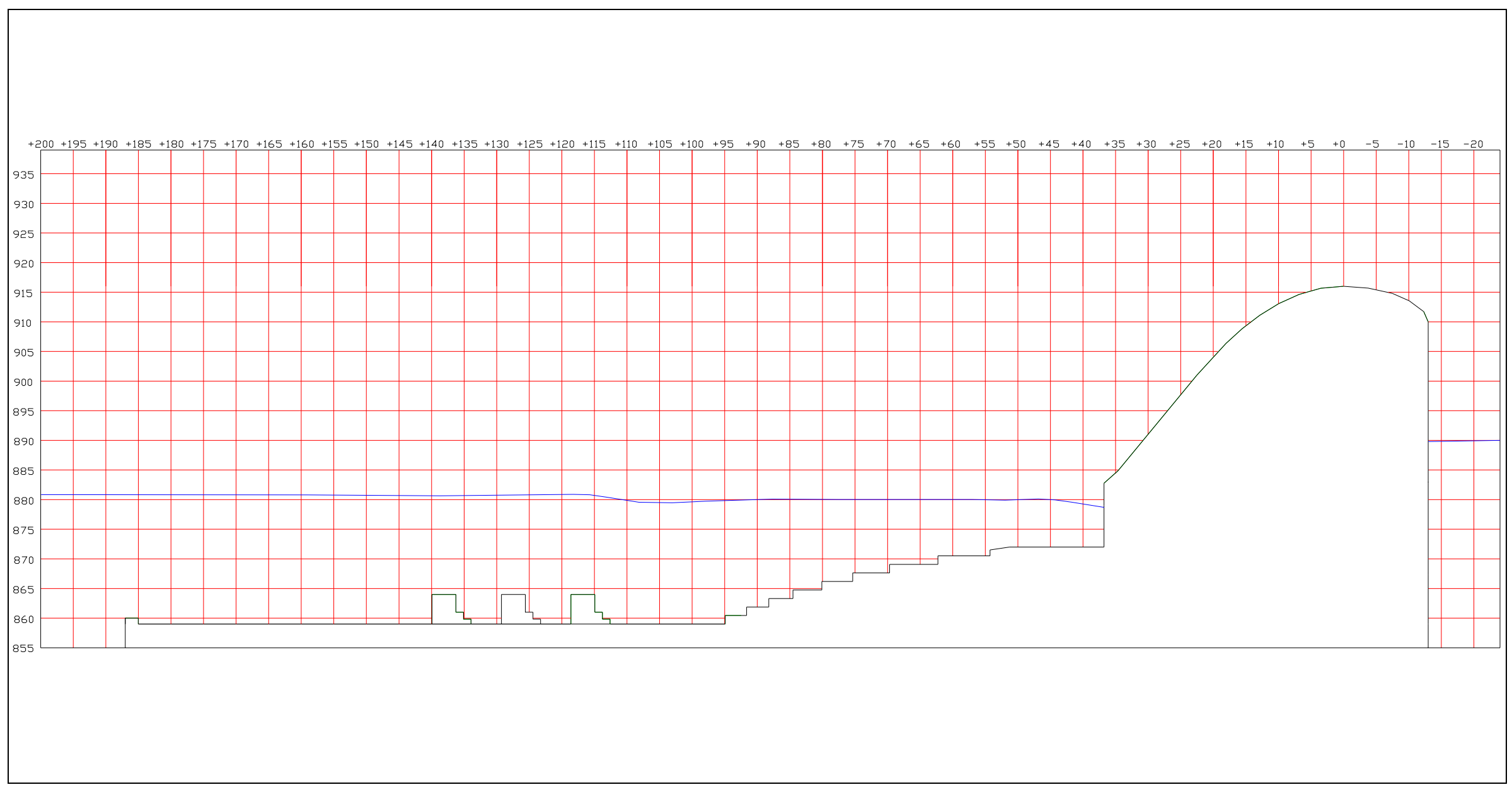

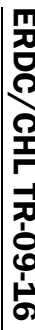

Figure 12a. Water surface profile for Condition 1, Monoliths 10-11-12. 


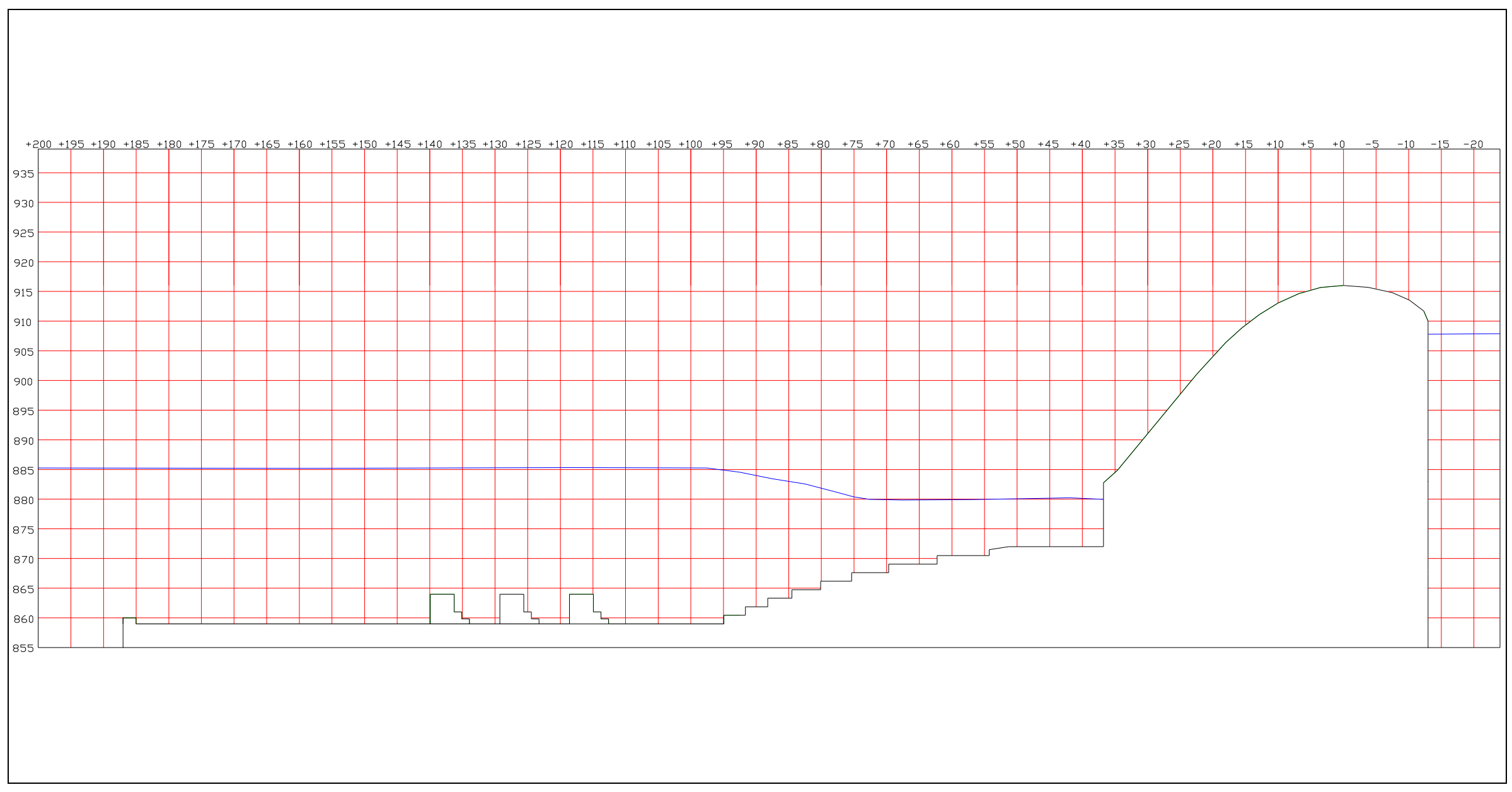

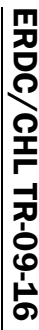

Figure 12b. Water surface profile for Condition 2, Monoliths 10-11-12. 


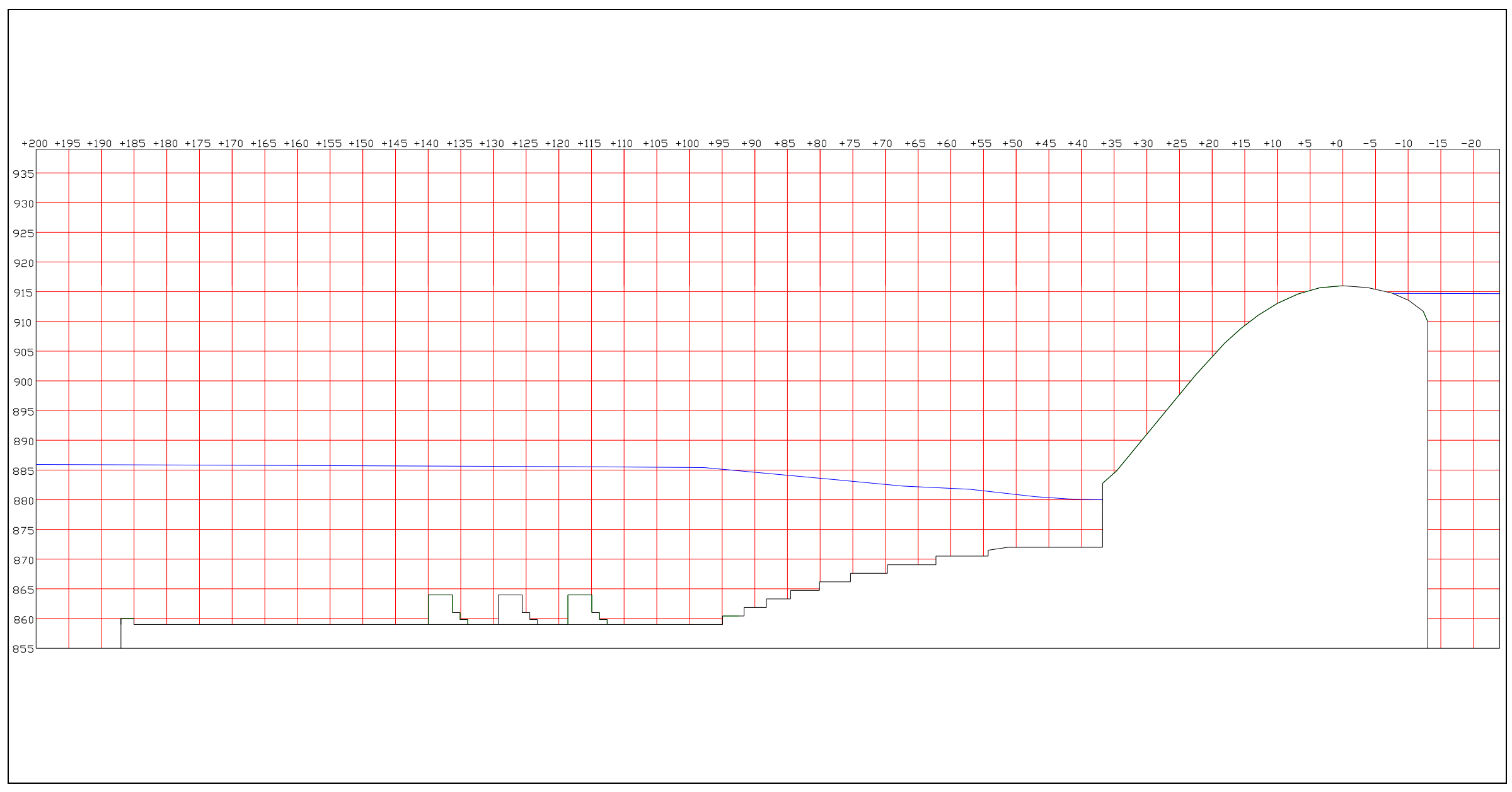

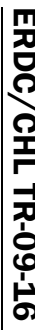

Figure 12c. Water surface profile for Condition 3, Monoliths 10-11-12. 


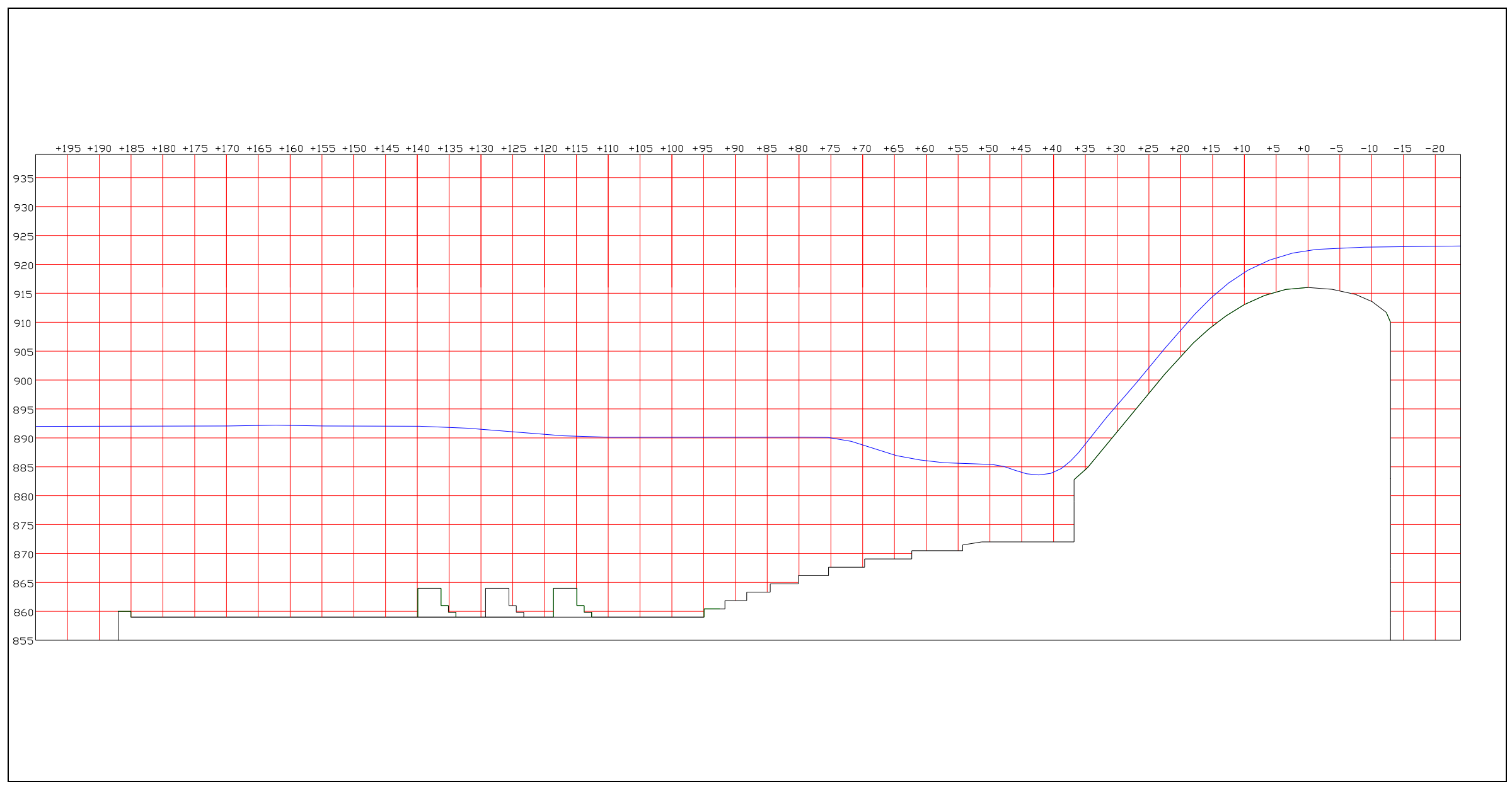

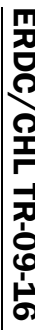

Figure 12d. Water surface profile for Condition 4, Monoliths 10-11-12. 


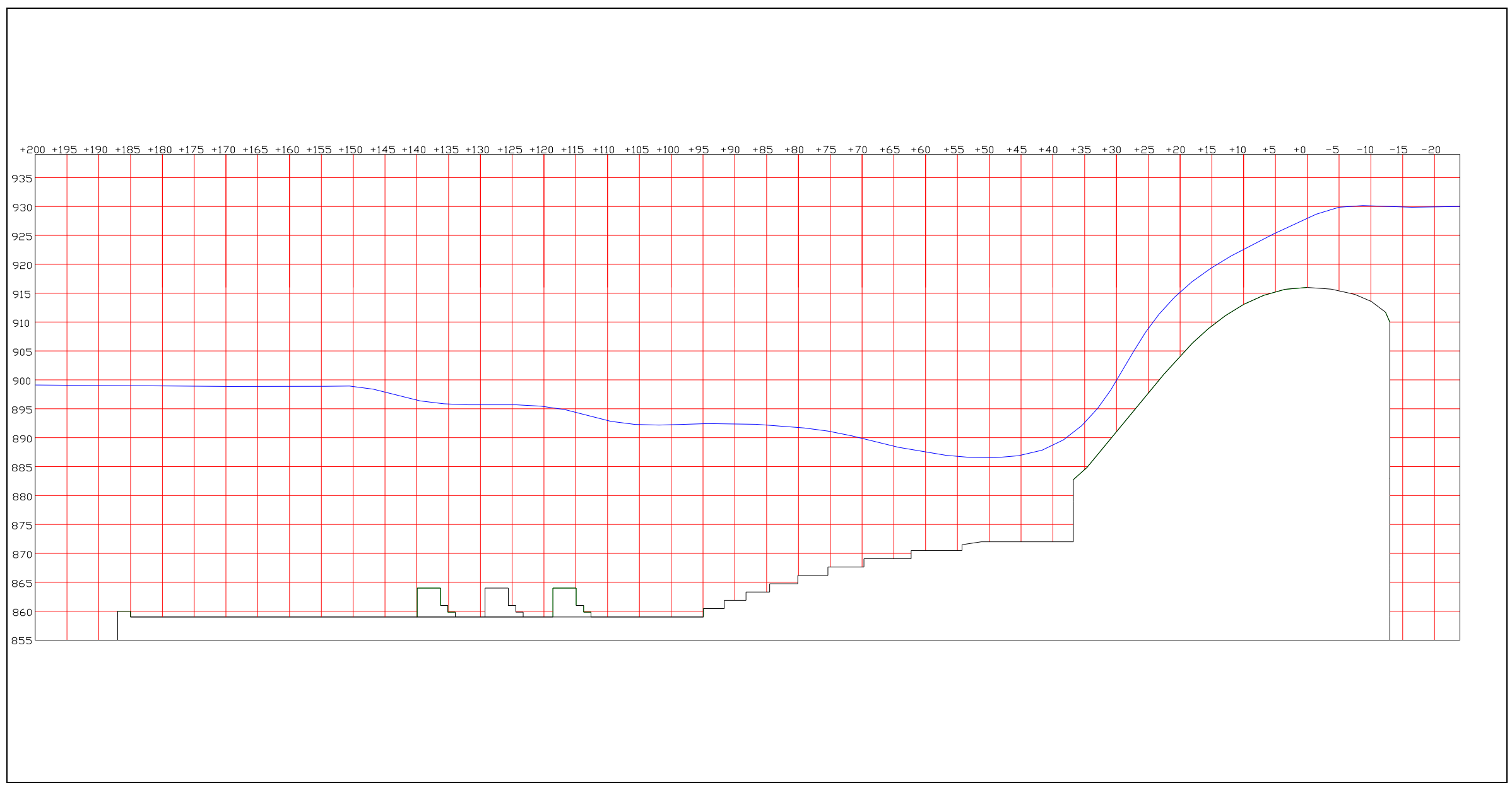

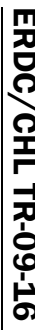

Figure 12e. Water surface profile for Condition 5, Monoliths 10-11-12. 


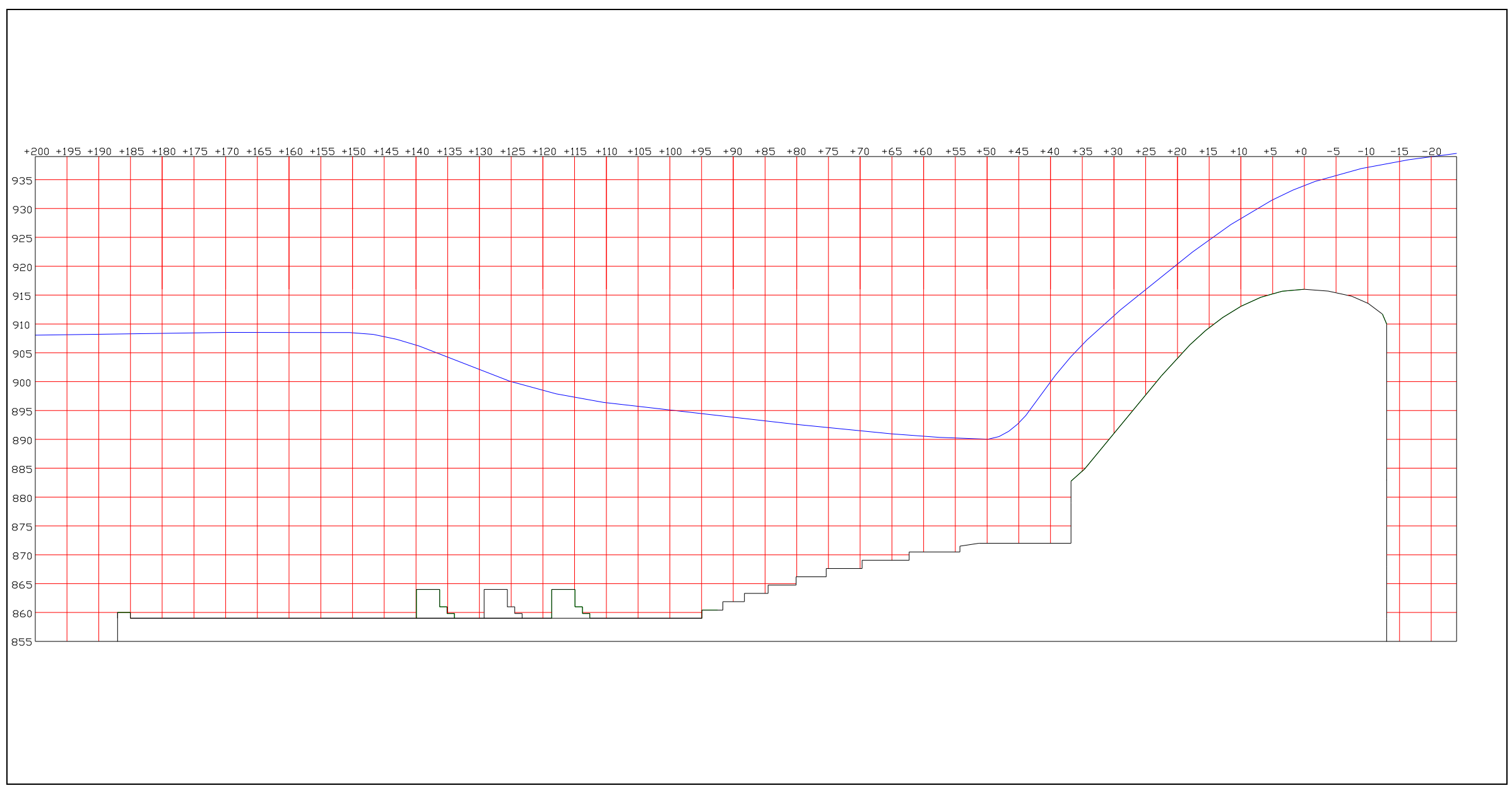

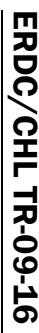

Figure 12f. Water surface profile for Condition 6, Monoliths 10-11-12. 


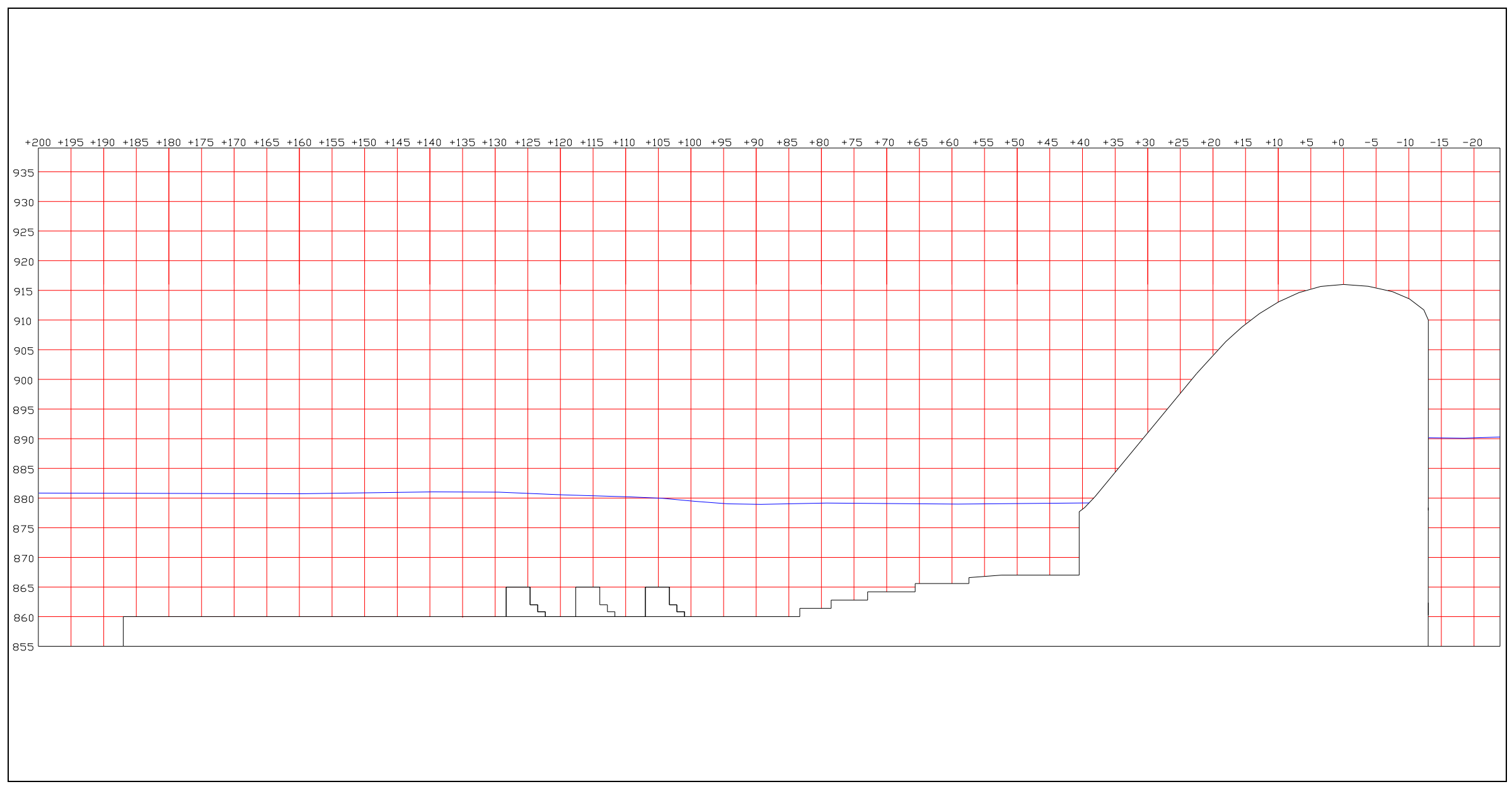

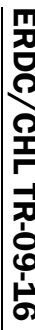

Figure 13a. Water surface profile for Condition 1, Monoliths 13-14-15. 


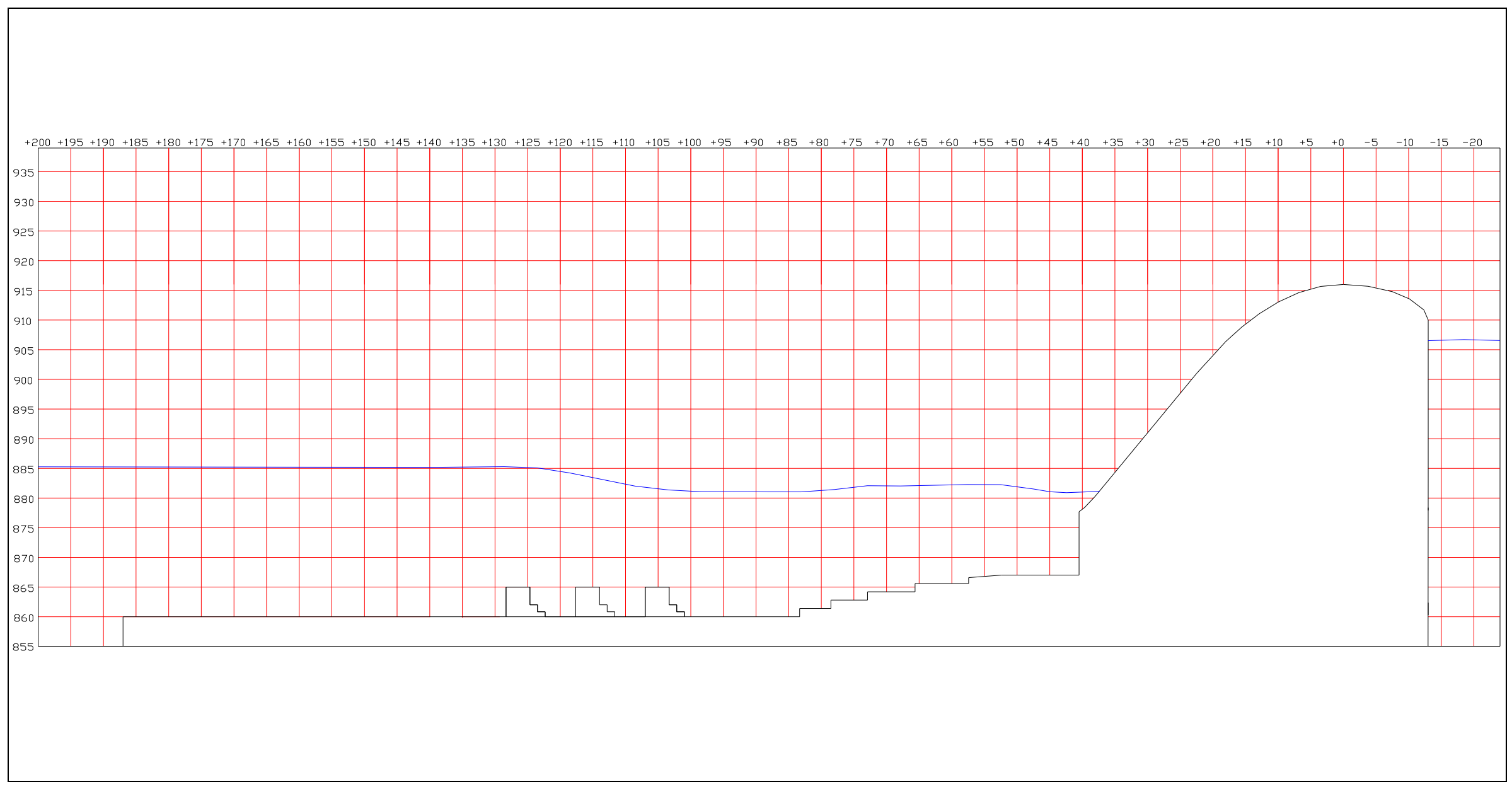

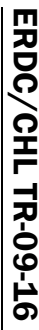

Figure 13b. Water surface profile for Condition 2, Monoliths 13-14-15. 


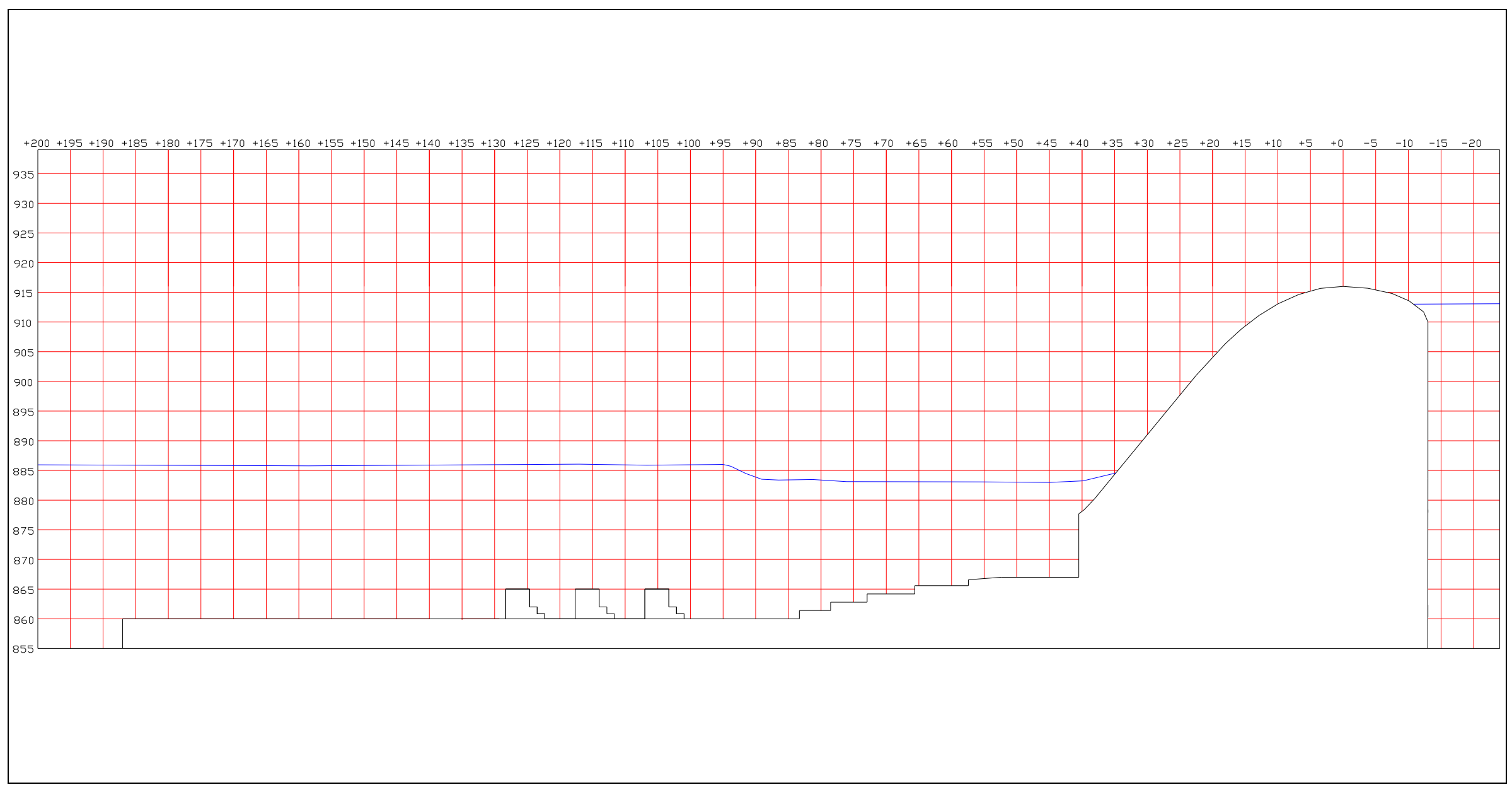

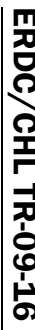

Figure 13c. Water surface profile for Condition 3, Monoliths 13-14-15. 


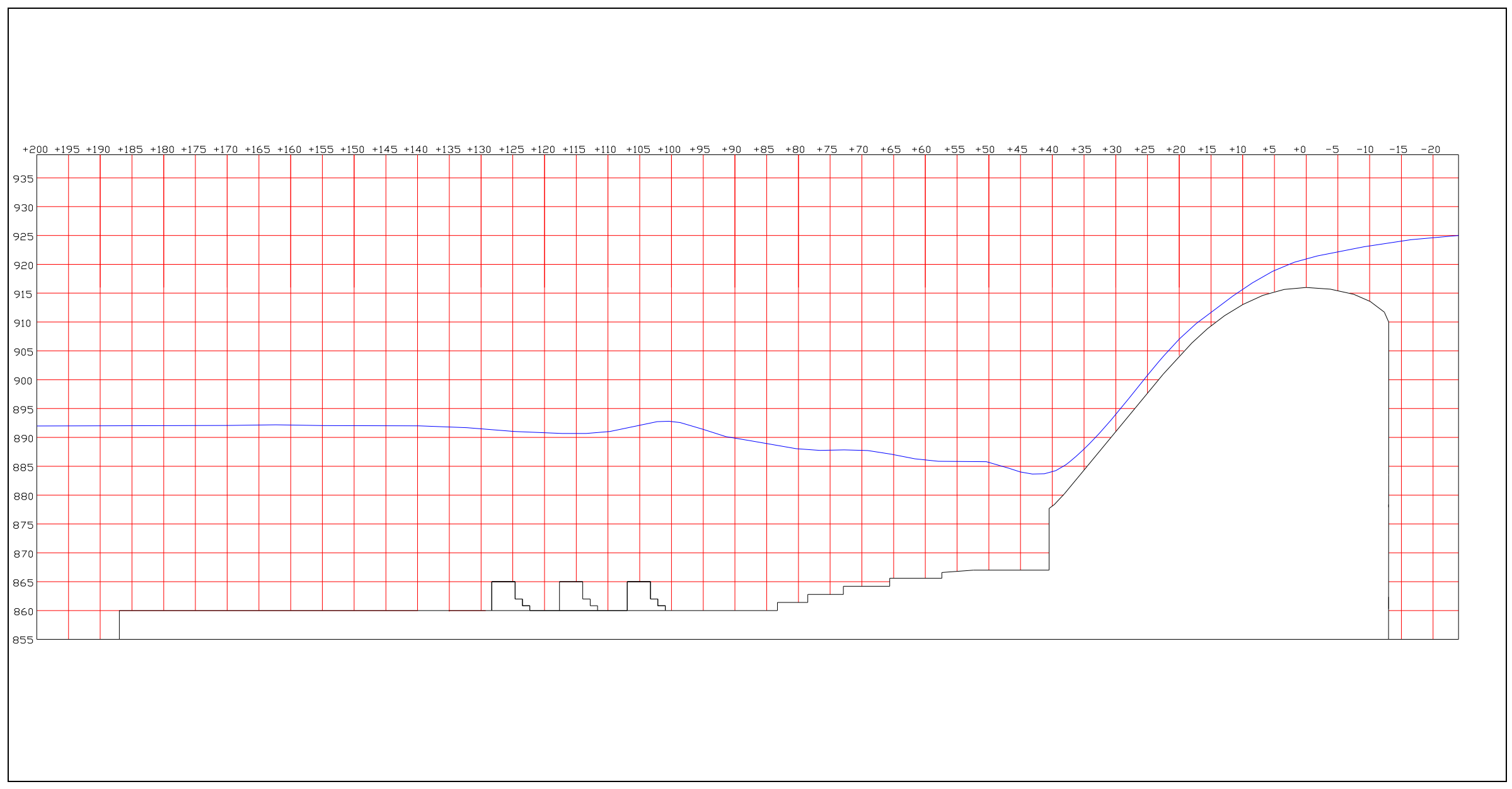

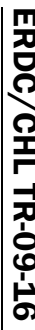

Figure 13d. Water surface profile for Condition 4, Monoliths 13-14-15. 


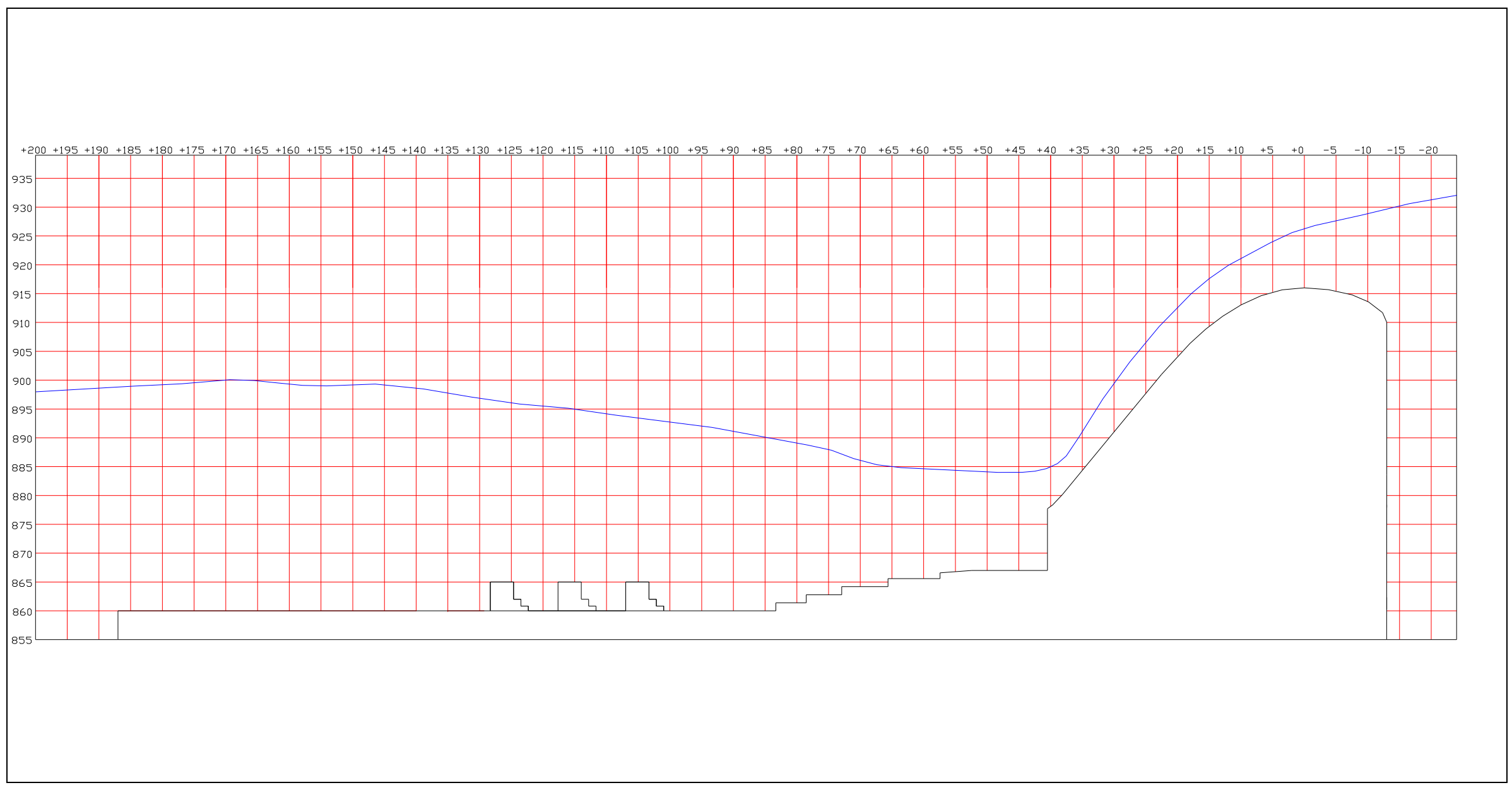

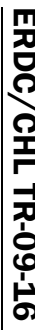

Figure 13e. Water surface profile for Condition 5, Monoliths 13-14-15. 


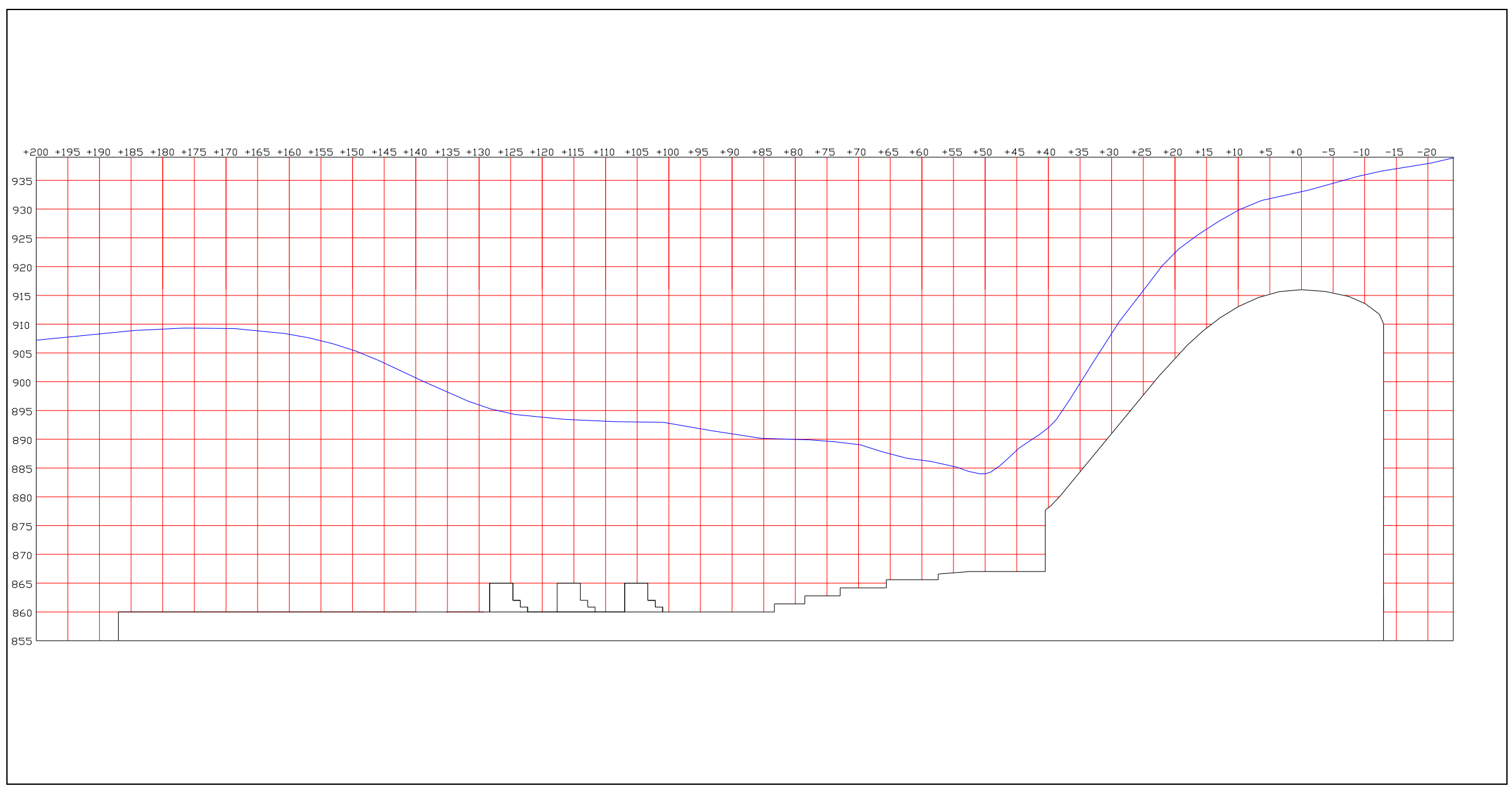

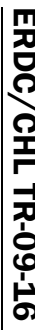

Figure 13f. Water surface profile for Condition 6, Monoliths 13-14-15. 


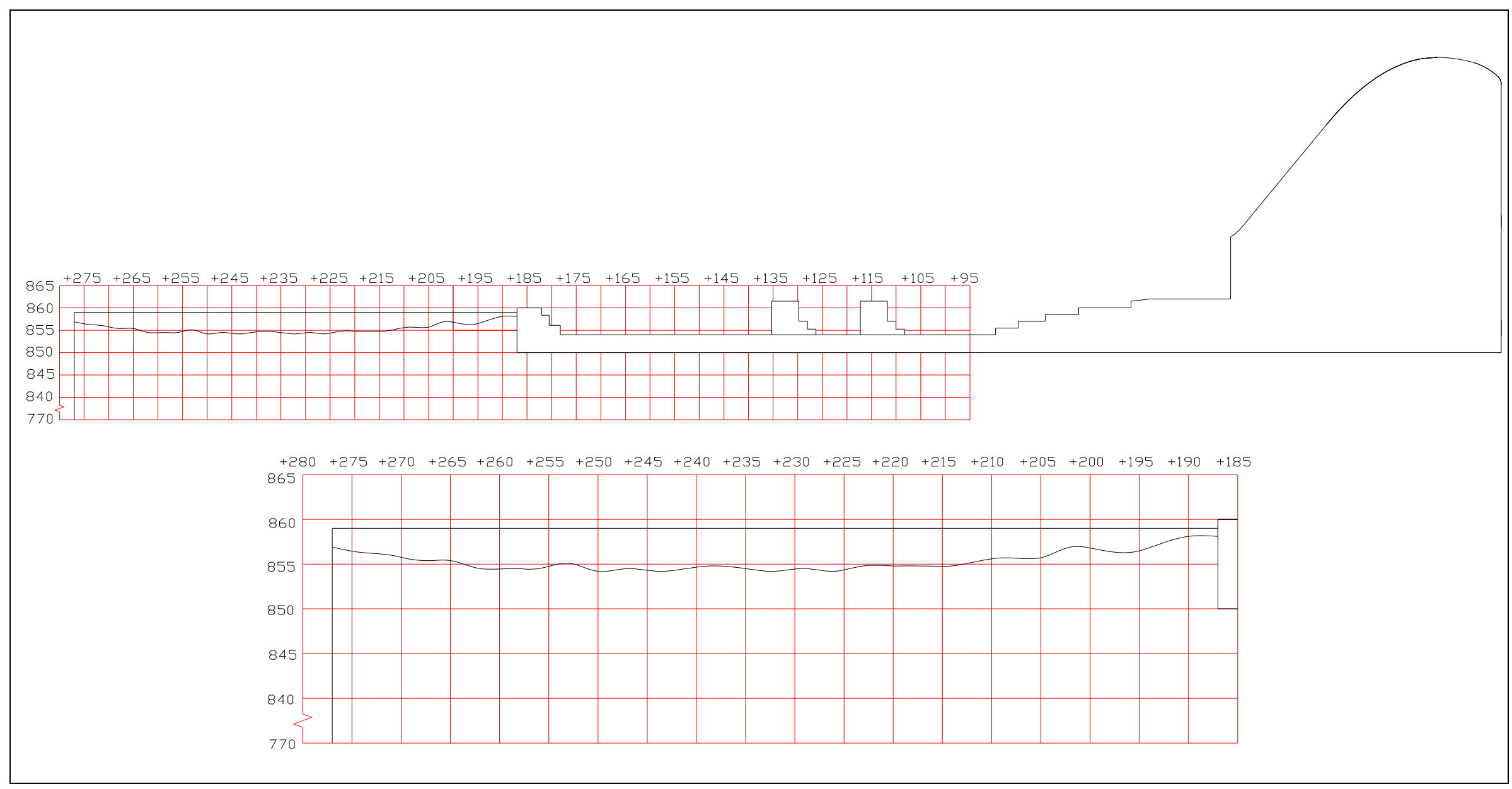

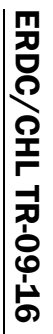

Figure 14a. Erosion pattern for Monoliths 7-8-9with end sill intact. 


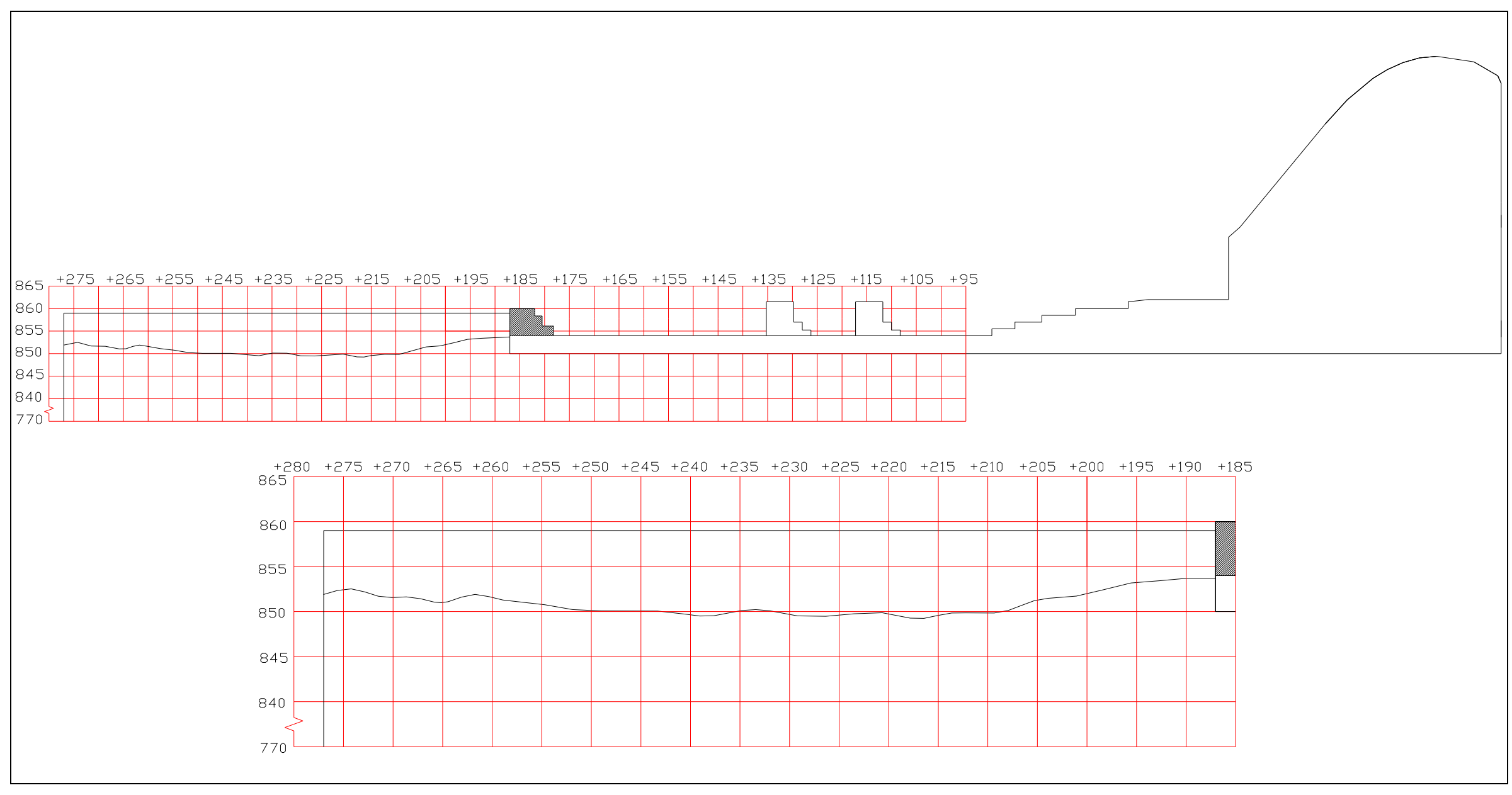

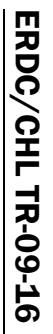

Figure 14b. Erosion pattern for Monoliths 7-8-9 with end sill removed. 


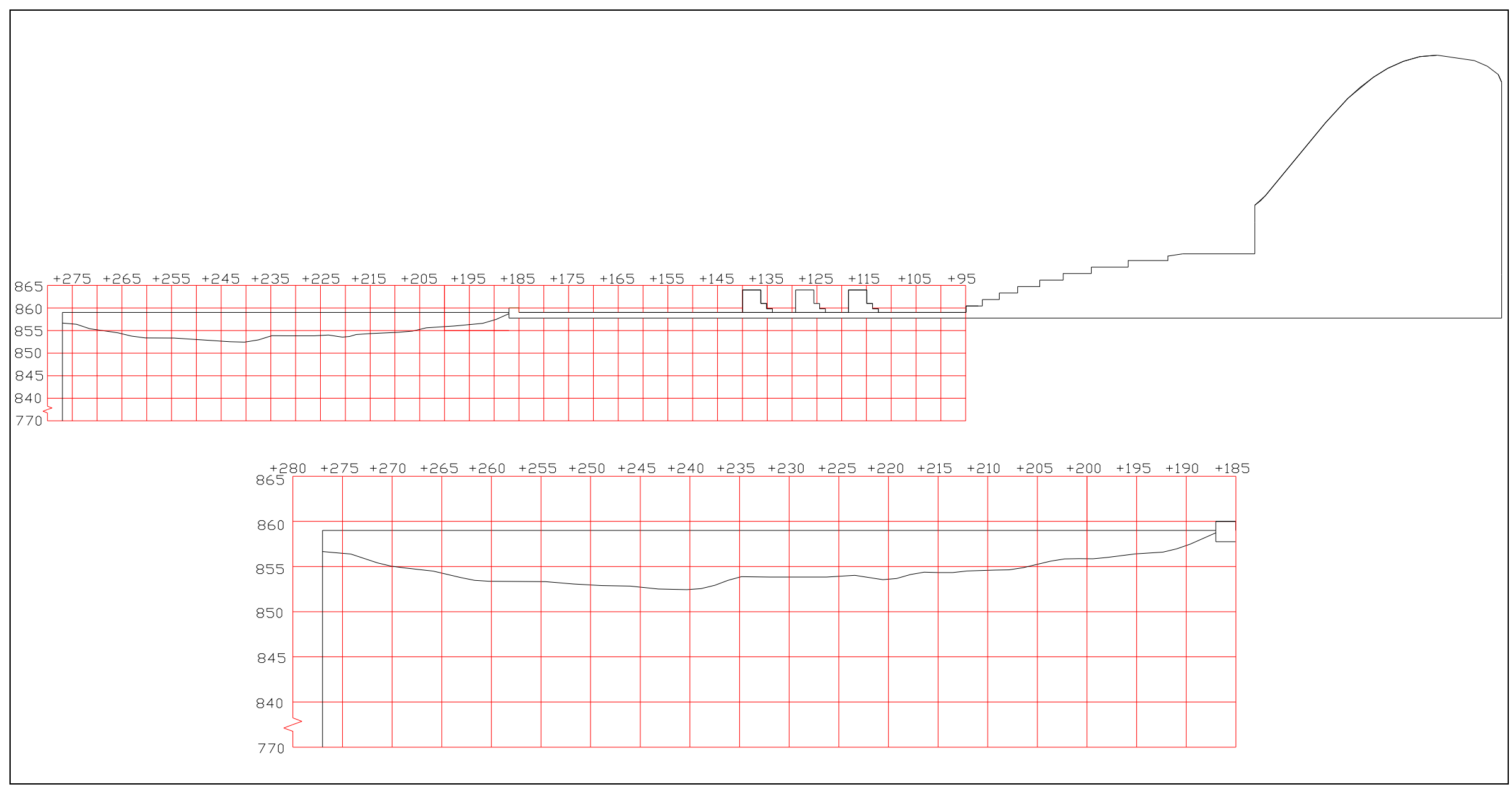



Figure 15a. Erosion pattern for Monoliths 10-11-12 with end sill intact. 


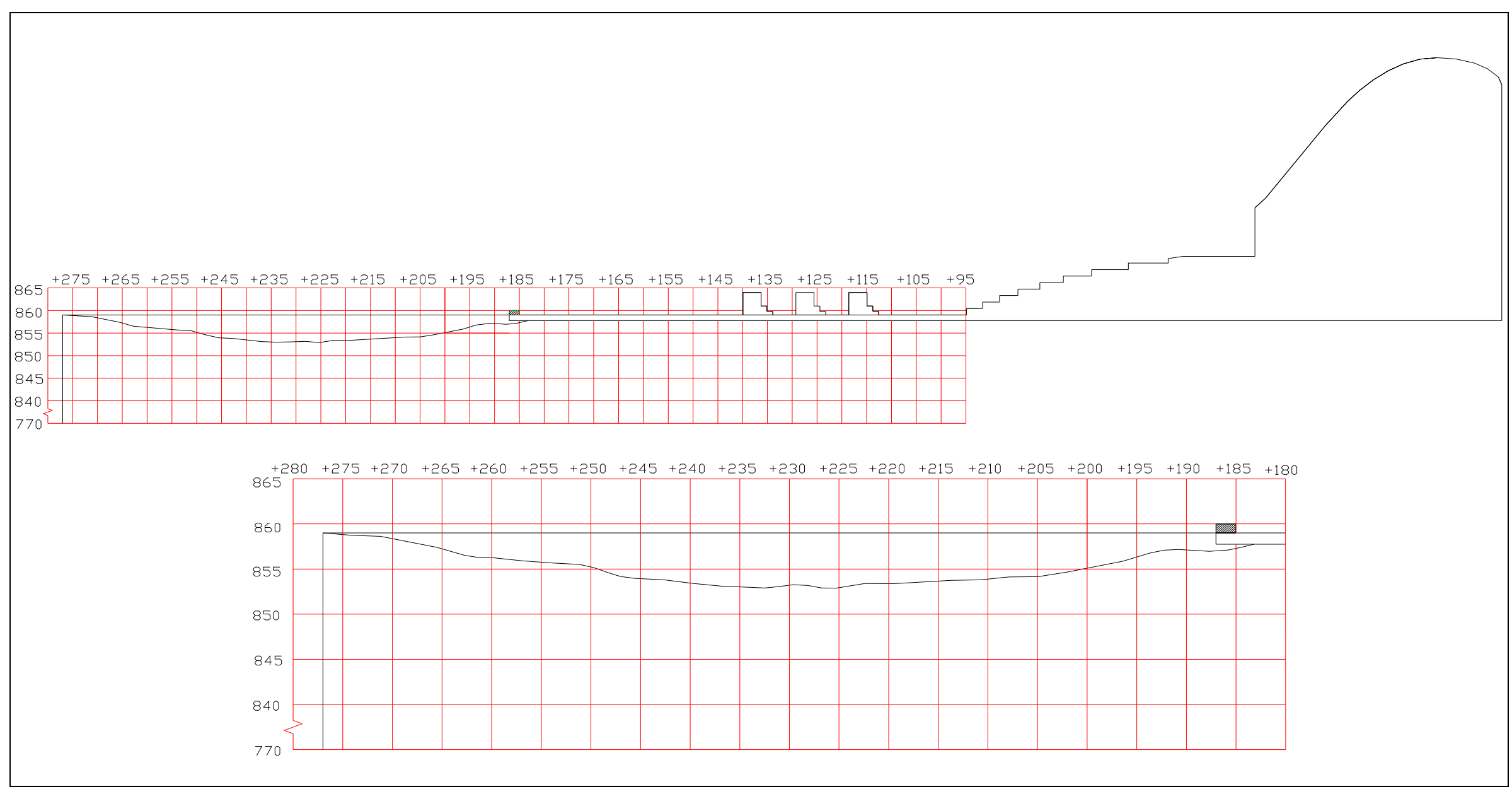

Figure 15b. Erosion pattern for Monoliths 10-11-12 with end sill removed. 


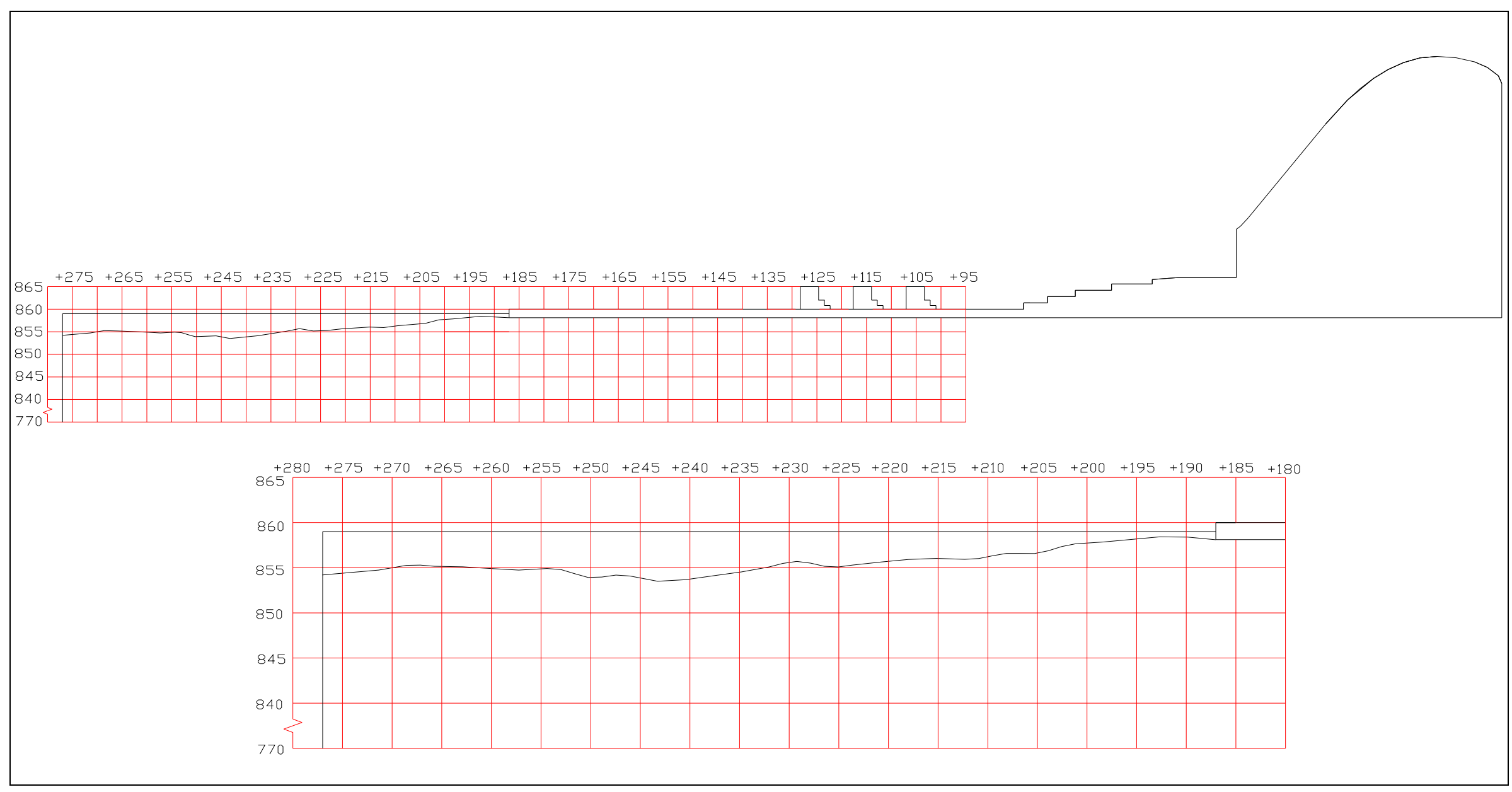

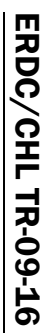

Figure 16. Erosion pattern for Monoliths 13-14-15. 


\section{Conclusions}

A physical model study was conducted to collect pressure and moveable bed data for several flow conditions at Dover Dam. Water surface elevations for these conditions were documented and rating curves were developed for the sluices, spillway crest, and the structure as a whole as part of the study.

During testing, a higher than anticipated pool elevation was produced by the PMF. The increased pool elevation was apparent for all three sets of Monoliths and was approximately three to four feet, prototype, higher than the estimated pool elevation. The higher pool elevation was found to be a result of tailwater effects on the sluice discharge.

Pressures were measured using both piezometers and pressure cells to provide average and time series data. The pressure readings indicate that potential cavitation damage to the top face and downstream face of the baffle blocks for Monoliths 7, 8, and 9 may occur with flow conditions 5, 6, and 7 , where the average pressure exceeds $-15 \mathrm{ft}$ of water. It should be noted that the increased head, associated with the PMF, did not produce pressures on the downstream spillway face low enough to exceed spillway design guidance for cavitation, as this is generally a concern when spillways are subjected to an increase in head.

The moveable bed portion of the model showed no significant erosion around the end sill or under the stilling basin, but it is important to note that the material used in the model does not necessarily reflect the bed material present at the prototype. Moveable bed data was collected for conditions with both the end sill intact and removed to simulate possible erosion if the end sill were to be lost during a high flow event.

The results of this study are limited to the conditions discussed in this report. 


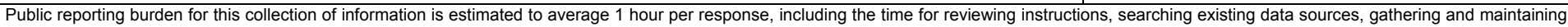

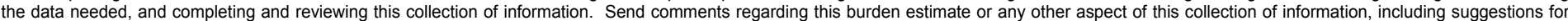

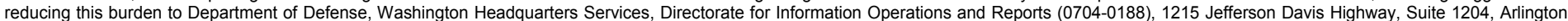

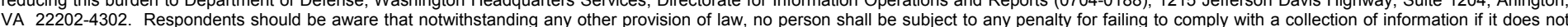
display a currently valid OMB control number. PLEASE DO NOT RETURN YOUR FORM TO THE ABOVE ADDRESS.
1. REPORT DATE (DD-MM-YYYY)
September 2009
2. REPORT TYPE
Final report

\section{TITLE AND SUBTITLE}

Dover Dam Physical Model Study, Tuscarawas River, Dover, OH

3. DATES COVERED (From - To)

5a. CONTRACT NUMBER

5b. GRANT NUMBER

5c. PROGRAM ELEMENT NUMBER

5d. PROJECT NUMBER

5e. TASK NUMBER

5f. WORK UNIT NUMBER

8. PERFORMING ORGANIZATION REPORT NUMBER

ERDC/CHL TR-09-16

U.S. Army Engineer Research and Development Center

Coastal and Hydraulic Laboratory

3909 Halls Ferry Road

Vicksburg, MS 39180-6199

\section{SPONSORING / MONITORING AGENCY NAME(S) AND ADDRESS(ES)}

10. SPONSOR/MONITOR'S ACRONYM(S)

U.S. Army Corps of Engineers

502 Eighth Street

Huntington, WV 25701

11. SPONSOR/MONITOR'S REPORT $\operatorname{NUMBER}(\mathbf{S})$

12. DISTRIBUTION / AVAILABILITY STATEMENT

Approved for public release; distribution is unlimited

\section{SUPPLEMENTARY NOTES}

\section{ABSTRACT}

Dover Dam is located on the Tuscarawas and Muskingum Rivers near Dover, OH. Based on data collected since the dam's original construction, it is possible that the dam will be overtopped by the Probable Maximum Flood. Several design alternatives are being considered to address this issue. A physical model study was conducted at the U.S. Army Engineer Research and Development Center, Coastal and Hydraulics Laboratory to collect data for use in a structural stability analysis. During the experiments, pressures were measured and potential erosion areas were noted. Forces exerted on the baffle blocks and stilling basin, as well as the potential undermining of the stilling basin were of major interest during the study.

\section{SUBJECT TERMS}

Baffle block

Dover Dam
Erosion

Moveable bed

Muskingum River
Physical model

Probable maximum flood (PMF)

Stilling basin pressure

Tuscarawas River

\begin{tabular}{|c|c|c|c|c|c|}
\hline \multicolumn{3}{|c|}{ 16. SECURITY CLASSIFICATION OF: } & \multirow[t]{2}{*}{$\begin{array}{l}\text { 17. LIMITATION } \\
\text { OF ABSTRACT }\end{array}$} & \multirow{2}{*}{$\begin{array}{c}\text { 18. NUMBER } \\
\text { OF PAGES } \\
70\end{array}$} & \multirow{2}{*}{$\begin{array}{l}\text { 19a. NAME OF RESPONSIBLE } \\
\text { PERSON } \\
\begin{array}{l}\text { 19b. TELEPHONE NUMBER (include } \\
\text { area code) }\end{array}\end{array}$} \\
\hline $\begin{array}{l}\text { a. REPORT } \\
\text { UNCLASSIFIED }\end{array}$ & $\begin{array}{l}\text { b. ABSTRACT } \\
\text { UNCLASSIFIED }\end{array}$ & $\begin{array}{l}\text { c. THIS PAGE } \\
\text { UNCLASSIFIED }\end{array}$ & & & \\
\hline
\end{tabular}

